US Army Corps

of Engineers ${ }_{\circledast}$

Engineer Research and

Development Center

Military Engineering Basic Research Program

\title{
Quantifying Wave Breaking Shape and Suspended Sediment in the Surf Zone
}

Patrick J. Dickhudt, Nicholas J. Spore, Katherine L. Brodie,

November 2019 and A. Spicer Bak

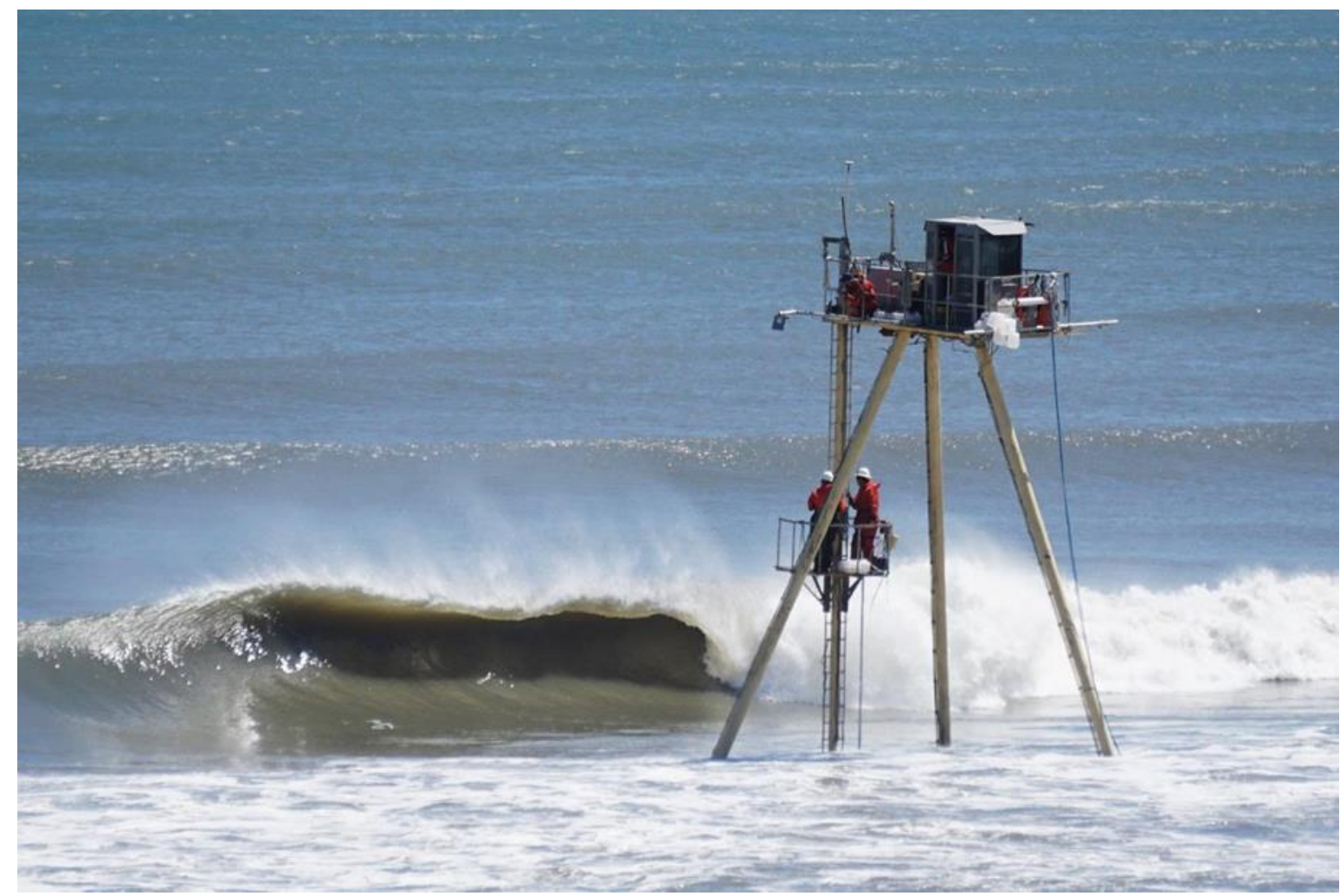


The US Army Engineer Research and Development Center (ERDC) solves the nation's toughest engineering and environmental challenges. ERDC develops innovative solutions in civil and military engineering, geospatial sciences, water resources, and environmental sciences for the Army, the Department of Defense, civilian agencies, and our nation's public good. Find out more at www.erdc.usace.army.mil.

To search for other technical reports published by ERDC, visit the ERDC online library at http://acwc.sdp.sirsi.net/client/default. 


\section{Quantifying Wave Breaking Shape and Suspended Sediment in the Surf Zone}

Patrick J. Dickhudt, Nicholas J. Spore, Katherine L. Brodie, and A. Spicer Bak

Coastal and Hydraulics Laboratory

US Army Engineer Research and Development Center

1261 Duck Road

Duck, NC 27949

Final report

Approved for public release; distribution is unlimited.

Prepared for US Army Engineer Research and Development Center

Coastal and Hydraulics Laboratory

3909 Halls Ferry Road

Vicksburg, MS 39180-6199

Under Program Element No. 611102T2200, Project No. 471930, Task No. 6.1 T22 


\section{Abstract}

This technical report describes a field experiment conducted from 18 November 2016 to 26 October 2017 at the Coastal and Hydraulics Laboratory, Field Research Facility, as part of a 6.1 Military Engineering Basic Research Project titled New Field Measurements and Parameterizations to Predict Wave Breaking Shape from Environmental Forcing. This report provides an overview of the project, presents the motivation and goals of the project, describes the suite of instrumentation and experimental procedure, documents the field data collection effort, and catalogs the raw data products.

DISCLAIMER: The contents of this report are not to be used for advertising, publication, or promotional purposes. Citation of trade names does not constitute an official endorsement or approval of the use of such commercial products. All product names and trademarks cited are the property of their respective owners. The findings of this report are not to be construed as an official Department of the Army position unless so designated by other authorized documents. 


\section{Contents}

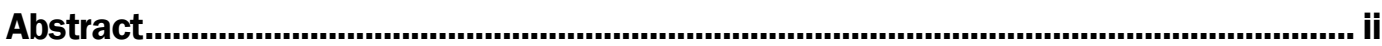

Figures and Tables..............................................................................................................

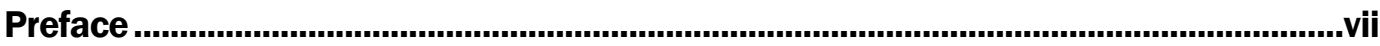

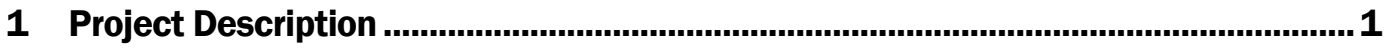

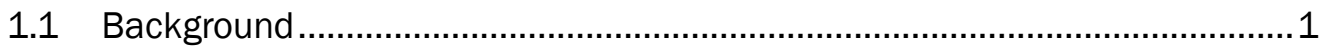

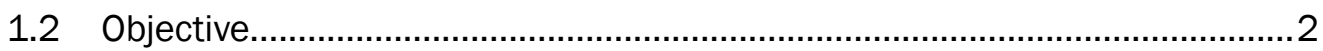

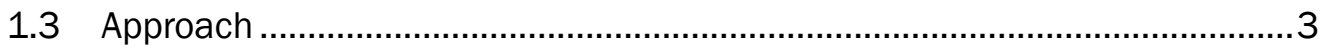

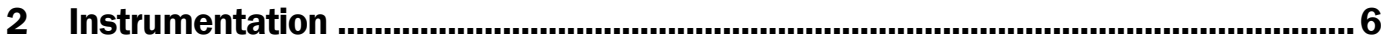

2.1 Coastal Research Amphibious Buggy (CRAB) as a sampling platform ...........6

2.2 Wave shape observations ...................................................................... 7

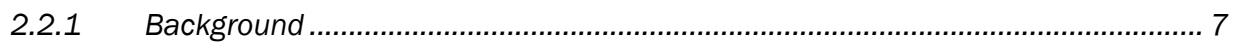

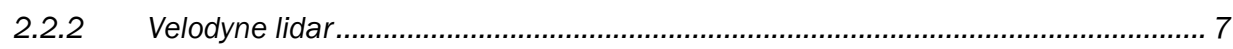

2.3 Suspended sediment instrumentation .................................................. 8

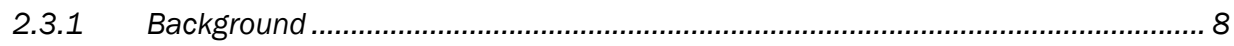

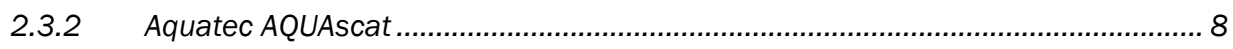

2.3.3 Nortek Vector and Sontek Triton acoustic Doppler velocimeters (ADVs)................ 9

2.3.4 Sequoia Scientific LISST-ABS ........................................................................ 10

2.3.5 Wetlabs ECONTU and ECOBB3 …............................................................ 10

2.4 Suspended sediment sampling ..............................................................

3 Field Experiment ..............................................................................................12

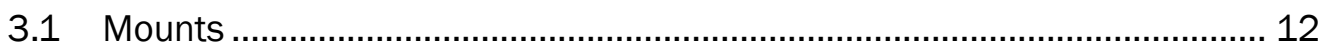

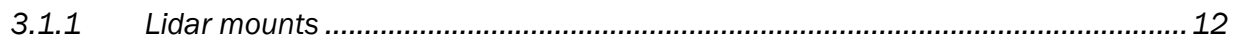

S.1.2 Suspended sediment instrument mounts .......................................................... 12

3.2 Sampling effort overview .......................................................... 12

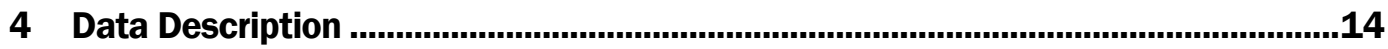

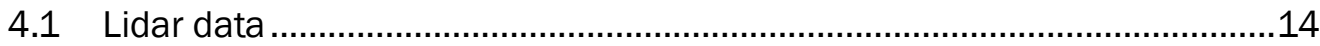

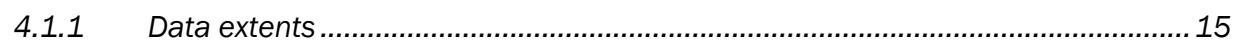

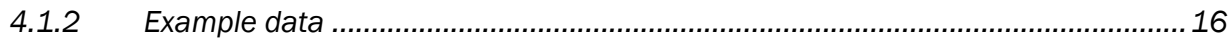

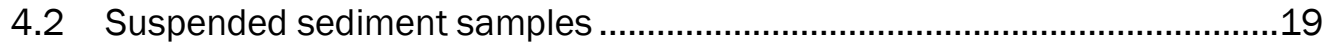

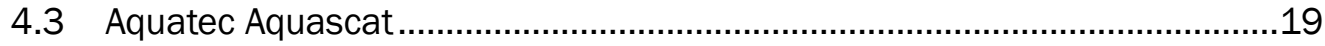

4.4 Nortek Vector and Sontek Triton acoustic Doppler velocimeter (ADV)........ 22

4.5 WetLabs ECONTU and ECOBB3 ........................................................... 26

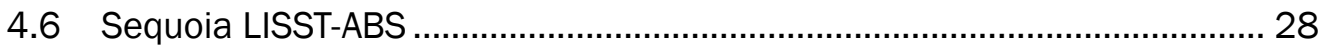

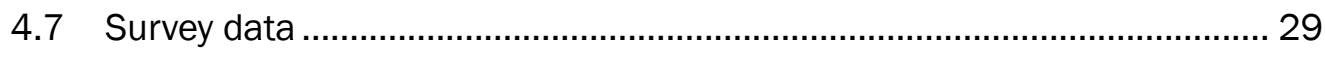

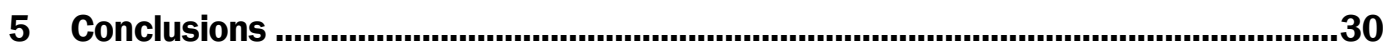

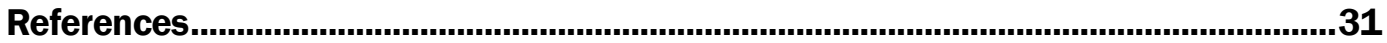


Appendix: Experiment Station Log and Field Conditions ..........................................33

Acronyms and Abbreviations...................................................................................52

Report Documentation Page 


\section{Figures and Tables}

\section{Figures}

Figure 1. Picture from the north side of FRF pier illustrating spatial variability in wave breaking type in Duck, NC. (Photo by Jon Carter.).....

Figure 2. (A) Development of robust, customizable, instrument mounting system for the CRAB. (B) The Velodyne lidar mount extended off the CRAB and could be located fore or aft. (C) Suspended sediment instruments were mounted to a beam and could be adjusted to modify instrument height above the seabed.

Figure 3. Velodyne lidar drawing with dimensions

Figure 4. Five-minute time series of acoustic backscatter amplitude from

Aquascat $1 \mathrm{MHz}$ transducer illustrating intuitive visual nature of Aquatec ABS

data aiding in data interpretation including identification of seabed, suspended

sediment, and entrained bubbles. Color scale is backscatter intensity with yellow

representing strong backscattering (sediment or bubbles) and blue representing

weak backscattering (relatively clear water).

Figure 5. CRAB sampling at or just inshore of the breakpoint during plunging breakers on 04 April 2017.

Figure 6. Map-view of spatial extent of 3D point clouds of the water surface ( $y$ axis is in the alongshore direction; $x$-axis is in the cross-shore direction) from the Velodyne lidar on the CRAB. Colors correspond to reflectance of the sea-surface, with warmer colors representing higher reflectivity. (A) Lidar 3D point cloud illustrating wider coverage after a breaking wave when relict foam is present on the sea-surface. (B) Lidar 3D point cloud illustrating narrower coverage before a breaking wave when there is less foam.

Figure 7. Elevation cross sections through 3D lidar point clouds from the CRAB of four different types of waves: non-breaking waves (top row), plunging breaking (second row), spilling breaking (third row), and an already broken bore (bottom row). Notice the lidar returns off of the CRAB above the water surface.

Figure 8. Lidar-observed sea-surface elevation vs. cross-shore position through time (colors, vertical axis) while a plunging breaker breaks. Each subsequent time-step $(0.1 \mathrm{sec})$ is shown in a separate color and offset $2 \mathrm{~m}$ in the vertical.

Figure 9. Example $1 \mathrm{~min}$ time series of acoustic backscatter amplitude from (A) $1 \mathrm{MHz}$, (B) $2 \mathrm{MHz}$, and (C) $4 \mathrm{MHz}$ transducers of the Aquatec Aquascat ABS. Color scale is backscatter intensity with yellow representing strong backscattering (sediment or bubbles) and blue weak backscattering (relatively clear water).

Figure 10. Example 1 min time series of (A) eastward current velocity, (B) northward current velocity, and (C) upward current velocity from the Sontek Triton ADV.

Figure 11. Example 1 min time series of (A) pressure, (B) current speed, and (C) current direction from the Sontek Triton ADV.

Figure 12. Example 1 mintime series of beam intensity (counts) from (A) beam 1 , (B) beam 2, and (C) beam 3 from the Sontek Triton ADV.

Figure 13. Example 1 min time series of beam correlation (a quality-control parameter) from the Sontek Triton ADV. 
Figure 14. Example 1 min time series of optical backscatter at (A) $470 \mathrm{~nm}$, (B) $532 \mathrm{~nm}$, and (C) $700 \mathrm{~nm}$ from the WetLabs ECOBB3.

Figure 15. Example 1-min time series of acoustic backscatter in units of uncalibrated concentration from the Sequoia LISST-ABS.

\section{Tables}

Table 1. Table of experiment dates including number of stations sampled and instrumentation used on each day. 


\section{Preface}

This study was conducted for the US Army Engineer Research and Development Center, Coastal and Hydraulics Laboratory (ERDC-CHL), under the Military Engineering Basic Research Program, Program Element No. 611102T2200, Project No. 471930, Task No. 6.1 T22. The technical monitor was Mr. Nicholas Boone.

The work was performed by the Coastal Observations and Analysis Branch of the Flood and Storm Protection Division, ERDC-CHL. At the time of publication of this report, Dr. Jeffrey P. Waters was Branch Chief; Dr. Cary A. Talbot was Division Chief; and Ms. Pam Kinnebrew was Lead Technical Director, Military Engineering Programs.

The Deputy Director of ERDC-CHL was Mr. Jeffrey R. Eckstein, and the Director was Dr. Ty V. Wamsley.

COL Teresa A. Schlosser was the Commander of ERDC, and the Director was Dr. David W. Pittman. 


\section{Project Description}

\subsection{Background}

Laboratory experiments have identified relationships between environmental forcing conditions, wave breaking type, and wave breaking depth parameters (Camenen and Larson 2007). However, these relationships have not been thoroughly evaluated in the field due to difficulties in quantifying observed wave shape and seabed elevation in the surf zone (Weishar and Byrne 1978). As a result, the relationships remain poorly constrained, and spatial and temporal variations in wave breaking type are not incorporated in wave models (e.g., STWAVE) used by the US Army Corps of Engineers (USACE) or the Army to predict wave heights in the surf zone and at the shoreline during surf-zone trafficability assessments. Additionally, laboratory experiments suggest breaking type (spilling or plunging, Figure 1) can change alongshore sediment transport rates by $300 \%$ by influencing sediment suspensions (Smith et al. 2009). However, morphological evolution models, which predict how the coastline changes in response to waves, do not parameterize variations in sediment transport due to wave breaking type in their transport formulations.

Suspended sediment concentrations are important, not only for alongshore transport rates but also because they impact water column visibility. The optical properties of coastal waters affect the performance of lidar and other optical sensors. For example, in turbid or aerated water, bathymetric lidar cannot penetrate to the seabed preventing measurements of bathymetry and/or detection of mines and other obstacles in the water column.

Improved model predictions of wave transformation, breaking, and the resultant sediment transport across the surf zone could therefore improve USACE's and the Army's ability to (1) forecast morphologic change in the dynamic surf zone, (2) predict favorable conditions for collecting important remotely sensed wave and bathymetry parameters, and (3) characterize the physical navigability, for both swimmers and vehicular traffic, of the surf zone. These capabilities will provide enhanced littoral geospatial intelligence that can improve USACE's management of flood risks and navigation channels, prediction and prevention of storm 
damages, as well as the Army's battlespace awareness in denied coastal ports of debarkation.

\subsection{Objective}

The field experiment described in this report supported a military engineering basic research project titled New Field Measurements and Parameterizations to Predict Wave Breaking Shape from Environmental Forcing. The objective of this project was to identify the environmental forcing factors that determine wave shape and breaking type in the surf zone of a natural beach. The data were collected to relate wave shape and breaking type to wave energy dissipation and sediment transport processes with the goal of improving predictive models of seabed morphological evolution, wave transformation, and surf-zone trafficability. The goal of this project was to evaluate (1) if high-resolution threedimensional (3D) observations of the water surface elevation could be used to automatically quantify wave shape and breaking type in the field; (2) if wave breaking type could be well predicted by comparing local observations of seabed slope to offshore wave steepness; and (3) how wave breaking type affected the concentration and vertical distribution of suspended sediment in the water column. Successful completion of this project required development of measurement techniques to collect field observations of wave breaking type and suspended sediment. These techniques were developed in the first year of the project and then used to execute a field experiment in fall of 2018 at the U.S. Army Engineer Research and Development Center (ERDC), Field Research Facility (FRF) in Duck, NC (Figure 1). The experiment setup and data collected in this field effort are described in detail in this report. Data analysis and results will be presented in follow-on journal articles and/or technical reports. 
Figure 1. Picture from the north side of FRF pier illustrating spatial variability in wave breaking type in Duck, NC. (Photo by Jon Carter.)

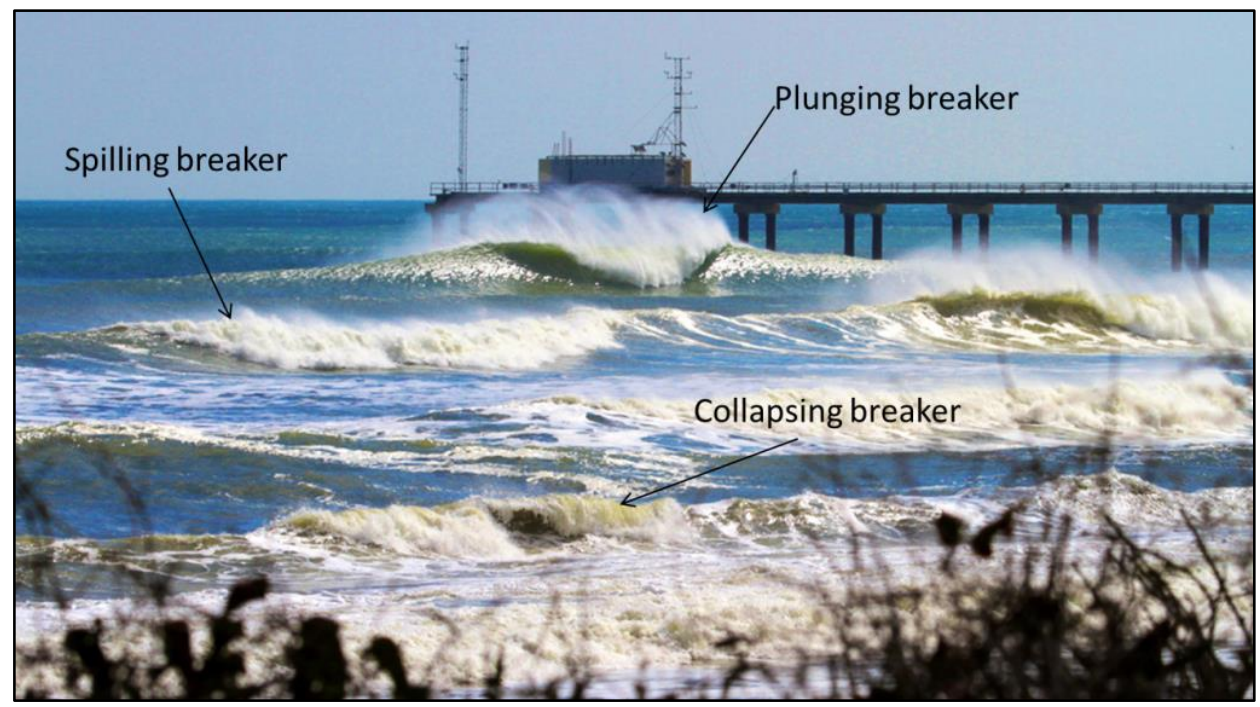

\subsection{Approach}

To accomplish this project's research objectives, a field experiment was conducted that focused on coupling remotely sensed observations of wave shape and breaking type with in situ observations of bed level changes, slopes, and suspended sediment concentrations. This experiment was conducted at the FRF between 18 November 2016 and 26 October 2017 utilizing the Coastal Research Amphibious Buggy (CRAB, Figure 2) as a sampling platform. A total of 88 stations were occupied resulting in over 45 hours of on-station data collection from a suite of subaerial and subaqueous sensors (Table 1).

Data were collected over a range of environmental conditions spanning 18 days and include the following:

1. Cross-shore transects of seabed elevation measured with the CRAB Global Positioning System (GPS) (Figure 2A) at least once and often multiple times during each day's collection.

2. 3-D lidar observations of the water surface elevation designed to quantify wave shape and breaking type (Figure 2B).

3. Pumped water samples (Figure $2 \mathrm{C}$ ) during lidar wave observations, which provide direct measurements of suspended sediment concentrations.

4. Acoustic and optical backscatter measurements from a suite of sensors (Figure 2C) designed to quantify suspended sediment concentration 
and distribution simultaneous to the lidar wave observations and pumped water samples.

Section 2 details the instrumentation, Section 3 provides details on the field experiment, and Section 4 describes the data and example data plots. The appendix contains detailed descriptions of each day's sampling effort, environmental conditions, and available data.

Table 1. Table of experiment dates including number of stations sampled and instrumentation used on each day.

\begin{tabular}{|c|c|c|c|c|c|c|c|}
\hline Date & $\begin{array}{c}\text { Number } \\
\text { of } \\
\text { Stations }\end{array}$ & $\mathrm{SSC}^{1}$ & Opt Turb² & $\begin{array}{l}\text { LISST- } \\
\text { ABS }^{3}\end{array}$ & Aquascat & $\mathrm{ADV}^{4}$ & Lidar \\
\hline Nov 18, 2016 & 5 & $x$ & $x$ & & $x$ & $x$ & $x$ \\
\hline Jan 12, 2017 & 4 & $x$ & & & $x$ & $x$ & $x$ \\
\hline Apr 04, 2017 & 4 & $x$ & $x$ & & $x$ & $x$ & $x$ \\
\hline Sep 06, 2017 & 2 & $x$ & $x$ & & $x$ & & $x$ \\
\hline Sep 07, 2017 & 5 & $x$ & $x$ & & $x$ & & $x$ \\
\hline Sep 08, 2017 & 3 & $x$ & $x$ & & $x$ & & $x$ \\
\hline Sep 13, 2017 & 7 & $x$ & $x$ & $x$ & $x$ & $x$ & $x$ \\
\hline Sep 21, 2017 & 6 & $x$ & $x$ & $x$ & $x$ & $x$ & $x$ \\
\hline Sep 29, 2017 & 5 & $x$ & $x$ & $x$ & $x$ & $x$ & $x$ \\
\hline Oct 03, 2017 & 6 & $x$ & $x$ & $x$ & $x$ & $x$ & $x$ \\
\hline Oct 04, 2017 & 8 & $x$ & $x$ & $x$ & $x$ & $x$ & $x$ \\
\hline Oct 05, 2017 & 5 & & $x$ & $x$ & $x$ & $x$ & $x$ \\
\hline Oct 16, 2017 & 3 & & & & & & $x$ \\
\hline Oct 18, 2017 & 6 & $x$ & $x$ & $x$ & $x$ & $x$ & $x$ \\
\hline Oct 19, 2017 & 4 & $x$ & $x$ & $x$ & $x$ & $x$ & $x$ \\
\hline Oct 20, 2017 & 3 & & & & & & $x$ \\
\hline Oct 25, 2017 & 6 & $x$ & $x$ & $x$ & $x$ & $x$ & $x$ \\
\hline Oct 26, 2017 & 6 & $x$ & $x$ & $x$ & $x$ & $x$ & $x$ \\
\hline
\end{tabular}

${ }^{1} \mathrm{SSC}=$ Suspended Sediment Concentration

2 Opt Turb = optical turbidity

3 LISST-ABS $=$ product name of acoustic backscatter sensor

${ }^{4} \mathrm{ADV}=$ acoustic Doppler velocimeter 
Figure 2. (A) Development of robust, customizable, instrument mounting system for the CRAB. (B) The Velodyne lidar mount extended off the CRAB and could be located fore or aft. (C) Suspended sediment instruments were mounted to a beam and could be adjusted to modify instrument height above the seabed.

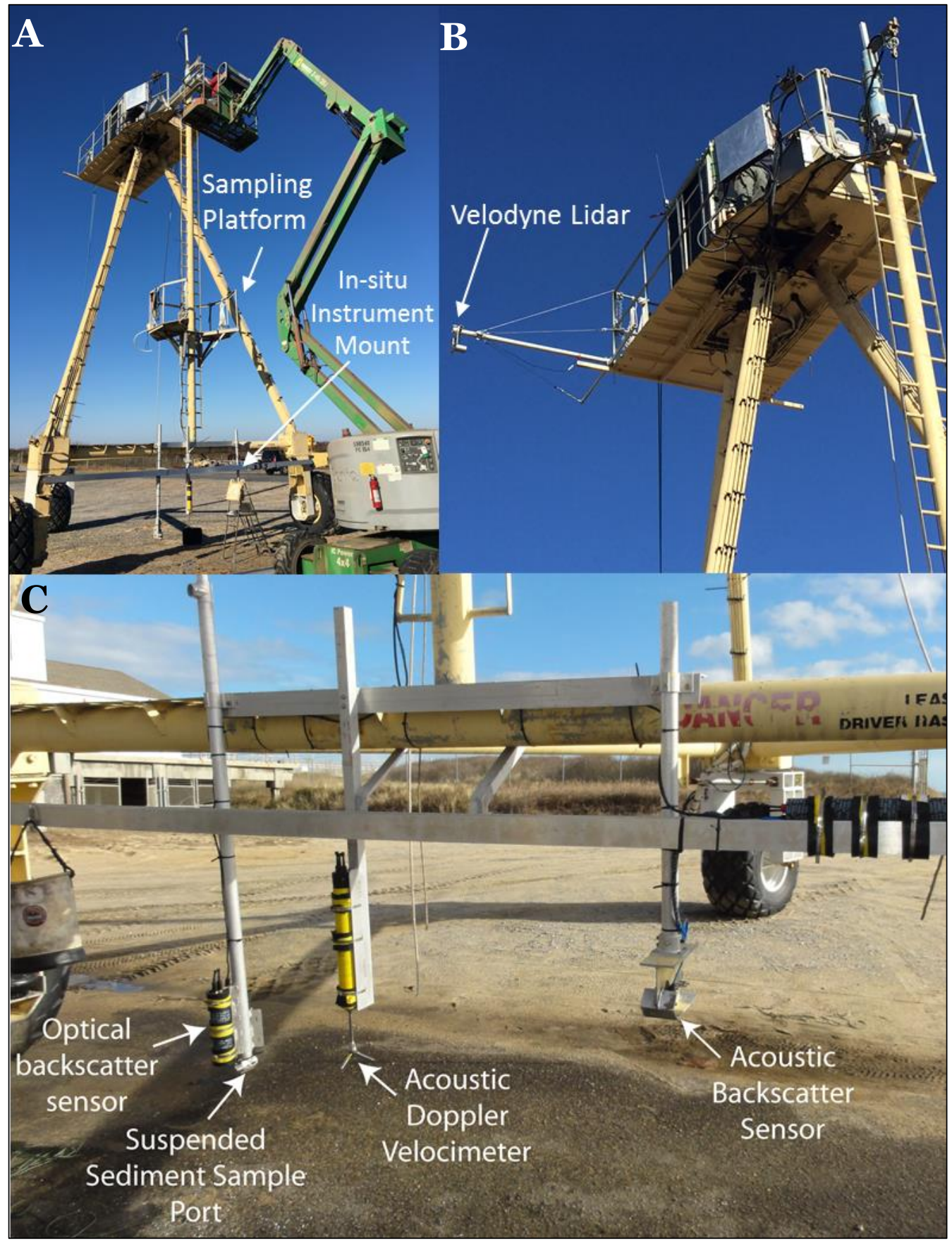




\section{Instrumentation}

This experiment utilized remotely sensed and in situ field observation techniques to quantify wave shape, bed evolution, and suspended sediment concentrations in the surf zone. These measurements relied on a diverse suite of instruments including high-frame rate lidar (Section 2.2), profiling acoustic backscatter sensors (ABS) (Section 2.3.2), acoustic Doppler velocimeters (Section 2.3.3), and optical and acoustic backscatter single point sensors (Section 2.3.4 and 2.3.5). In addition, suspended sediment samples were collected in close proximity to the subaqueous sensors (Section 2.4).

\subsection{Coastal Research Amphibious Buggy (CRAB) as a sampling platform}

The CRAB is a 10.7 meter (m)-tall, three-wheeled amphibious research vehicle capable of driving or parking in the surf zone providing a mobile but stable platform for data collection. Instruments can be mounted to numerous locations on the CRAB, facilitating subaerial and subaqueous measurements. The ability of the CRAB to move throughout the surf zone provided the potential to measure numerous types of waves (shoaling, spilling, and plunging) in a single field collection effort by moving to different locations.

Instrument mounts were designed, fabricated, and tested to attach a suite of instruments to the CRAB, above and below water. The mounts were designed to provide stable, rugged attachment points for instruments while providing high-quality measurements. In the case of the lidar, this required an unobstructed path from the laser to the water surface and minimal disturbance of incoming waves by the footprint of the CRAB. In the case of suspended sediment measurements, this required safely mounting the instruments within tens of centimeters of the seabed while minimizing flow disturbance and scour associated with the wheels or frame of the CRAB.

When parked in breaking waves, the CRAB slowly sinks into the seabed, changing the elevation of sensors relative to the sea surface or seabed. The CRAB tended to sink faster in stronger waves but was not allowed to sink more than approximately $0.3 \mathrm{~m}$ to prevent damage to the subaqueous instruments. In general, the CRAB would sink approximately 0.1 to $0.3 \mathrm{~m}$ 
over a period of 10 to 30 minutes (min). As a result, the height of subaqueous sensors and water sample intake relative to the seafloor changed over time. This allowed samples to be collected very close to the seabed $(\sim 0.1 \mathrm{~m})$.

\subsection{Wave shape observations}

\subsubsection{Background}

While lidar has traditionally been used to measure terrain elevation data (topographic or bathymetric), recent field experiments with terrestrial lidar scanners (Blenkinsopp et al. 2010; Brodie et al. 2012; Almeida et al. 2013; Vousdoukas et al. 2014; Brodie et al. 2015) have documented the ability to use lidar to simultaneously measure the elevation of the beach topography and the free surface of seawater, particularly of aerated breaking waves. Specifically, lidar can measure sea-surface elevations on the centimeter scale, quantifying the shape of waves as they propagate and providing new insight into spatial variations in wave characteristics across the surf zone (Brodie et al. 2015; Carini 2019).

In this experiment, a new, high-frame rate 3D lidar developed for the robotics and self-driving car industries to map the $3 \mathrm{D}$ structure of breaking waves at centimeter-scale resolution was used, providing a new ability to quantify wave shape and breaking type in the surf zone. The ability to capture data in three-dimensions could improve identification and quantification of wave shapes. These new scanners are significantly less expensive, smaller, and lighter weight than traditional mapping scanners, permitting more flexible mounting configurations.

\subsubsection{Velodyne lidar}

The Velodyne HDL-32E lidar scanner (Figure 3) is a relatively lightweight (1 kilogram) and compact unit $(8.5$ centimeters $[\mathrm{cm}] \times 14 \mathrm{~cm})$ that houses a multi-channel array of 903 nanometer $(\mathrm{nm})$ lasers. The scanner utilizes 32 laser channels, each scanning a single line in space as the head of the unit rotates. The combination of these channels, which are aligned at $1.33^{\circ}$ increments with a vertical field of view (FOV) of $41.34^{\circ}$ that illuminates a $360^{\circ}$ horizontal FOV at $0.1^{\circ}-0.4^{\circ}$ angular resolution depending on rotation rate. It has an effective measurement range up to $100 \mathrm{~m}$ and a manufacturer reported accuracy of $+/-2 \mathrm{~cm}$. Data were collected at a 
frame rate of 10 hertz $(\mathrm{Hz})$ in this experiment and were time-stamped with GPS time.

Figure 3. Velodyne lidar drawing with dimensions.

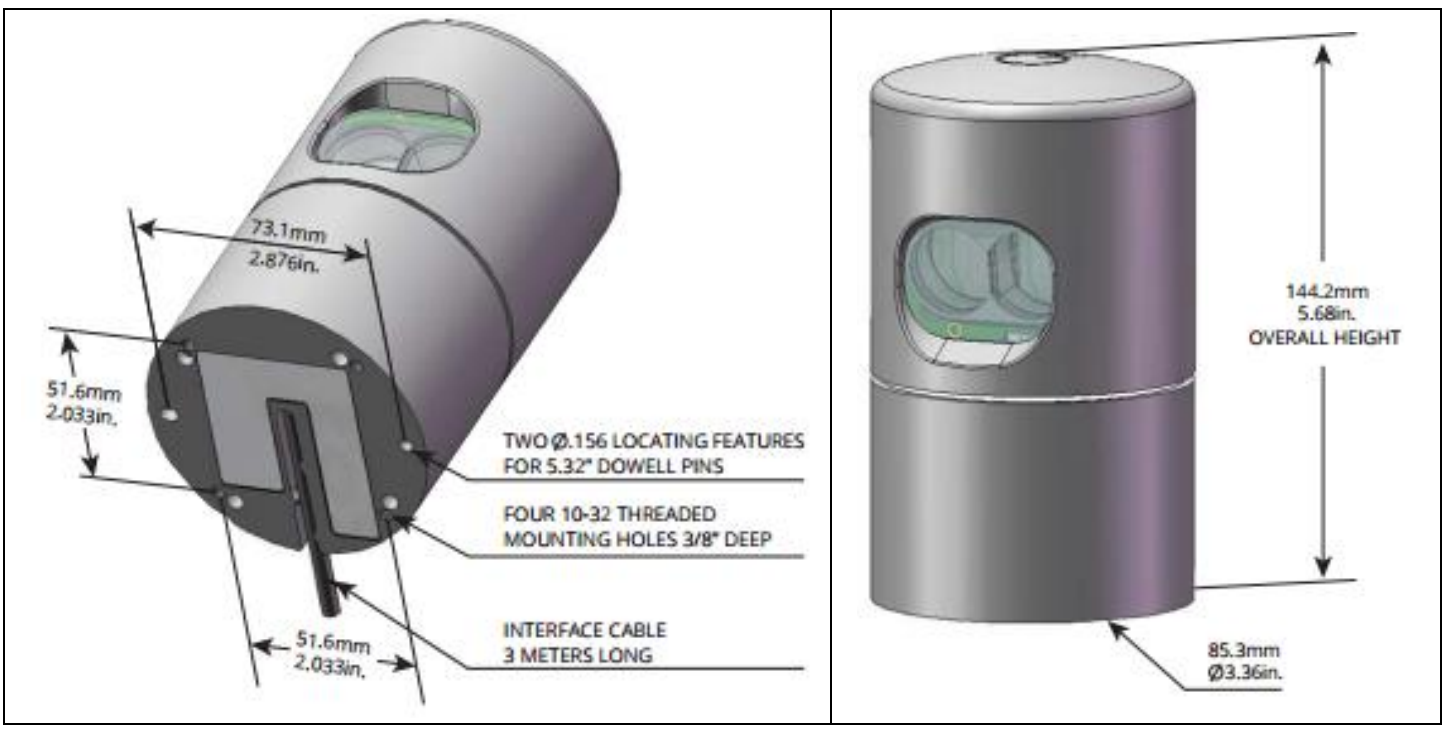

\subsection{Suspended sediment instrumentation}

\subsubsection{Background}

Accurately measuring suspended sediment concentration in the surf zone is notoriously challenging due to large gradients in sediment concentration (in space and time) and high concentrations of entrained air bubbles associated with breaking waves. Multiple instruments measuring acoustic and optical backscatter over a range of frequencies (Sections 2.3.2 - 2.3.5) were deployed simultaneously to evaluate suitability for measuring suspended sediment concentration under breaking waves. By analyzing the response of a suite of instruments, the aggregated data may provide a clearer picture for data analysis and interpretation. Additionally, techniques were developed and refined for collecting in situ suspended sediment samples to be used as ground truth as well as developing calibrations for individual sensors.

\subsubsection{Aquatec AQUAscat}

The Aquatec AQUAscat ABS (Figure 2C) used 1 megahertz (MHz), $2 \mathrm{MHz}$, and $4 \mathrm{MHz}$ sound to measure profiles of acoustic backscatter in the water column. Acoustic backscatter intensity is a proxy for suspended sediment concentration. The ABS measures acoustic backscatter in bins as small as 
$1 \mathrm{~cm}$ and as a profiling instrument, can be pointed towards the seafloor with potential to measure suspended sediment concentration very close to the seabed. Additionally, because the seabed was easily identified in ABS data, the elevation of the concentration measurements could be precisely determined. ABS profile measurements aided in data interpretation by providing a two-dimensional picture of backscatter in the water column allowing visualization what the ABS and other instruments were seeing (Figure 4).

Figure 4. Five-minute time series of acoustic backscatter amplitude from Aquascat 1 $\mathrm{MHz}$ transducer illustrating intuitive visual nature of Aquatec ABS data aiding in data interpretation including identification of seabed, suspended sediment, and entrained bubbles. Color scale is backscatter intensity with yellow representing strong backscattering (sediment or bubbles) and blue representing weak backscattering (relatively clear water).

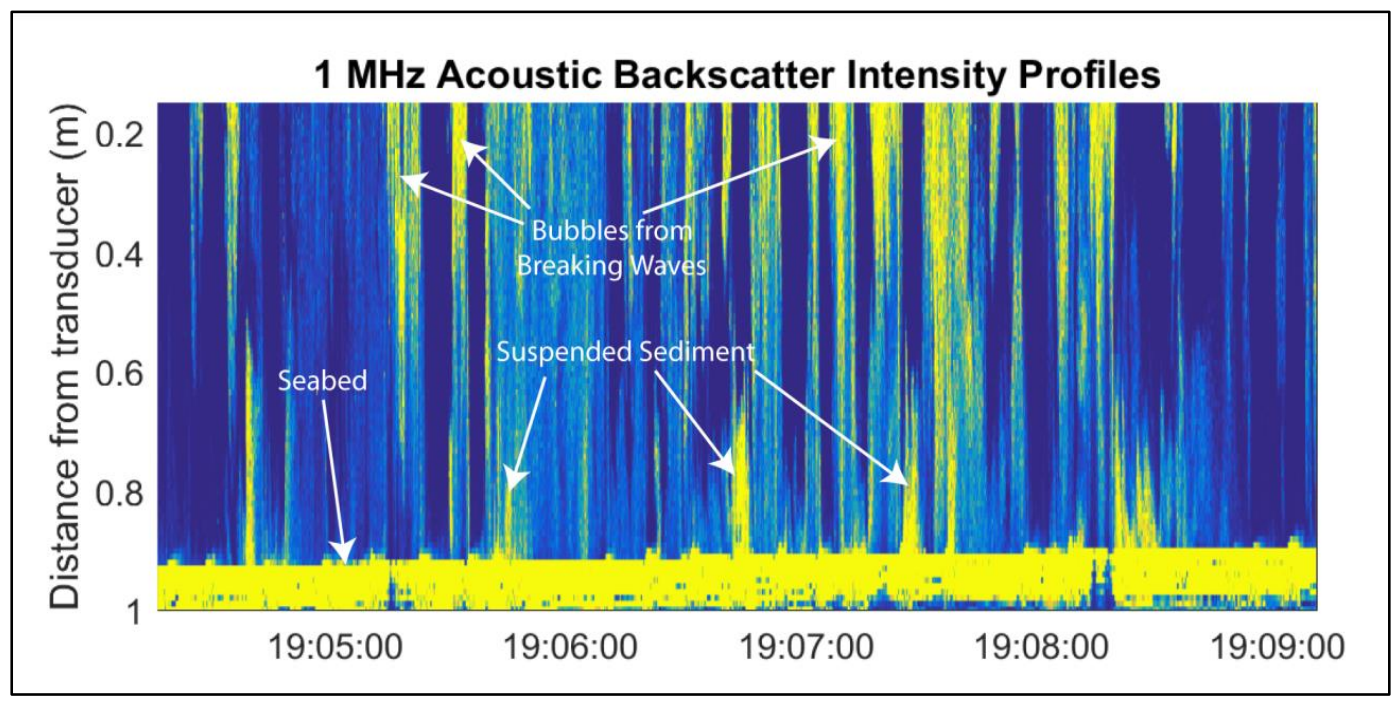

\subsubsection{Nortek Vector and Sontek Triton acoustic Doppler velocimeters} (ADVs)

ADVs have been widely used in the oceanographic community to collect high-quality flow and wave data in the surf zone, continental shelf, and elsewhere. The Nortek Vector and Sontek Triton ADVs use sound to precisely and accurately measure $3 \mathrm{D}$ water flow velocities in a small sample volume $\left(\sim 1 \mathrm{~cm}^{3}\right)$. Additionally, these instruments measure pressure and acoustic backscatter intensity. The pressure data combined with the directional flow velocity data can provide directional wave statistics. The acoustic backscatter data may be a good proxy for suspended sediment concentration (Fugate and Friedrichs 2002; Ha et al. 2009). The distance from the $\mathrm{ADV}$ transducer to the sample volume is 
relatively small and thus may minimize signal losses due to attenuation along the path length preserving accuracy in suspended sediment concentration estimates. The Nortek Vector emits a $6 \mathrm{MHz}$ acoustic pulse with a sample volume $15 \mathrm{~cm}$ from the tranducer while the Sontek Triton emits a $10 \mathrm{MHz}$ acoustic pulse with a sample volume $10 \mathrm{~cm}$ from the transducer.

\subsubsection{Sequoia Scientific LISST-ABS}

The Sequoia Scientific LISST-ABS is a compact $8 \mathrm{MHz}$ acoustic backscatter sensor. The $8 \mathrm{MHz}$ acoustic frequency was chosen by the manufacturer to minimize instrument response dependence on sediment grain size. The LISST-ABS has a short acoustic path length with the measurement volume located approximately 0.05 to $0.1 \mathrm{~m}$ from the sensor. Similar to the ADVs, the short path length of the LISST-ABS may minimize signal losses due to attenuation along the path length preserving accuracy in suspended sediment concentrations estimates. The LISST-ABS performs some internal pre-processing and reports data in uncalibrated concentration grams per liter $\left(\mathrm{g} / \mathrm{L}^{-1}\right)$. Specifically, it sampled at $1000 \mathrm{~Hz}$ and reported a $1 \mathrm{~Hz}$ average value. The $1 \mathrm{~Hz}$ average backscatter value was first corrected for attenuation along its path using a 30-second (sec) averaged attenuation derived from the backscatter at two distances along the acoustic path with the assumption that concentration does not vary along the path. A laboratory calibration derived from $75-90$ micron glass beads was then applied to the attenuation corrected backscatter to derive the uncalibrated concentration. Note that the $30 \mathrm{sec}$ averaged attenuation correction was not likely to be suitable in the surf zone where suspended sediment concentration could vary by orders of magnitude over time scales of seconds.

\subsubsection{Wetlabs ECONTU and ECOBB3}

WetLabs ECO sensors are small optical sensors that use light of discrete wavelengths scattered at $124^{\circ}$ as a proxy for suspended sediment concentration. The ECONTU uses light at $700 \mathrm{~nm}$ while the ECOBB3 has three individual sensors that measure scattered light at three wavelengths (470, 532, and $700 \mathrm{~nm}$ ).

The backscatter response of optical sensors can be quite sensitive to the size of suspended particles (Downing 2006). In practice, this can result in optical sensors preferentially measuring small particles (clay and silt) 
while being significantly less responsive to similar concentrations of coarser sediment (sand). These sensors offer the advantage of measuring concentration in a small volume very close to the sensor, so attenuation of the signal is not a concern unless concentrations are very high (Kineke and Sternberg 1992).

\subsection{Suspended sediment sampling}

The backscattered signal for the optical and acoustic sensors described above may provide a reliable proxy for sediment concentration in the surf zone. To evaluate this and ultimately to convert these backscatter data to actual concentrations, calibration samples were collected.

In situ suspended sediment samples were collected with a 12-volt direct current pump mounted on the CRAB crow's nest. An intake hose was run from the pump down a pipe where the end was secured at a nominal height of $40 \mathrm{~cm}$ above the bed. The pipe was generally in a fixed position, but on a few occasions, the height above the bed varied. The SSC sample height above the bed is included as a data variable with the data file.

After collection, suspended sediment samples were analyzed in the lab to determine the concentrations of suspended sand ( $>63$ microns $[\mu \mathrm{m}]$ ), suspended fines $(<63 \mu \mathrm{m})$, and total SSC (sand + fines). Suspended sand concentration was determined as the mass of sediment retained on a 63 $\mu \mathrm{m}$ sieve per volume of sample. Total fines concentration was determined via filtration as the amount of sample collected on $934 \mathrm{AH}$ filter after the sand has been removed with the $63 \mu \mathrm{m}$ sieve. Total suspended sediment concentration was the sum of the sand and fines concentrations. For the sand and fine fractions, contribution of organic and inorganic matter to the total SSC was estimated by loss on ignition, determined by muffling the samples at $55 \mathrm{OC}^{\circ}$ for 4 hours. 


\section{Field Experiment}

\subsection{Mounts}

\subsubsection{Lidar mounts}

A horizontal arm and stabilizer were developed to mount the Velodyne scanner on the CRAB. Mounting locations were chosen to allow the scanner to measure the free surface in an area primarily outside of the CRAB footprint, ensuring that wave shapes were not affected by the physical structure of the CRAB. Multiple mounts were fabricated for the Velodyne lidar so it could be mounted fore and aft on the CRAB working platform (Figure 2B).

\subsubsection{Suspended sediment instrument mounts}

A subaqueous instrument mounting system for the CRAB was developed using a horizontal aluminum I-beam bolted below the rear crossbeam (Figure 2A and 2C). Multiple mounts projected below this I-beam allowing instruments to be mounted very close to the bed. These mounts were made to be easily modified and adjustable, allowing the height of the instruments above the bed to be altered as desired. Additionally, a mount was developed that allows an intake port for a suspended sediment sampling pump to be mounted very near the instruments.

\subsection{Sampling effort overview}

The CRAB provided a mobile platform that allowed data collections to be targeted in locations with ideal environmental conditions such as directly on a shallow sandbar where waves were most actively breaking (Figure 5). Additionally, the CRAB's mobility allowed for sampling of a range of wave conditions (i.e., shoaling, breaking, bores) with minimal effort by driving to a different part of the surf zone. A typical data collection from the CRAB began by first driving along a transect from the beach to well offshore of the wave breaking zone. As the CRAB is also a survey vessel, this provided an accurate bathymetric cross section at the sampling location to relate to the characteristics of the breaking waves. The suspended sediment and lidar data collections then proceeded by occupying multiple (two to eight) stations in the cross shore (see the Appendix). Each station was occupied for 20 to $40 \mathrm{~min}$ with instruments sampling continuously and suspended sediment samples collected periodically to collect a range of 
concentrations. The CRAB moved to new stations as necessary, following the zone of maximum wave breaking, to ensure optimal data returns from the Velodyne lidar. After completion of on-station sampling, a final survey transect was typically collected with the CRAB. On some days, stations were occupied on multiple cross-shore transects to adapt as conditions evolved over time (e.g., change in wind or water level resulting in no wave breaking).

Figure 5. CRAB sampling at or just inshore of the breakpoint during plunging breakers on 04 April 2017.

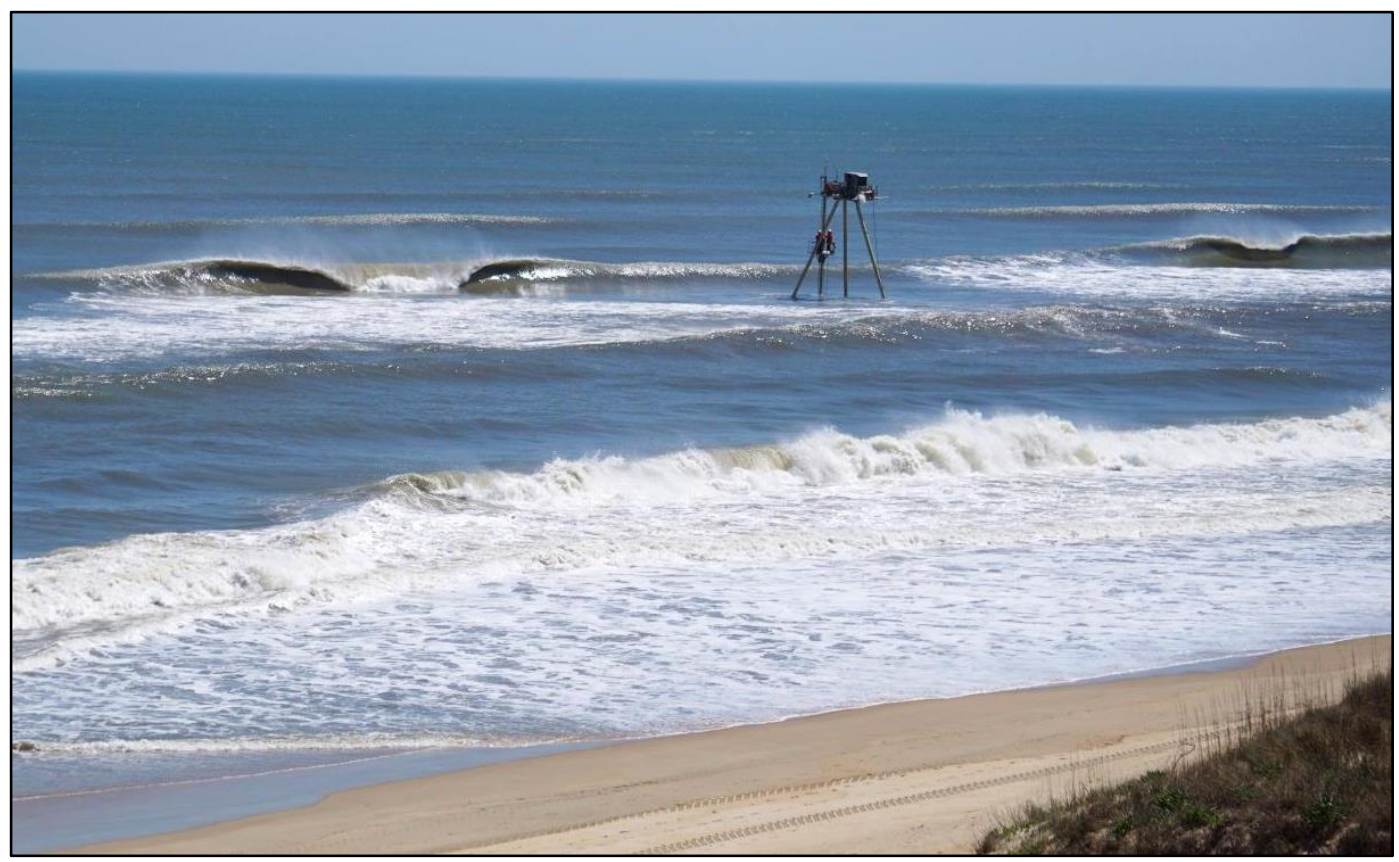




\section{Data Description}

\subsection{Lidar data}

The Velodyne HDL-32E measured $3 \mathrm{D}$ elevations at $10 \mathrm{~Hz}$ for $30 \mathrm{~min}$ at each sampling location, with all the data collected at that location contained within a single packet capture (.pcap) file (Velodyne native format). Within the .pcap file, two UDP ${ }^{1}$ data streams were recorded: laser firing data and position data. The laser firing data contains GPS timing information, rotation information, the returns from the 32 individual lasers (report distance to the nearest $0.2 \mathrm{~cm}$ ), and return intensity information from o to 255 counts. The positioning data contains the onboard gyrometer and accelerometer information as well as the GPS timestamp and National Marine Electronics Association sentence corresponding to the sensor's orientation and position.

The raw .pcap files can be viewed in the open-source VeloView software. This provides the data user the ability to visualize the laser returns through time and offers some simple mensuration tools and data attribute filtering. In addition to being viewed in VeloView, the pcap files can be decoded and data extracted for further processing, including rectification, filtering, and wave processing. Due to the long-duration near-stationary collects, neither the scanner's internal gyroscope and accelerometer nor a secondary external INS/GNSS ${ }^{2}$ system could be used to orient the scanner in space during data rectification (these systems drift when stationary for long periods of time). Instead, the sea-surface returns were leveled in the cross and along-shore directions to determine the pitch and roll of the scanner, and the surveyed GPS coordinates of the corners of the CRAB platform (which were visible in the scans) were used to define the heading. Offsets between the lidar center and the nearest GPS receiver were applied to the GPS coordinates and used to position the scan in space. This rectification procedure assumes a flat sea surface in the cross- and alongshore directions (neglecting any cross-shore setup or setdown and alongshore sea-surface gradients). In addition, as of this technical report, only a single rectification matrix for each scan was determined, and any motions of the CRAB during the collection were not accounted for. Due to

\footnotetext{
1 User Datagram Protocol)

2 Inertial Navigation System/Global Navigation Satellite System
} 
the immense size and spatial complexity, the laser data are not stored on a THREDDS $^{1}$ server. Individuals interested in obtaining a copy of the data should contact the authors of this report.

\subsubsection{Data extents}

Initial results indicated that the scanner provided more surface returns over a larger area, particularly in the cross-shore direction, when foam or aerated water was present on the surface (Figure 6, compare A and B). As a result, locations in the scanners FOV that were at or onshore of the initiation of breaking provided a more continuous time series of sea-surface elevations than locations offshore of wave breaking that had less foam.

Figure 6. Map-view of spatial extent of 3D point clouds of the water surface (y-axis is in the alongshore direction; $x$-axis is in the cross-shore direction) from the Velodyne lidar on the CRAB. Colors correspond to reflectance of the sea-surface, with warmer colors representing higher reflectivity. (A) Lidar 3D point cloud illustrating wider coverage after a breaking wave when relict foam is present on the sea-surface. (B) Lidar 3D point cloud illustrating narrower coverage before a breaking wave when there is less foam.

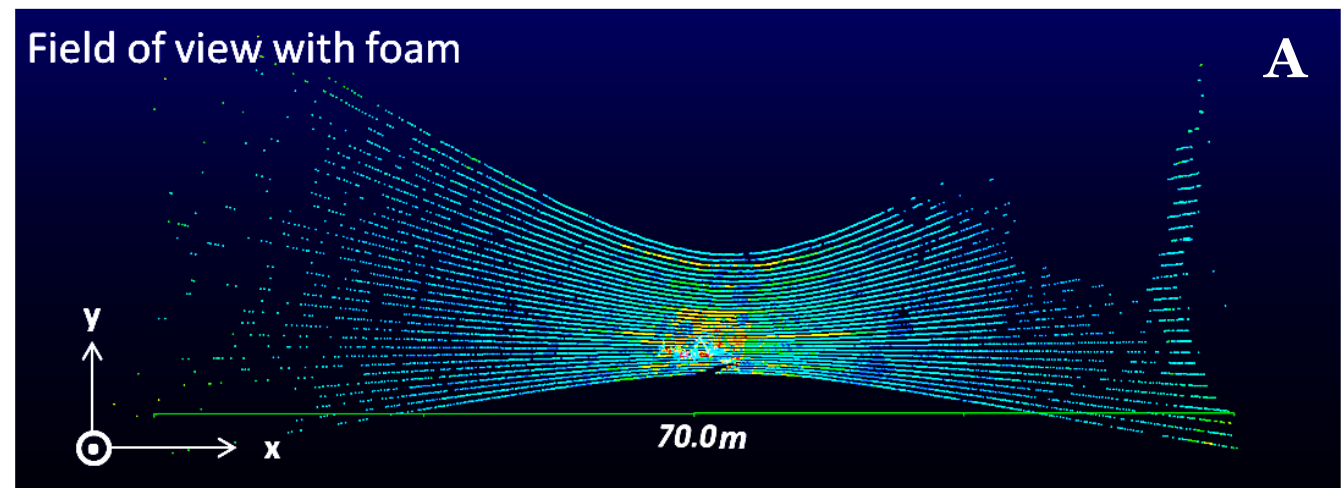

Field of view with no foam

1 Thematic Realtime Environmental Distributed Data Services 
In addition to foam, the scanner also recorded larger data extents when the sea surface was roughened (by wind) and when water clarity was reduced, though these effects were not quantified. Temporally variable data extents will require careful processing techniques to ensure that any wave parameters extracted are robust when less than one wavelength is visible (e.g., Carini 2019).

\subsubsection{Example data}

During the data collection efforts on 04 April 2017, a wide range of breaking and non-breaking wave shapes were observed (Figure 7). The authors determined that wave breaking type was best identifiable when the data were viewed as if looking along the wave crest. Using time series of data from this vantage point, a conceptual model of wave breaking type definitions was developed and is briefly described here and illustrated in Figure 7. Non-breaking waves were characterized by low-surface roughness on the front face, peak, and back slope of the wave (top row, Figure 7). Plunging breakers were characterized by steep front faces, with elliptical-shaped voids between the overturning wave face and notyet-broken front slope of the wave (second row, Figure 7). Significant spray was visible streaming off the front face of the wave. Spilling breakers were characterized by a high surface roughness on the front face of the wave, sometimes with spray streaming off of the top (third row, Figure 7). Already broken bores were visually similar to spilling breakers; however, the patch of surface roughness on the front face of the wave extended all the way down to flat, still water in front of the wave from the initial moment the wave was visible by the scanner (bottom row, Figure 7). In addition, the rear face of the bores had a lower slope than the rear face of spilling breakers. This qualitative conceptual model will be used to develop automated wave classification code for quantitative analysis of wave characteristics. 
Figure 7. Elevation cross sections through 3D lidar point clouds from the CRAB of four different types of waves: non-breaking waves (top row), plunging breaking (second row), spilling breaking (third row), and an already broken bore (bottom row). Notice the lidar returns off of the CRAB above the water surface.

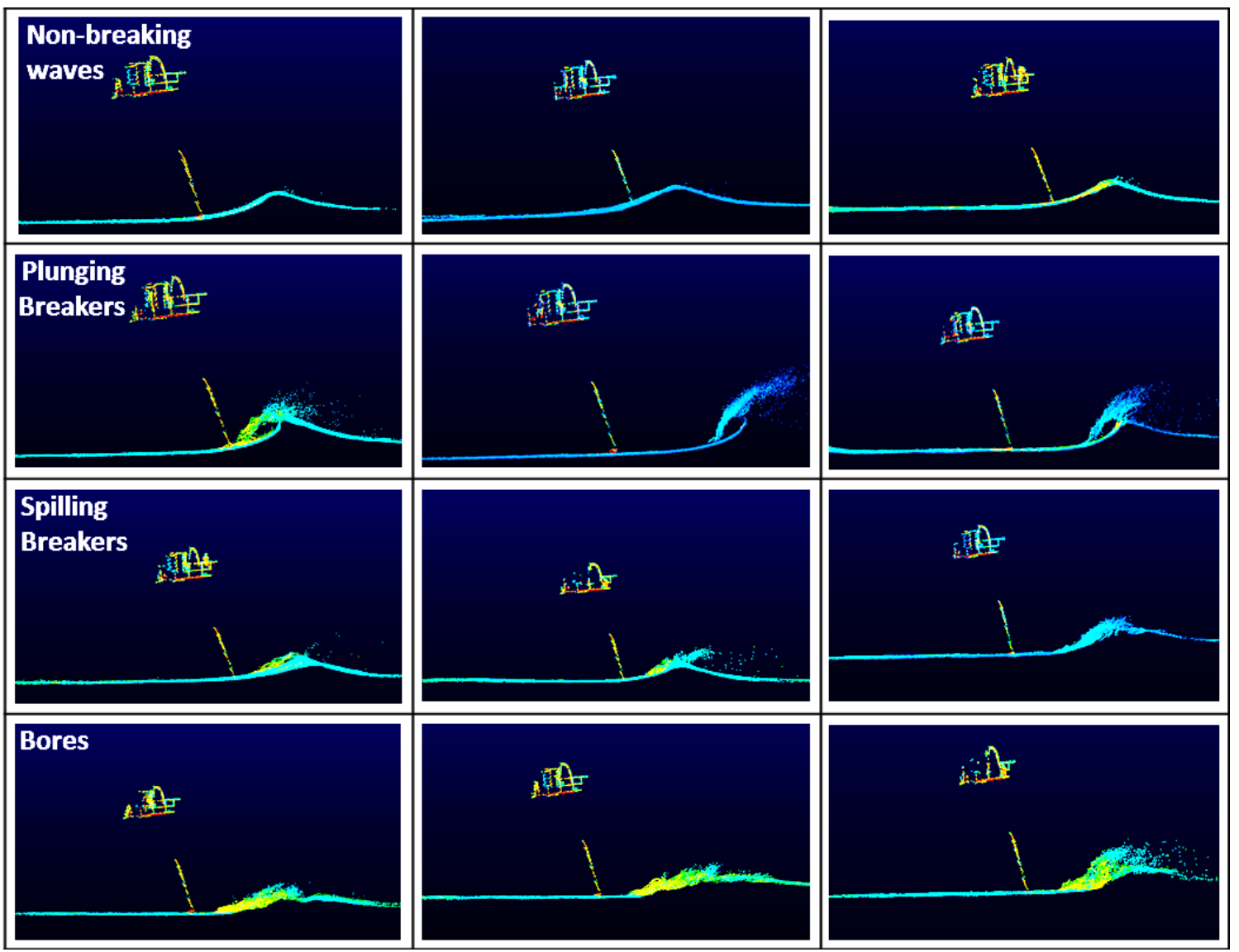

In addition to classifying the type of wave, the shape evolution of each wave can be quantified at high temporal evolution $(10 \mathrm{~Hz})$ from each scan and used to evaluate the detailed cross-shore evolution of wave shape changes during wave breaking. For example, Figure 8 shows the temporal evolution (vertical axes, colors) of an individual plunging breaker moving through the lidar's field of view on 25 October 2017. 
Figure 8. Lidar-observed sea-surface elevation vs. cross-shore position through time (colors, vertical axis) while a plunging breaker breaks. Each subsequent time-step

$(0.1 \mathrm{sec})$ is shown in a separate color and offset $2 \mathrm{~m}$ in the vertical.

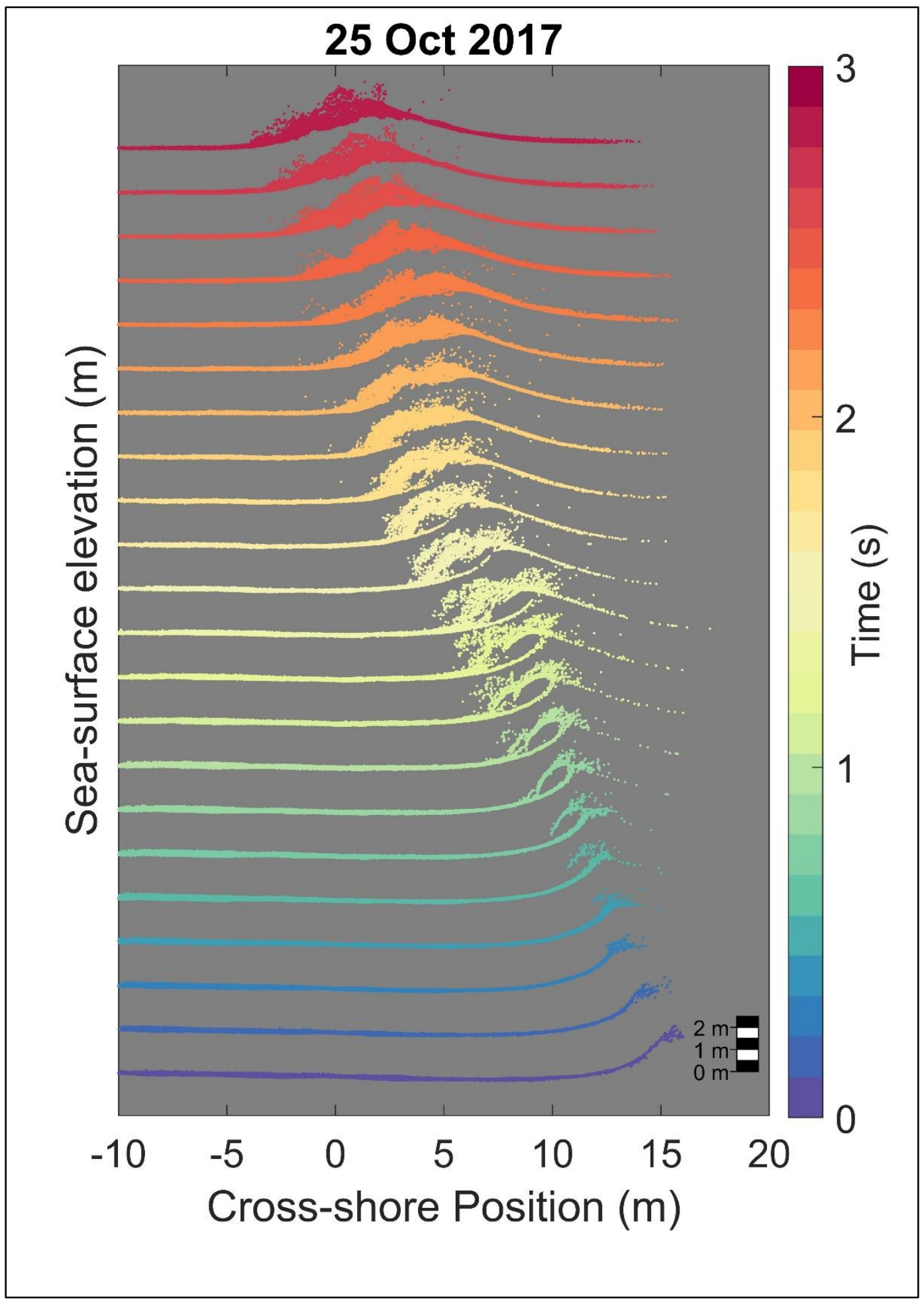




\subsection{Suspended sediment samples}

A total of 266 suspended sediment samples were collected, processed, and analyzed. Total suspended sediment concentration ranged from 0.023 grams per liter (g/L) to $2.20 \mathrm{~g} / \mathrm{L}$. Suspended sand concentration ranged from $0.007 \mathrm{~g} / \mathrm{L}$ to $2.18 \mathrm{~g} / \mathrm{L}$. This large range in sand concentration $(\sim 3$ orders of magnitude) demonstrates that these techniques can be used to collect samples suitable for instrument calibration. Suspended fines concentration ranged from $0.004 \mathrm{~g} / \mathrm{L}$ to $0.471 \mathrm{~g} / \mathrm{L}$.

Suspended sediment data and supporting metadata were converted to netCDF format (https://www.unidata.ucar.edu/software/netcdf/docs/index.html) and are available at

https://chlthredds.erdc.dren.mil/thredds/catalog/frf/projects/WaveShape/SuspendedSediment/catalog html in a single netCDF file. Data provided in the netCDF file include sample time, sample location, nominal sample height above bottom, total sample volume, total SSC, organic SSC from LOI ${ }^{1}$, inorganic SSC, and organic fraction for both the sand and fine fractions.

\subsection{Aquatec Aquascat}

The Aquatec Aquascat ABS sampled from the top of the hour to 58 min after the hour resulting in up to 2 min data gaps on some stations. The Aquascat measured acoustic backscatter amplitude in $1 \mathrm{~cm}$ bins with four acoustic transducers ranging in frequency from $1 \mathrm{MHz}$ to $4 \mathrm{MHz}$ (Figure 9). The combination of frequencies as well as profile length, transducer location, and transducer orientation were modified over time to produce a diversity of configurations for evaluating instrument performance as well as processing techniques (e.g., developing algorithms to account for attenuation due to suspended sediment or bubbles). The total recorded profile distance ranged from 1.2 to $2.5 \mathrm{~m}$ with some portion of the profile always extending below the seabed to ensure a complete profile to the seafloor. Transducer orientation included vertical, horizontal, and skew (meaning a $45^{\circ}$ angle between vertical and horizontal), and the frequency combinations included (1) $1 \mathrm{MHz}, 1 \mathrm{MHz}, 2 \mathrm{MHz}, 4 \mathrm{MHz}$ and (2) $1 \mathrm{MHz}, 1$ $\mathrm{MHz}, 4 \mathrm{MHz}, 4 \mathrm{MHz}$. In data from transducers in a vertical orientation, the surface of the seabed can be easily identified. The elevation, orientation, and frequency for each beam are specified within the netCDF

\footnotetext{
1 loss on ignition
} 
data files in the variable attributes for each beams acoustic backscatter amplitude variable (ABS1, $\left.\mathrm{ABS} 2, \mathrm{ABS}_{3}, \mathrm{ABS} 4\right)$.

The ABS acoustic backscatter amplitude was sampled at either $40 \mathrm{~Hz}$ or $8 \mathrm{o} \mathrm{Hz}$. Intervals of eight samples were averaged by the instrument during collection, returning data at $5 \mathrm{~Hz}$ or $10 \mathrm{~Hz}$. The returned backscatter amplitude data had a near-field correction applied (Downing et al. 1995) and was corrected for attenuation by water (Fisher and Simmons 1977). The amplitude was further corrected for beam spreading and with a manufacturer-supplied system constant following common methods (e.g., Thorne and Hurther 2014).

In addition to multi-frequency profiles of acoustic backscatter amplitude, the ABS also reported pressure. The ABS housing and pressure sensor were mounted on the cross beam of the CRAB, $1.76 \mathrm{~m}$ above the ground when parked on a level surface. Due to its higher elevation, the pressure sensor may have been out of the water either continuously or intermittently when parked on shallow stations. The pressure record was corrected for local barometric pressure variations.

The ABS returned a profile of acoustic backscatter from the transducer to the end of the path length (1.2 to 2.5 meters) including the water column and seabed and providing an easy-to-interpret, qualitative picture of what all instruments are seeing. For example, from a short burst of ABS data (Figure 4), it is easily discernable how high suspended sediments are being suspended into the water column and when and how deep bubbles are being mixed down. This was an invaluable resource for data interpretation and complemented the time series of point measurements provided by the other acoustic and optical sensors. Additionally, by recording profiles of acoustic backscatter extending beyond the seabed, the seabed could be identified, and the height of the sensors relative to the seabed to be accurately determined at all times. This was critical as it demonstrated that the CRAB sank into the seabed when on station, effectively changing the height above the bed of instruments over time.

The ABS data were converted to netCDF format and are available at https://chlthredds.erdc.dren.mil/thredds/catalog/frf/projects/WaveShape/AquatecABS/catalog.html

An ABS netCDF file was created for each station occupied during the experiment. Data provided in the netCDF file includes station location, 
sample time, time series of backscatter profiles from the four acoustic transducers, and pressure time series. The netCDF files are stored in daily folders with a netCDF Markup Language (.ncml) file in each that aggregates the data for a given day and allows all ABS data from that day to be accessible at a single endpoint.

Figure 9. Example 1 min time series of acoustic backscatter amplitude from (A) $1 \mathrm{MHz}$, (B) $2 \mathrm{MHz}$, and (C) $4 \mathrm{MHz}$ transducers of the Aquatec Aquascat ABS. Color scale is backscatter intensity with yellow representing strong backscattering (sediment or bubbles) and blue weak backscattering (relatively clear water).

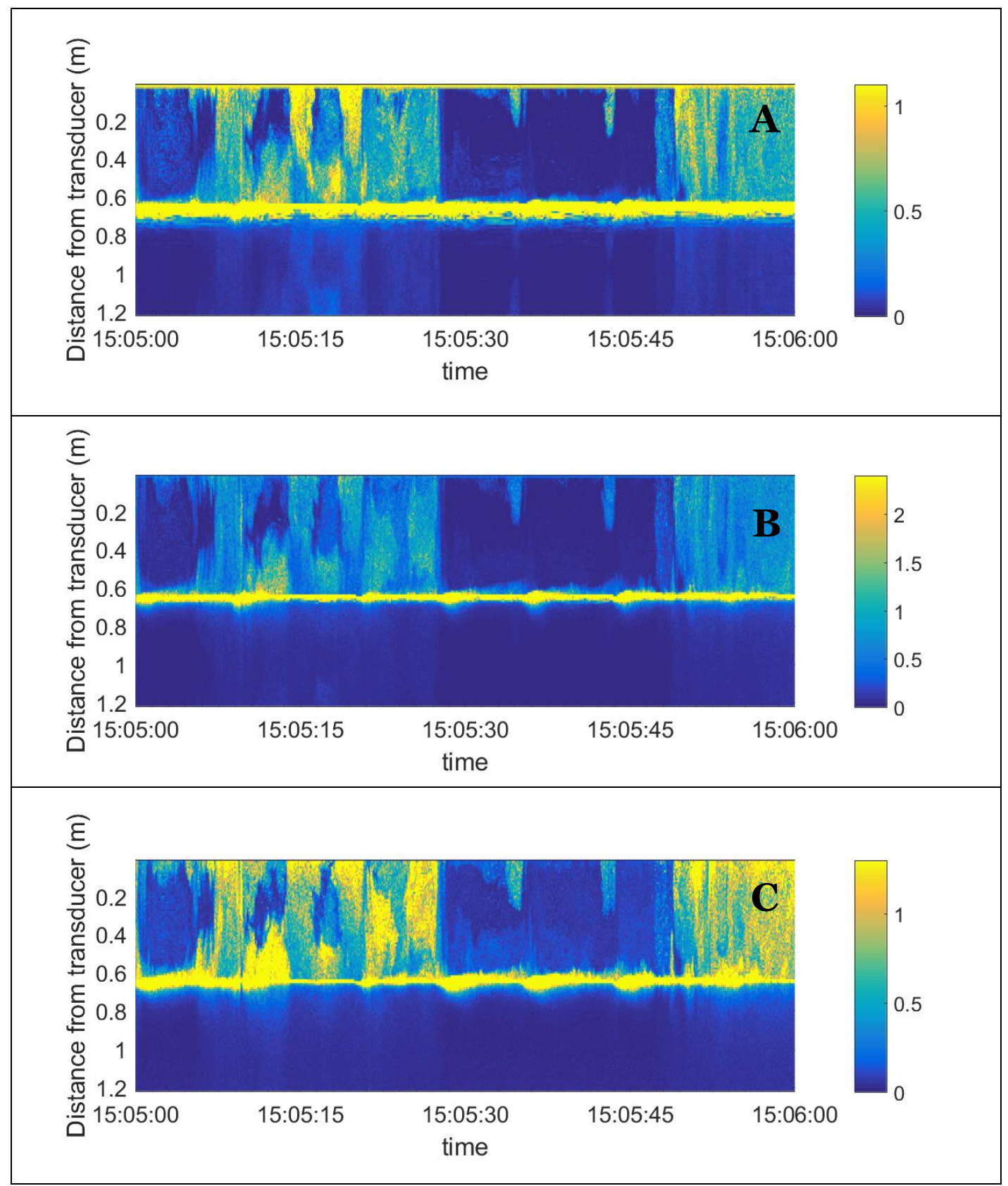




\subsection{Nortek Vector and Sontek Triton acoustic Doppler velocimeter (ADV)}

The Nortek Vector and Sontek Triton ADVs were oriented with transducers facing the seabed and collected $2 \mathrm{~Hz}$ samples of $3 \mathrm{D}$ velocity and acoustic backscatter $0.50 \mathrm{~m}$ above the seabed on 18 November 18 2016 and 12 January 122017 and $0.40 \mathrm{~m}$ above the bed for the remaining experiment dates. The pressure sensor was $0.37 \mathrm{~m}$ above the acoustic sample volume on the Vector and $0.30 \mathrm{~m}$ on the Triton. Both ADVs collected data in 6144 sample bursts (51.2 min long) starting at the top of the hour, resulting in data gaps of up to approximately 8 min on some stations.

The Nortek and Triton ADV data were converted to netCDF format and are available at

https://chlthredds.erdc.dren.mil/thredds/catalog/frf/projects/WaveShape/VectorADV/catalog.html and

https://chlthredds.erdc.dren.mil/thredds/catalog/frf/projects/WaveShape/TritonADV/catalog.html

A netCDF file was created for the ADV data for each station occupied during the experiment. Data provided in the netCDF file includes station location, sample time, and time series of current speed, direction, east, north, and vertical velocity, intensity (signal strength), correlation, and pressure. One-minute example ADV time series are presented in Figures 10, 11, 12, and 13. Velocity direction was rotated using a local magnetic correction of $-11.2^{\circ}$. The pressure record was corrected for local barometric pressure variations. The NetCDF files are stored in daily folders with a .$n c m l$ in each that aggregates the data for a given day and allows all ADV data from that day to be accessible at a single endpoint. 
Figure 10. Example 1 min time series of (A) eastward current velocity, (B) northward current velocity, and $(C)$ upward current velocity from the Sontek Triton ADV.

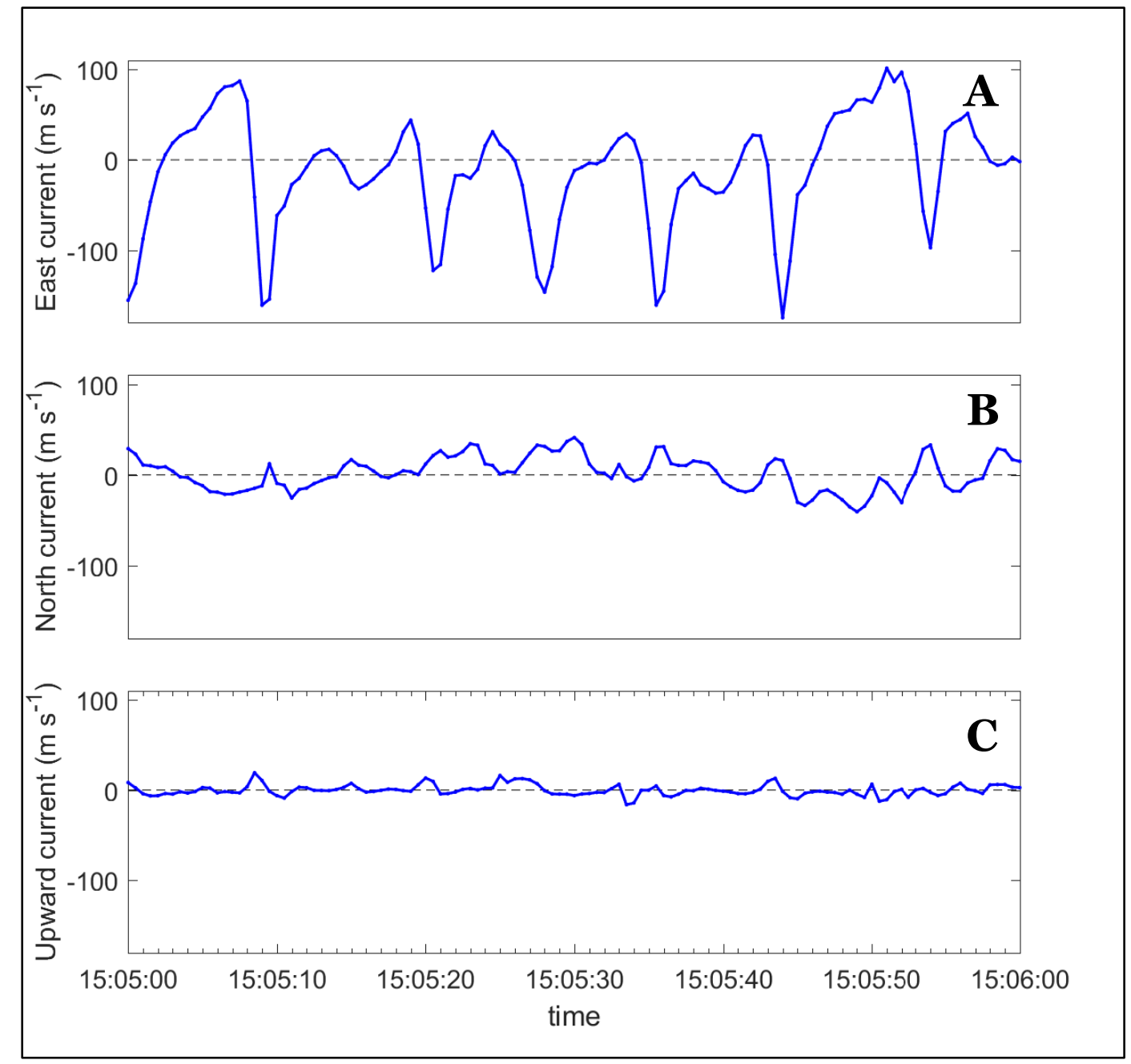


Figure 11. Example 1 min time series of (A) pressure, (B) current speed, and (C) current direction from the Sontek Triton ADV.

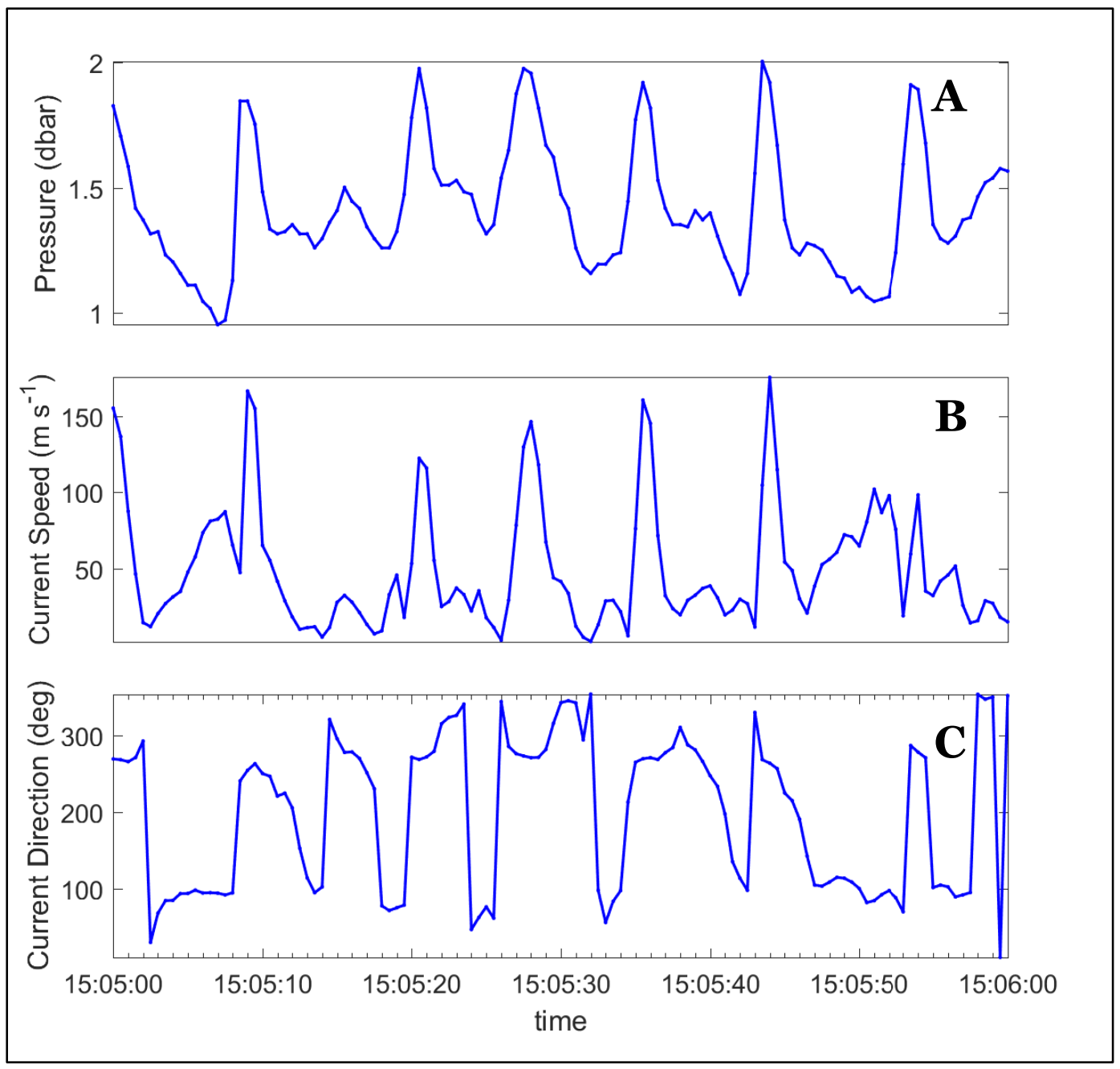


Figure 12. Example 1 mintime series of beam intensity (counts) from (A) beam 1, (B) beam 2, and (C) beam 3 from the Sontek Triton ADV.

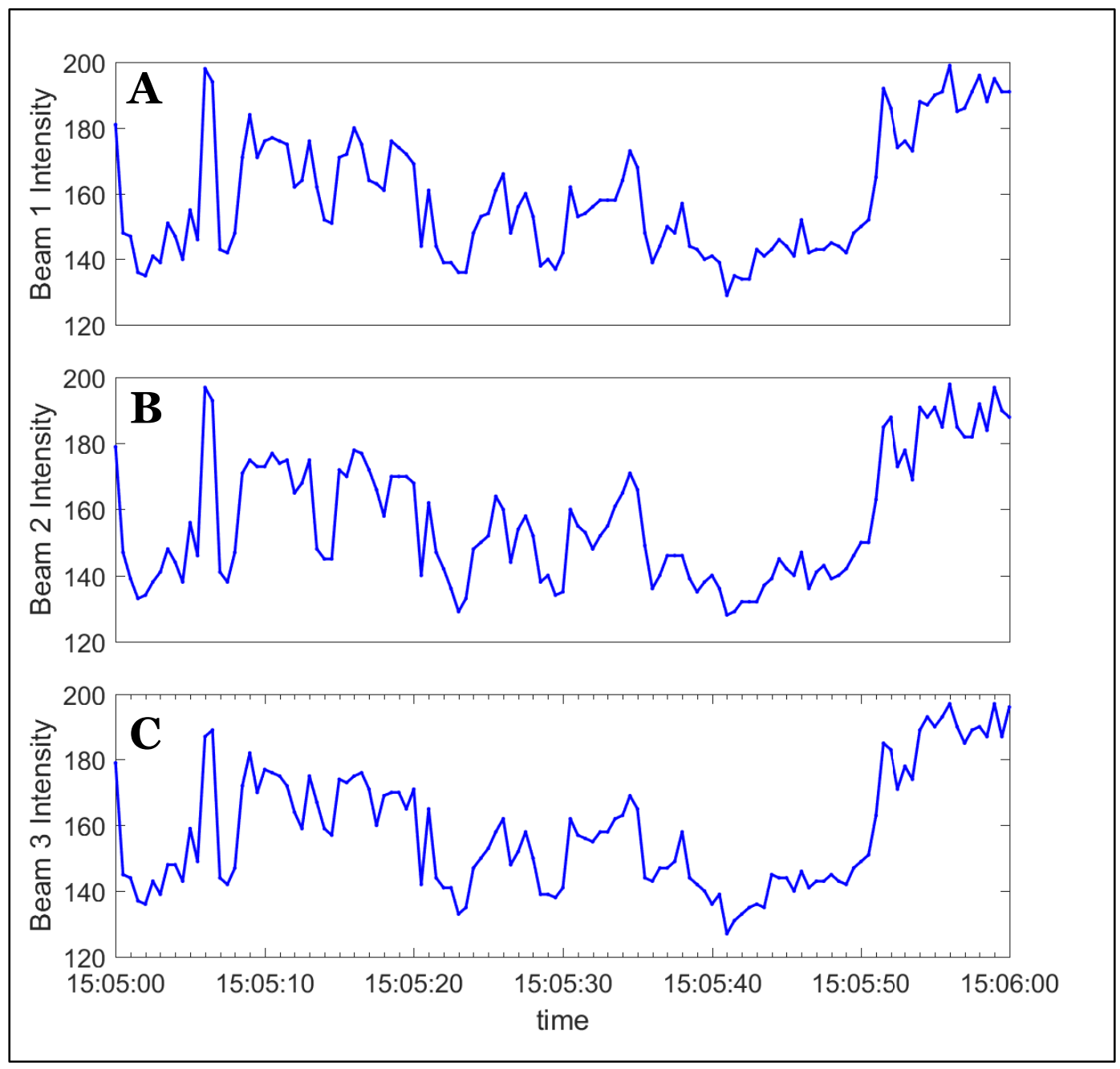


Figure 13. Example $1 \mathrm{~min}$ time series of beam correlation (a quality-control parameter) from the Sontek Triton ADV.

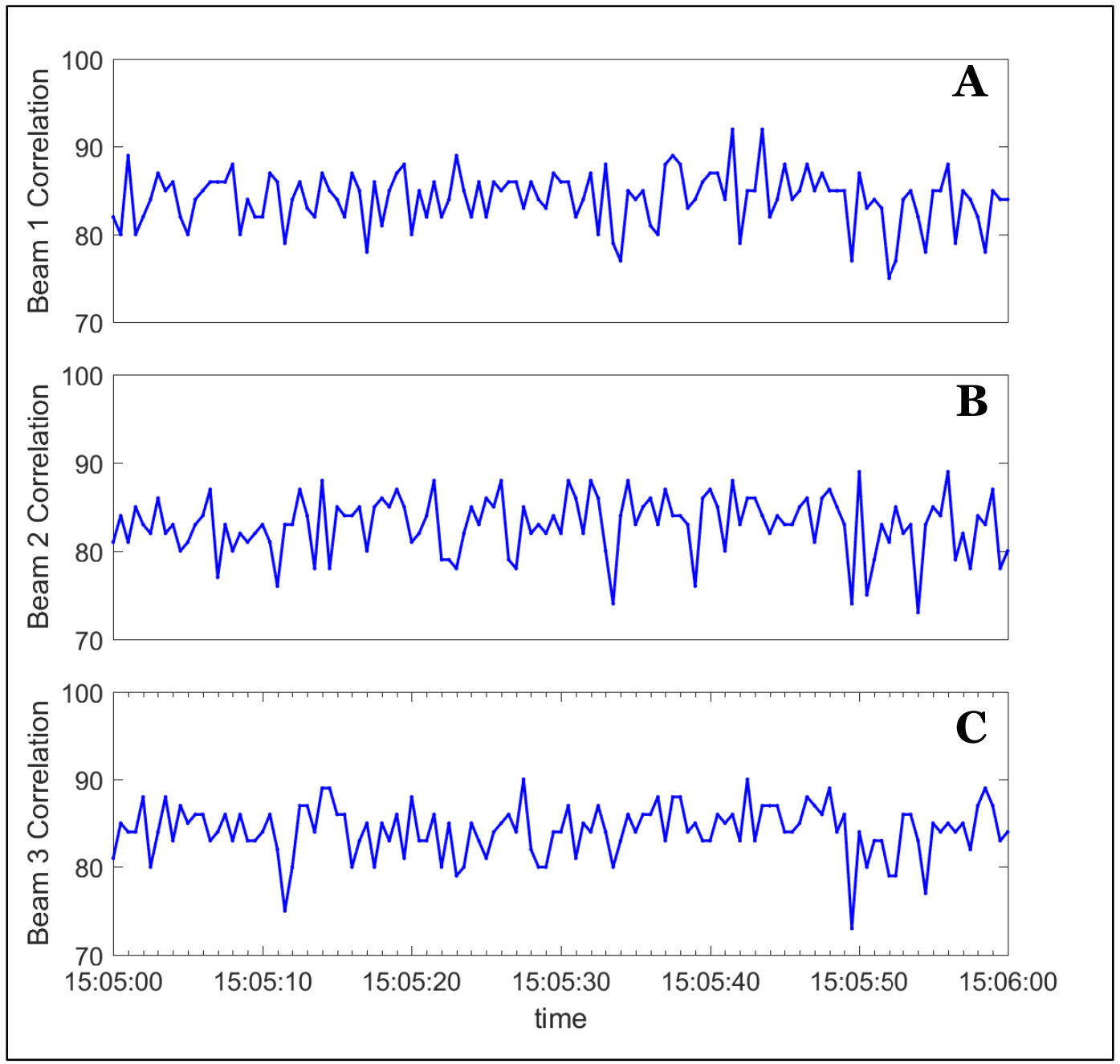

\subsection{WetLabs ECONTU and ECOBB3}

A WetLabs ECONTU was mounted vertically looking down from the sample intake pipe approximately $0.5 \mathrm{~m}$ above bottom on 18 November 18 2016 and a WetLabs ECOBB3 was mounted in the same location on 12 January 12 2017, and at $0.40 \mathrm{~m}$ for the remainder of the experiment. The ECONTU measured optical backscatter at $700 \mathrm{~nm}$ while the ECOBB3 measured optical backscatter at $470 \mathrm{~nm}, 532 \mathrm{~nm}$, and $700 \mathrm{~nm}$. The response of both units was factory calibrated and reported in nephelometric turbidity units.

An example time series of Wetlabs $\mathrm{ECOBB}_{3}$ data is presented in Figure 14. Preliminary analysis of data from these optical backscatter sensors indicated that they were much more sensitive to the fine sediment 
in suspension than to sand. The surprisingly high concentrations of fine sediment (approximately 0.03 to $0.5 \mathrm{~g} / \mathrm{L}$ ) overwhelmed the sensor response, generally resulting in a relative insensitivity to suspended sand concentrations. However, it has been demonstrated at this site (Battisto 2000) that the fines concentration varies slowly (time scale of hours) while the sand concentration varies on much shorter time scales (seconds), and a low percentile backscatter return can be subtracted from the time series record to isolate the instrument response to suspended sand.

The WetLabs ECO optical backscatter data were converted to netCDF format and are available at https://chlthredds.erdc.dren.mil/thredds/catalog/frf/projects/WaveShape/ECONTU_opticalTurbidity/cat alog.html and https://chlthredds.erdc.dren.mil/thredds/catalog/frf/projects/WaveShape/BB3_opticalTurbidity/catalog $\underline{. h t m l}$.

A netCDF file was created for the ECO data for each station occupied during the experiment. Data provided in the netCDF file include station location, sample time, and time series of the optical backscatter for each wavelength available. The netCDF files are stored in daily folders with a .$n c m l$ in each that aggregates the data for a given day and allows all ECO optical turbidity data from that day to be accessible at a single endpoint. 
Figure 14. Example $1 \mathrm{~min}$ time series of optical backscatter at (A) $470 \mathrm{~nm}$, (B) $532 \mathrm{~nm}$, and (C) $700 \mathrm{~nm}$ from the WetLabs ECOBB3.

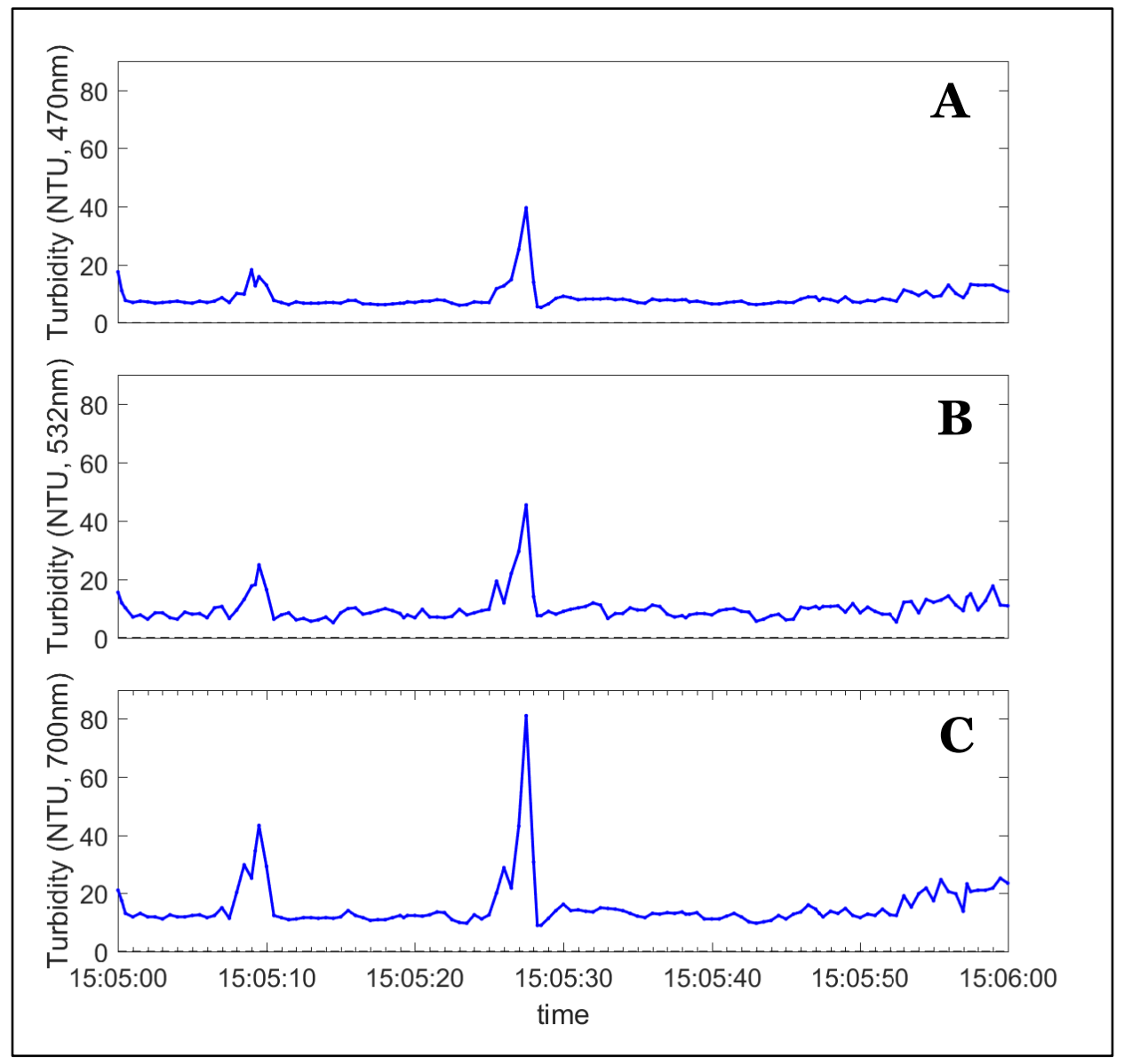

\subsection{Sequoia LISST-ABS}

The Sequoia Scientific LISST-ABS was mounted horizontally on the sample intake pipe at the same elevation as and directly adjacent to the WetLabs ECO (Figure 2C). The LISST-ABS sampled continuously at $1 \mathrm{~Hz}$ and reported acoustic backscatter uncalibrated concentration. An example 1 min time series of LISST-ABS data is presented in Figure 15.

The Sequoia LISST-ABS acoustic backscatter data were converted to netCDF format and are available at https://chlthredds.erdc.dren.mil/thredds/catalog/frf/projects/WaveShape/LISST_ABS/catalog.html

A netCDF file was created for the LISST-ABS data for each station occupied during the experiment. Data provided in the netCDF file include station location, sample time, and time series of the acoustic backscatter. The netCDF files are stored in daily folders with a .ncml in each that 
aggregates the data for a given day and allows all LISST-ABS data from that day to be accessible at a single endpoint.

Figure 15. Example 1-min time series of acoustic backscatter in units of uncalibrated concentration from the Sequoia LISST-ABS.

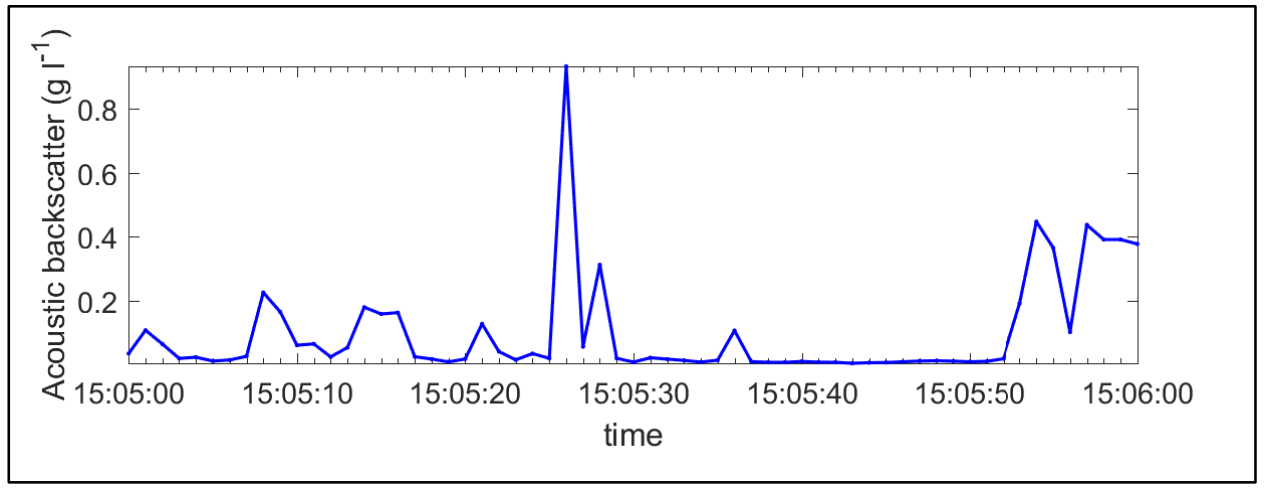

\subsection{Survey data}

Cross-shore bathymetric transects were collected with the CRAB to complement the lidar and suspended sediment measurements. Survey transects were collected from the dune to approximately $5 \mathrm{~m}$ depth at least once per day and often two or more times to constrain any changes that may occur during the days sampling effort. Similar to the suspended sediment instrumentation time-series data, the survey data were converted into netCDF format and are available at https://chlthredds.erdc.dren.mil/thredds/catalog/frf/projects/WaveShape/SurveyTransect/catalog.html

A netCDF file was created for each individual survey transect and includes elevation, latitude, longitude, and along and across shore coordinates in the FRF coordinate system. Similar to other measurements, survey transect netCDF files are stored in daily folder. However, a single. $\mathrm{ncml}$ was created allowing all survey data from this project to be accessible at a single endpoint. The naming convention of individual files includes the date, time, and along-shore FRF coordinate of the transect. For example, the transect in file

FRF-ocean_WaveShape_SurveyTransect_20170921-1831-yo716.nc

was collected on 21 September 2017 at 18:31 Coordinated Universal Time (UTC) along FRF along-shore coordinate $716 \mathrm{~m}$. Examples of surveys plotted as bathymetric profiles can be found in the Appendix. 


\section{Conclusions}

This technical report documents field activities and data collected during an intensive field effort executed in 2016 and 2017 at the ERDC FRF in Duck, NC, in support of an ERDC Basic Research Program project, entitled New Field Measurements and Parameterizations to Predict Wave Breaking Shape from Environmental Forcing. These experiments were conducted to provide an extensive data set to be used in evaluating how environmental forcing factors influence wave shape and wave breaker type. This may contribute to the understanding and predictive ability relating to wave energy dissipation, sediment transport, and seabed morphological evolution in the surf zone.

A total of 88 stations was occupied between November 2016 and October 2017, producing an extensive data set from a suite of sub-aerial and subaqueous instruments over a wide range of environmental conditions. The FRF's amphibious CRAB was used as a survey and mobile in situ data collection platform providing logistical flexibility and allowing optimum locations to be targeted on each sampling day.

All survey and sub-aqueous instrument data were converted to netCDF format complete with metadata and archived on the Coastal and Hydraulics Thredds server at https://chlthredds.erdc.dren.mil/thredds/catalog/frr/projects/WaveShape/catalog.html

The point cloud data from the Velodyne lidar were too large to be efficiently archived and shared via netCDF and THREDDS and will be disseminated by the authors upon request. 


\section{References}

Almeida, L. P., G. Masselink, P. E. Russell, M. Davidson, T. Poate, R. Mccall, C. Blenkinsopp, and I. L. Turner. 2013. "Observations of the Swash Zone on a Gravel Beach during a Storm Using a Laser-Scanner (Lidar).” J. Coastal Res. 65: 636-641. https://doi.org/10.2112/SI65-108.1

Blenkinsopp, C. E., M. A. Mole, I. L. Turner, and W. L. Peirson. 2010. "Measurements of the Time-Varying Free-Surface Profile across the Swash Zone Obtained Using an Industrial LIDAR.” Coastal Eng. 57: 1059-1065.

Brodie, K. L., B. Raubenheimer, S. Elgar, R. K. Slocum, and J. E. McNinch. 2015. "Lidar and Pressure Measurements of Inner-Surfzone Waves and Setup.” Journal of Atmospheric and Oceanic Technology 32(10): 1945-1959.

Brodie, K. L., R. K. Slocum, and J. E. McNinch. 2012. "New Insights into the Physical Drivers of Wave Runup from a Continuously Operating Terrestrial Laser Scanner.” Oceans, IEEE 8. doi:10.1109/0CEANS.2012.6404955. CrossRef

Camenen, B., and M. Larson. 2007. "Predictive Formulas for Breaker Depth Index and Breaker Type.” Journal of Coastal Research 23(4): 1028-1041.

Carini, R. J. 2019. Geometry, Kinematics and Energetics of Surf Zone Waves near the Onset of Breaking Using Remote Sensing. PhD dissertation. University of Washington.

Downing, A., P. D. Thorne, and C. E. Vincent. 1995. "Backscattering from a Suspension in the Near Field of a Piston Transducer." The Journal of the Acoustical Society of America 97(3): 1614-1620.

Downing, John. 2006. "Twenty-Five Years with OBS Sensors: The Good, the Bad, and the Ugly." Continental Shelf Research 26(17-18): 2299-2318.

Fisher, F. H., and V. P. Simmons. 1977. "Sound Absorption in Sea Water." The Journal of the Acoustical Society of America 62(3): 558-564.

Fugate, David C., and Carl T. Friedrichs. 2002. "Determining Concentration and Fall Velocity of Estuarine Particle Populations Using ADV, OBS, and LISST." Continental Shelf Research 22(11-13): 1867-1886.

Ha, H. K., W. Y. Hsu, J. Y. Maa, Y. Y. Shao, and C. W. Holland. 2009. “Using ADV Backscatter Strength for Measuring Suspended Cohesive Sediment Concentration." Continental Shelf Research 29(10): 1310-1316.

Kineke, G. C., and R. W. Sternberg. 1992. "Measurements of High Concentration Suspended Sediments Using the Optical Backscatterance Sensor." Marine Geology 108(3-4): 253-258.

Smith, E. R., P. Wang, B. A. Ebersole, and J. Zhang. 2009. "Dependence of Total Longshore Sediment Transport Rates on Incident Wave Parameters and Breaker Type.” Journal of Coastal Research 25(3):675-683. 
Thorne, P. D., and D. Hurther. 2014. "An Overview on the use of Backscattered Sound for Measuring Suspended Particle Size and Concentration Profiles in Non-Cohesive Inorganic Sediment Transport Studies.” Continental Shelf Research 73: 97-118.

Vousdoukas, M. I., T. Kirupakaramoorthy, H. Oumeraci, M. de la Torre, F. Wübbold, B. Wagner, and S. Schimmels. 2014. "The Role of Combined Laser Scanning and Video Techniques in Monitoring Wave-by-Wave Swash Zone Processes.” Coastal Eng. 83: 150-165. doi:10.1016/i.coastaleng.2013.10.013. CrossRef

Weishar, L., and R. Byrne. 1978. "Field Study of Breaking Wave Characteristics.” In Proceedings of the 16th International Conference on Coastal Engineering, Hamburg, Germany, ASCE. https://doi.org/10.9753/icce.v16.27 


\section{Appendix: Experiment Station Log and Field Conditions}

This appendix describes the oceanographic conditions, stations sampled, and instrumentation for each day of the experiment. A description of the layout of each page is as follows:

Figure A. ARGUS time exposure image of the shoreline and surf zone at the FRF in Duck, NC. The pier is just south of center at approximately along-shore coordinate 515. White bands in the water indicate the region of active wave breaking. Yellow triangles mark the station locations where data were collected from the CRAB on that day.

Figure B. Oceanographic and meteorological conditions for that day of the experiment. On each panel, the vertical gray bars indicate on station times when instruments were recording. The top panel is wind speed (black) and wind direction (gray). The middle panel is wave height from the $26 \mathrm{~m}$ Waverider (blue), $17 \mathrm{~m}$ Waverider (green), or $8 \mathrm{~m}$ array (black) and peak wave period from the $8 \mathrm{~m}$ array (gray). The $26 \mathrm{~m}$ Waverider was out of commission on October 25 and 26, so the $17 \mathrm{~m}$ Waverider was substituted. The $8 \mathrm{~m}$ array was included to provide a consistent data record for the duration of the study.

Figure C. GoPro image taken from the CRAB during sampling. Not available on all days but included when possible to provide a visual representation of that days conditions.

Figure D. Elevation transects recorded by the CRAB. All transects for a given day are included, and station locations are indicated by dots. The legend provides the along-shore coordinate and the time for each transect.

Table. The table provides time, coordinates, and data types collected for each station on a given day.

Description/Field notes. Summary of observations recorded by science team on the CRAB. 


\section{8-Nov-2016}
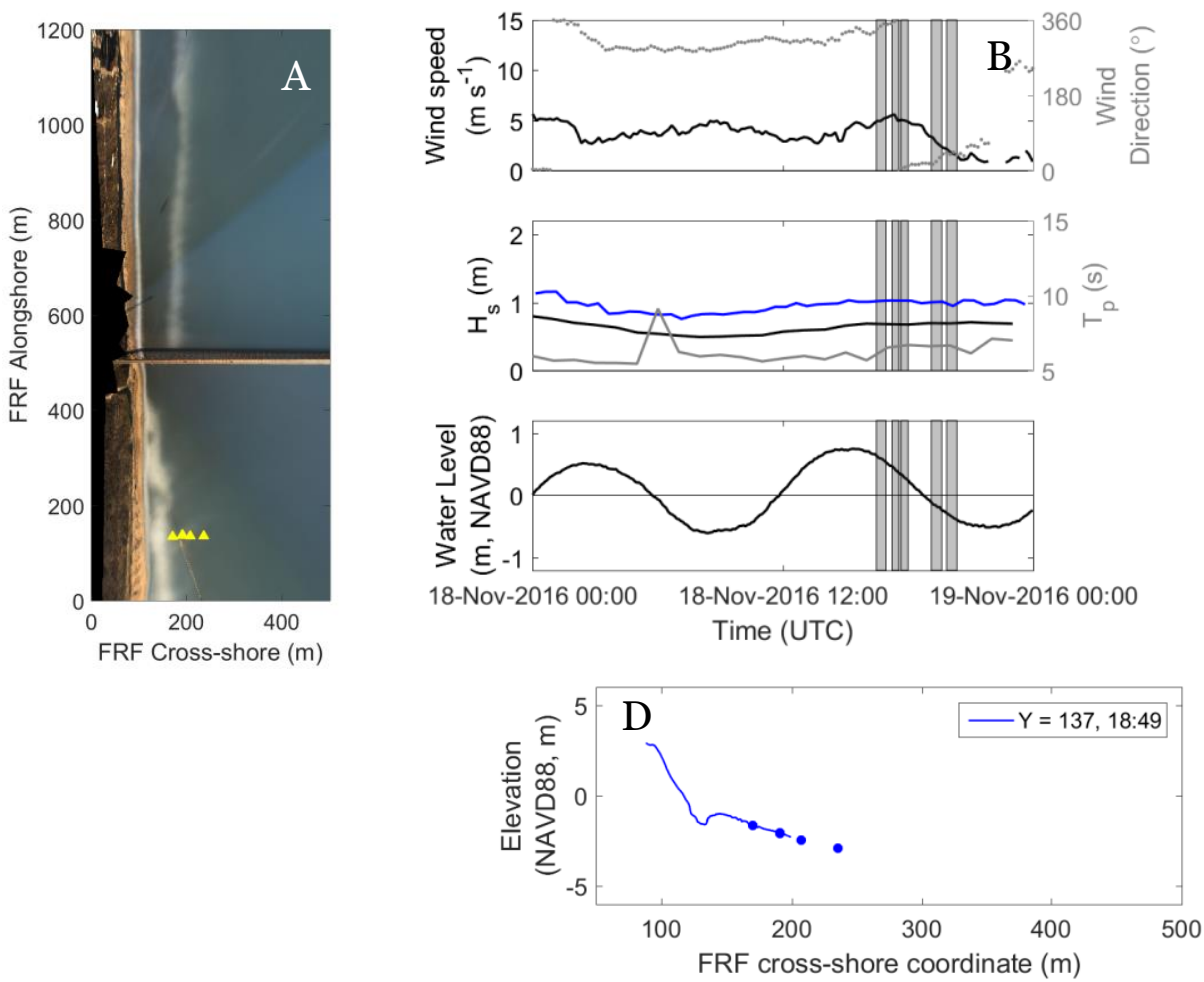

\begin{tabular}{|c|c|c|c|c|c|c|c|c|c|c|}
\hline $\begin{array}{c}\text { Station } \\
\#\end{array}$ & $\begin{array}{c}\text { Start } \\
\text { Time } \\
\text { (UTC) }\end{array}$ & $\begin{array}{c}\text { End } \\
\text { Time } \\
\text { (UTC) }\end{array}$ & $\begin{array}{c}\text { FRF } \\
\text { X }\end{array}$ & $\begin{array}{c}\text { FRF } \\
\text { Y }\end{array}$ & SSC & $\begin{array}{c}\text { Opt } \\
\text { Turb }\end{array}$ & $\begin{array}{c}\text { LISST } \\
\text { ABS }\end{array}$ & $\begin{array}{c}\text { Aqua } \\
\text {-scat }\end{array}$ & ADV & Lidar \\
\hline 1 & $16: 28$ & $16: 56$ & 236 & 136 & $x$ & $x$ & & $x$ & $x$ & \\
\hline 2 & $17: 13$ & $17: 33$ & 207 & 135 & $x$ & $x$ & & $x$ & $x$ & \\
\hline 3 & $17: 39$ & $17: 59$ & 170 & 135 & $x$ & $x$ & & $x$ & $x$ & \\
\hline 4 & $19: 06$ & $19: 36$ & 191 & 138 & $x$ & $x$ & & $x$ & $x$ & $x$ \\
\hline 5 & $19: 50$ & $20: 20$ & 191 & 137 & & $x$ & & $x$ & $x$ & $x$ \\
\hline
\end{tabular}

\section{Description/Field Notes}

First sampling of pilot experiment. Waves, $<1$ meter. Station 1 - waves shoaling but not breaking. Station 2 - just seaward of breakers. Station 3 at break point. Station 4 - side to waves, just inside breakpoint. Station 5 in shore break. 


\section{2-Jan-2017}
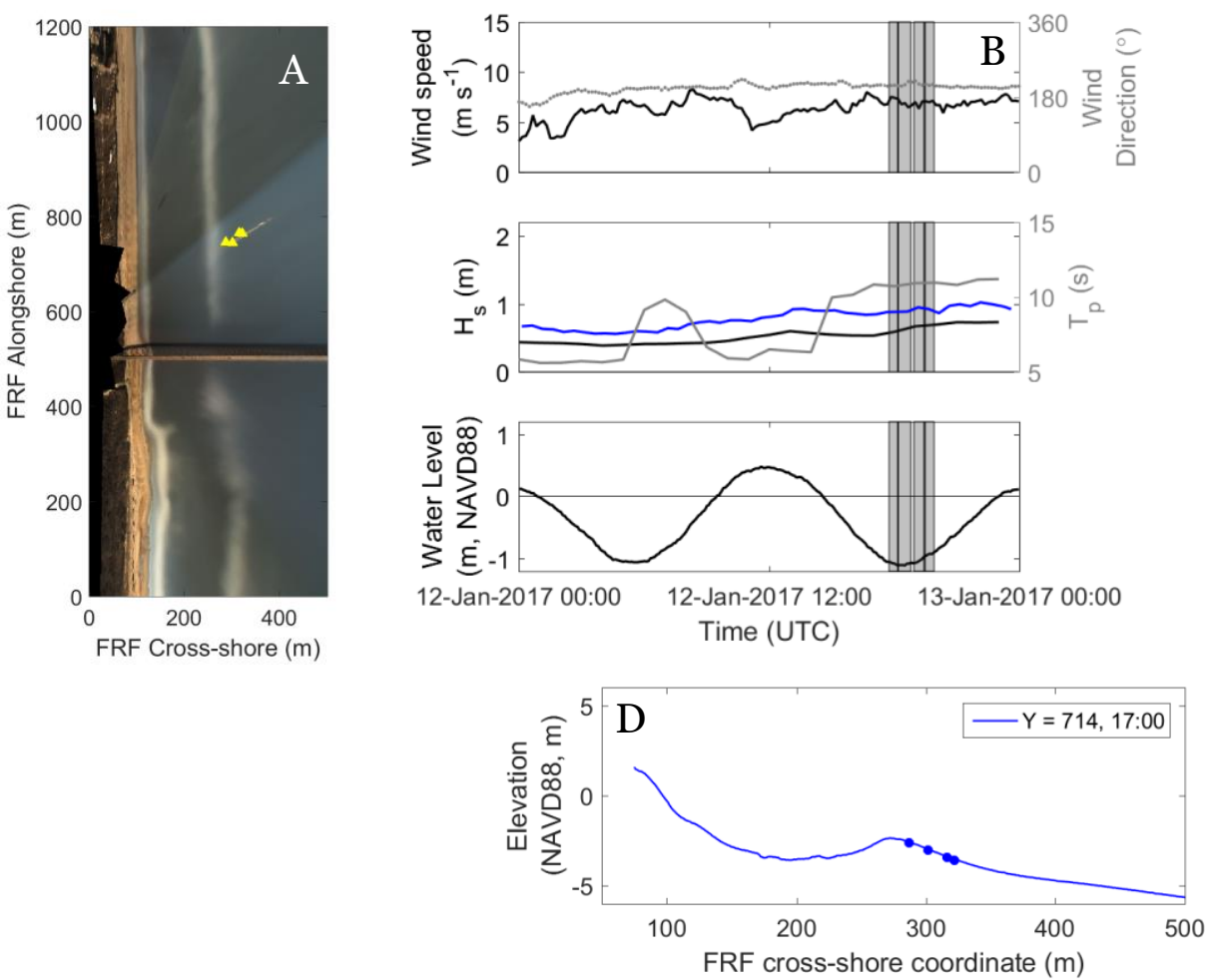

\begin{tabular}{|c|c|c|c|c|c|c|c|c|c|c|}
\hline $\begin{array}{c}\text { Station } \\
\#\end{array}$ & $\begin{array}{c}\text { Start } \\
\text { Time } \\
\text { (UTC) }\end{array}$ & $\begin{array}{c}\text { End } \\
\text { Time } \\
\text { (UTC) }\end{array}$ & $\begin{array}{c}\text { FRF } \\
\mathrm{X}\end{array}$ & $\begin{array}{c}\text { FRF } \\
\text { Y }\end{array}$ & SSC & $\begin{array}{c}\text { Opt } \\
\text { Turb }\end{array}$ & $\begin{array}{c}\text { LISST } \\
\text { ABS }\end{array}$ & $\begin{array}{c}\text { Aqua } \\
\text {-scat }\end{array}$ & ADV & Lidar \\
\hline 1 & $17: 44$ & $18: 09$ & 322 & 764 & $\mathrm{x}$ & & & $\mathrm{x}$ & $\mathrm{x}$ & $\mathrm{x}$ \\
\hline 2 & $18: 11$ & $18: 47$ & 316 & 765 & $\mathrm{x}$ & & & $\mathrm{x}$ & $\mathrm{x}$ & $\mathrm{x}$ \\
\hline 3 & $18: 56$ & $19: 25$ & 301 & 745 & $\mathrm{x}$ & & & $\mathrm{x}$ & $\mathrm{x}$ & $\mathrm{x}$ \\
\hline 4 & $19: 28$ & $19: 54$ & 287 & 746 & $\mathrm{x}$ & & & $\mathrm{x}$ & $\mathrm{x}$ & $\mathrm{x}$ \\
\hline
\end{tabular}

\section{Description/Field Notes}

Shallow linear sandbars. Optical turbidity sensor failed. Station 1 - outer sandbar, shoaling waves. Station 2 - just outside of breakpoint, shoaling waves. Station 3 - right at breakpoint. Station 4 - top of sandbar, in the breakers. 


\section{4-Apr-2017}
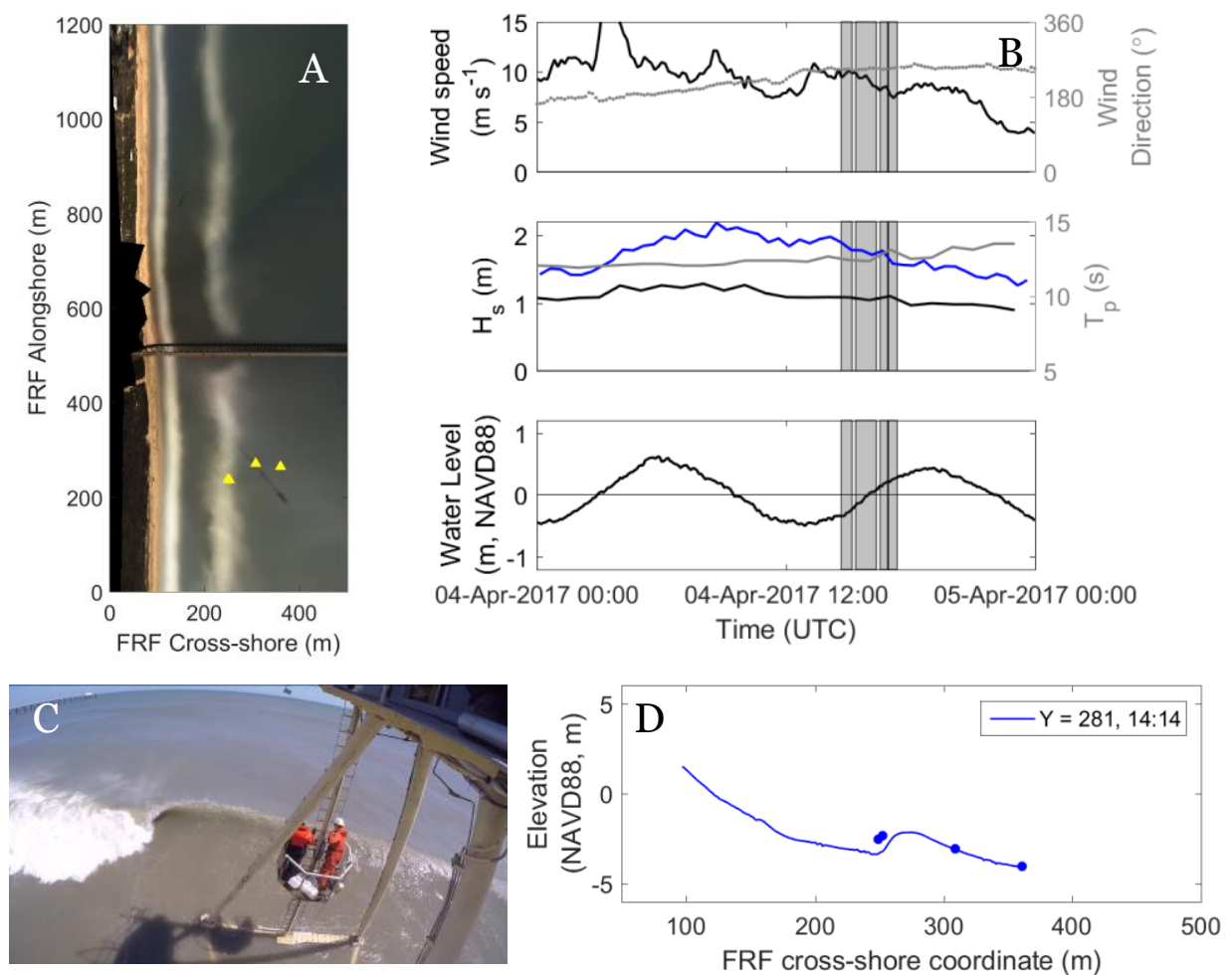

\begin{tabular}{|c|c|c|c|c|c|c|c|c|c|c|}
\hline $\begin{array}{c}\text { Station } \\
\#\end{array}$ & $\begin{array}{c}\text { Start } \\
\text { Time } \\
\text { (UTC) }\end{array}$ & $\begin{array}{c}\text { End } \\
\text { Time } \\
\text { (UTC) }\end{array}$ & $\begin{array}{c}\text { FRF } \\
\text { X }\end{array}$ & $\begin{array}{c}\text { FRF } \\
\text { Y }\end{array}$ & SSC & $\begin{array}{c}\text { Opt } \\
\text { Turb }\end{array}$ & $\begin{array}{c}\text { LISST } \\
\text { ABS }\end{array}$ & $\begin{array}{c}\text { Aqua- } \\
\text { scat }\end{array}$ & ADV & Lidar \\
\hline 1 & $14: 39$ & $15: 10$ & 361 & 264 & $x$ & $x$ & & $x$ & $x$ & $x$ \\
\hline 2 & $15: 20$ & $16: 20$ & 309 & 271 & $x$ & $x$ & & $x$ & $x$ & $x$ \\
\hline 3 & $16: 30$ & $16: 53$ & 249 & 237 & $x$ & $x$ & & $x$ & $x$ & $x$ \\
\hline 4 & $16: 55$ & $17: 20$ & 252 & 237 & $x$ & $x$ & & $x$ & $x$ & $x$ \\
\hline
\end{tabular}

\section{Description/Field Notes}

2 meter plunging waves. Station 1 - outside of breakpoint. Station 2 just outside of breakpoint. Most breaking waves out of view of lidar. Station 3 - Moved lidar to aft, starboard corner of crab. Just inside breakpoint. Great data from plunging waves. Station 4 - Moved enough to get CRAB out of scour hole and repeat station. 
06-Sep-2017
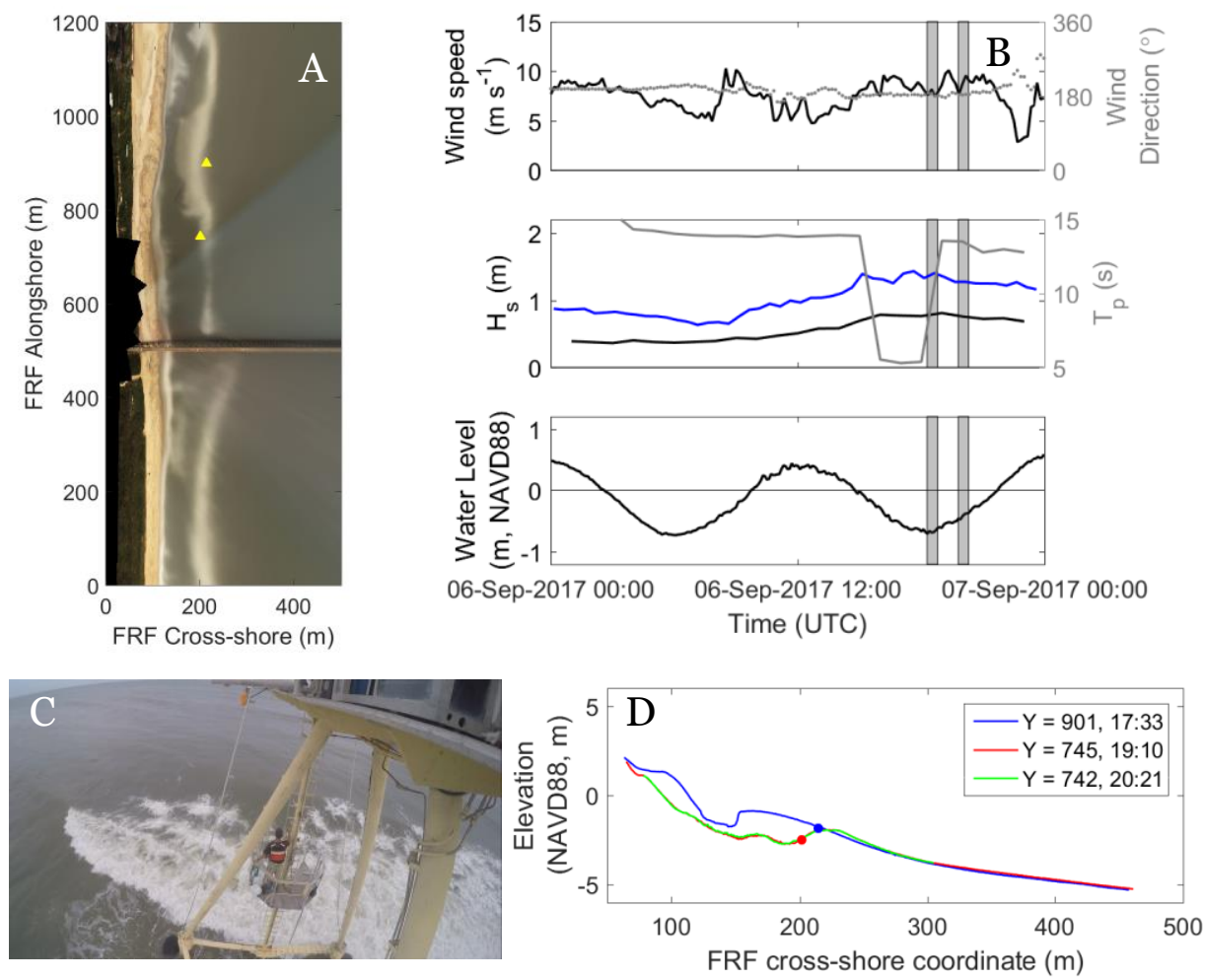

\begin{tabular}{|c|c|c|c|c|c|c|c|c|c|c|}
\hline $\begin{array}{c}\text { Station } \\
\#\end{array}$ & $\begin{array}{c}\text { Start } \\
\text { Time } \\
\text { (UTC) }\end{array}$ & $\begin{array}{c}\text { End } \\
\text { Time } \\
\text { (UTC) }\end{array}$ & $\begin{array}{c}\text { FRF } \\
\text { X }\end{array}$ & $\begin{array}{c}\text { FRF } \\
\text { Y }\end{array}$ & SSC & $\begin{array}{c}\text { Opt } \\
\text { Turb }\end{array}$ & $\begin{array}{c}\text { LISST } \\
\text { ABS }\end{array}$ & $\begin{array}{c}\text { Aqua- } \\
\text { scat }\end{array}$ & ADV & Lidar \\
\hline 1 & $18: 17$ & $18: 48$ & 215 & 899 & $\mathrm{x}$ & $\mathrm{x}$ & & $\mathrm{x}$ & & $\mathrm{x}$ \\
\hline 2 & $19: 48$ & $20: 18$ & 202 & 743 & $\mathrm{x}$ & $\mathrm{x}$ & & $\mathrm{x}$ & & $\mathrm{x}$ \\
\hline
\end{tabular}

\section{Description/Field Notes}

$1^{\text {st }}$ day of main experiment. Occupied stations on 2 transects. Mostly small $(\sim 0.8 \mathrm{~m})$, steep angle, short period waves. 


\section{7-Sep-2017}
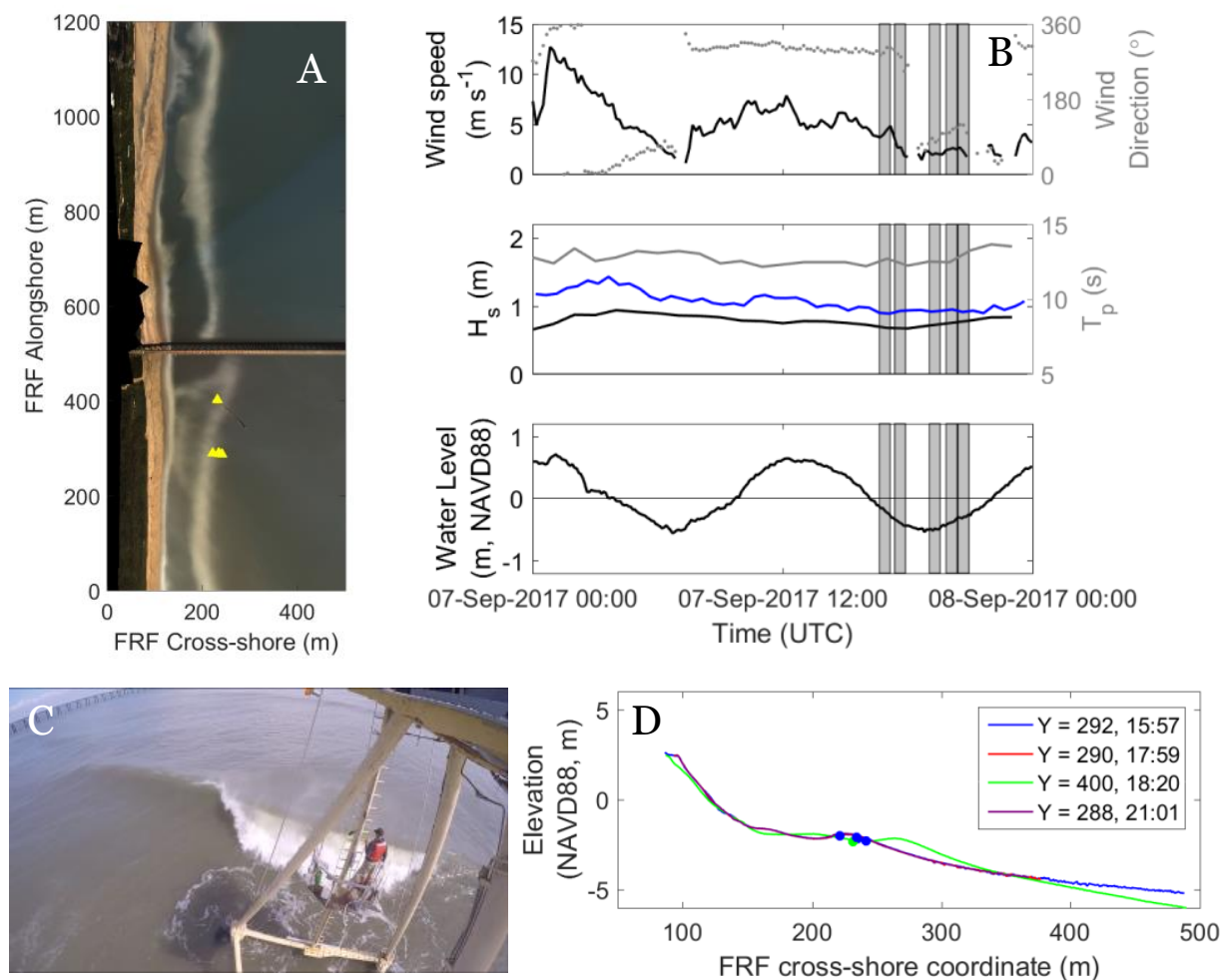

\begin{tabular}{|c|c|c|c|c|c|c|c|c|c|c|}
\hline $\begin{array}{c}\text { Station } \\
\#\end{array}$ & $\begin{array}{c}\text { Start } \\
\text { Time } \\
\text { (UTC) }\end{array}$ & $\begin{array}{c}\text { End } \\
\text { Time } \\
\text { (UTC) }\end{array}$ & $\begin{array}{c}\text { FRF } \\
\text { X }\end{array}$ & $\begin{array}{c}\text { FRF } \\
\text { Y }\end{array}$ & SSC & $\begin{array}{c}\text { Opt } \\
\text { Turb }\end{array}$ & $\begin{array}{c}\text { LISST } \\
\text { ABS }\end{array}$ & $\begin{array}{c}\text { Aqua- } \\
\text { scat }\end{array}$ & ADV & Lidar \\
\hline 1 & $16: 38$ & $17: 09$ & 221 & 290 & $x$ & $x$ & & $x$ & & $x$ \\
\hline 2 & $17: 22$ & $17: 53$ & 234 & 290 & $x$ & $x$ & & $x$ & & $x$ \\
\hline 3 & $19: 02$ & $19: 33$ & 231 & 402 & $x$ & $x$ & & $x$ & & $x$ \\
\hline 4 & $19: 50$ & $20: 22$ & 241 & 288 & $x$ & $x$ & & $x$ & & $x$ \\
\hline 5 & $20: 24$ & $20: 56$ & 234 & 289 & $x$ & $x$ & & $x$ & & $x$ \\
\hline
\end{tabular}

\section{Description/Field Notes}

Great waves! Swell from Major Hurricane Irma. Offshore wind. Steep, sometimes plunging waves with about 2 meter faces. Occupied 2 transects on south side of pier. 
08-Sep-2017
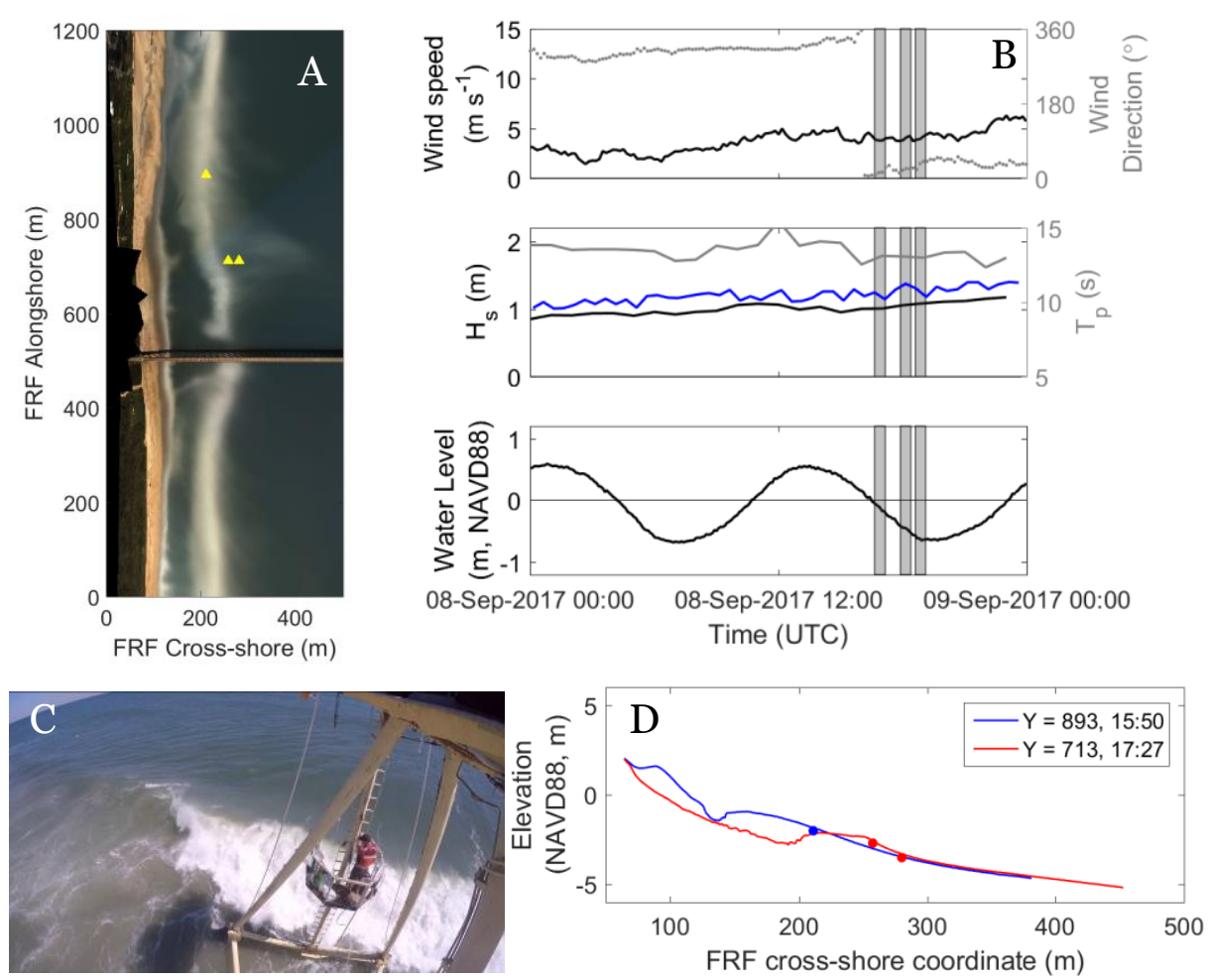

\begin{tabular}{|c|c|c|c|c|c|c|c|c|c|c|}
\hline $\begin{array}{c}\text { Station } \\
\#\end{array}$ & $\begin{array}{c}\text { Start } \\
\text { Time } \\
\text { (UTC) }\end{array}$ & $\begin{array}{c}\text { End } \\
\text { Time } \\
\text { (UTC) }\end{array}$ & $\begin{array}{c}\text { FRF } \\
\text { X }\end{array}$ & $\begin{array}{c}\text { FRF } \\
\text { Y }\end{array}$ & SSC & $\begin{array}{c}\text { Opt } \\
\text { Turb }\end{array}$ & $\begin{array}{c}\text { LISST } \\
\text { ABS }\end{array}$ & $\begin{array}{c}\text { Aqua- } \\
\text { scat }\end{array}$ & ADV & Lidar \\
\hline 1 & $16: 38$ & $17: 09$ & 211 & 894 & $x$ & $x$ & & $x$ & & $x$ \\
\hline 2 & $17: 53$ & $18: 23$ & 280 & 712 & $x$ & $x$ & & $x$ & & $x$ \\
\hline 3 & $18: 36$ & $19: 06$ & 258 & 712 & $x$ & $x$ & & $x$ & & $x$ \\
\hline
\end{tabular}

\section{Description/Field Notes}

Swell from Major Hurricane Irma still building. Light to moderate side shore wind. Waves too big to safely operate on south side so sampling north side of pier. Waves 2+ meters. Station 1 setup just inside of 2 meter face, clean peeling fairly steep rights. Appears to be very little fine sediment in water. Stations 2 and 3, big spilling waves. Very large rip current in the area. 


\section{3-Sep-2017}
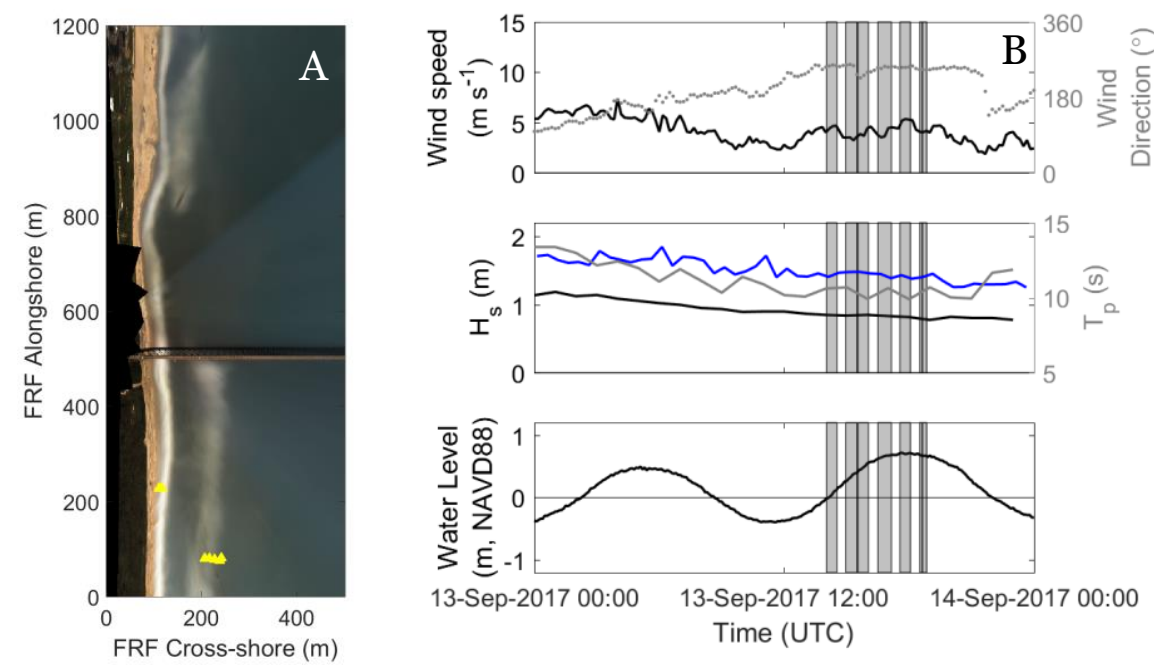

13-Sep-2017 00:00 13-Sep-2017 12:00 14-Sep-2017 00:00 Time (UTC)
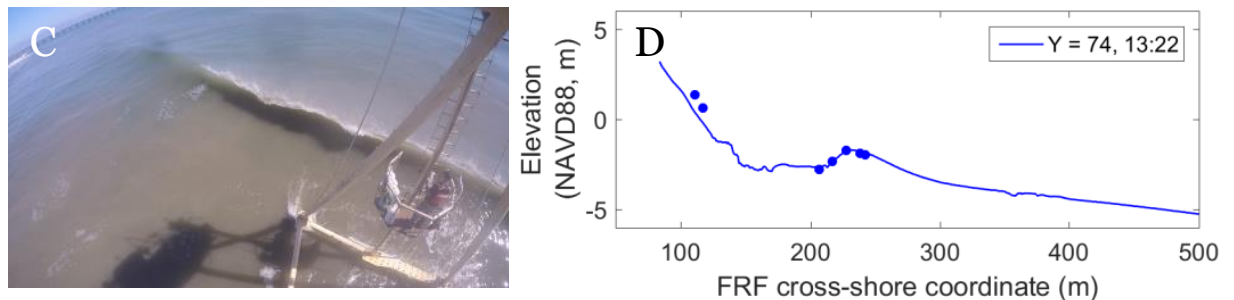

\begin{tabular}{|c|c|c|c|c|c|c|c|c|c|c|}
\hline $\begin{array}{c}\text { Station } \\
\#\end{array}$ & $\begin{array}{c}\text { Start } \\
\text { Time } \\
\text { (UTC) }\end{array}$ & $\begin{array}{c}\text { End } \\
\text { Time } \\
\text { (UTC) }\end{array}$ & $\begin{array}{c}\text { FRF } \\
\text { X }\end{array}$ & $\begin{array}{c}\text { FRF } \\
\text { Y }\end{array}$ & SSC & $\begin{array}{c}\text { Opt } \\
\text { Turb }\end{array}$ & $\begin{array}{c}\text { LISST } \\
\text { ABS }\end{array}$ & $\begin{array}{c}\text { Aqua- } \\
\text { scat }\end{array}$ & ADV & Lidar \\
\hline 1 & $14: 02$ & $14: 32$ & 242 & 81 & $x$ & $x$ & $x$ & $x$ & $x$ & $x$ \\
\hline 2 & $14: 58$ & $15: 30$ & 239 & 76 & $x$ & $x$ & $x$ & $x$ & $x$ & $x$ \\
\hline 3 & $15: 33$ & $16: 03$ & 228 & 77 & $x$ & $x$ & $x$ & $x$ & $x$ & $x$ \\
\hline 4 & $16: 30$ & $17: 09$ & 217 & 80 & $x$ & $x$ & $x$ & $x$ & $x$ & $x$ \\
\hline 5 & $17: 34$ & $18: 04$ & 207 & 80 & $x$ & $x$ & $x$ & $x$ & $x$ & $x$ \\
\hline 6 & $18: 31$ & $18: 38$ & 117 & 227 & $x$ & $x$ & $x$ & $x$ & $x$ & $x$ \\
\hline 7 & $18: 39$ & $18: 51$ & 111 & 227 & $x$ & $x$ & $x$ & $x$ & $x$ & $x$ \\
\hline
\end{tabular}

\section{Description/Field Notes}

Swell from Hurricane Jose. Offshore wind. Medium steep to modest plunging waves in the 1 to 1.7 meter range. Patchy muddy water. Lots of grass in water causing problems with pump. 


\section{1-Sep-2017}
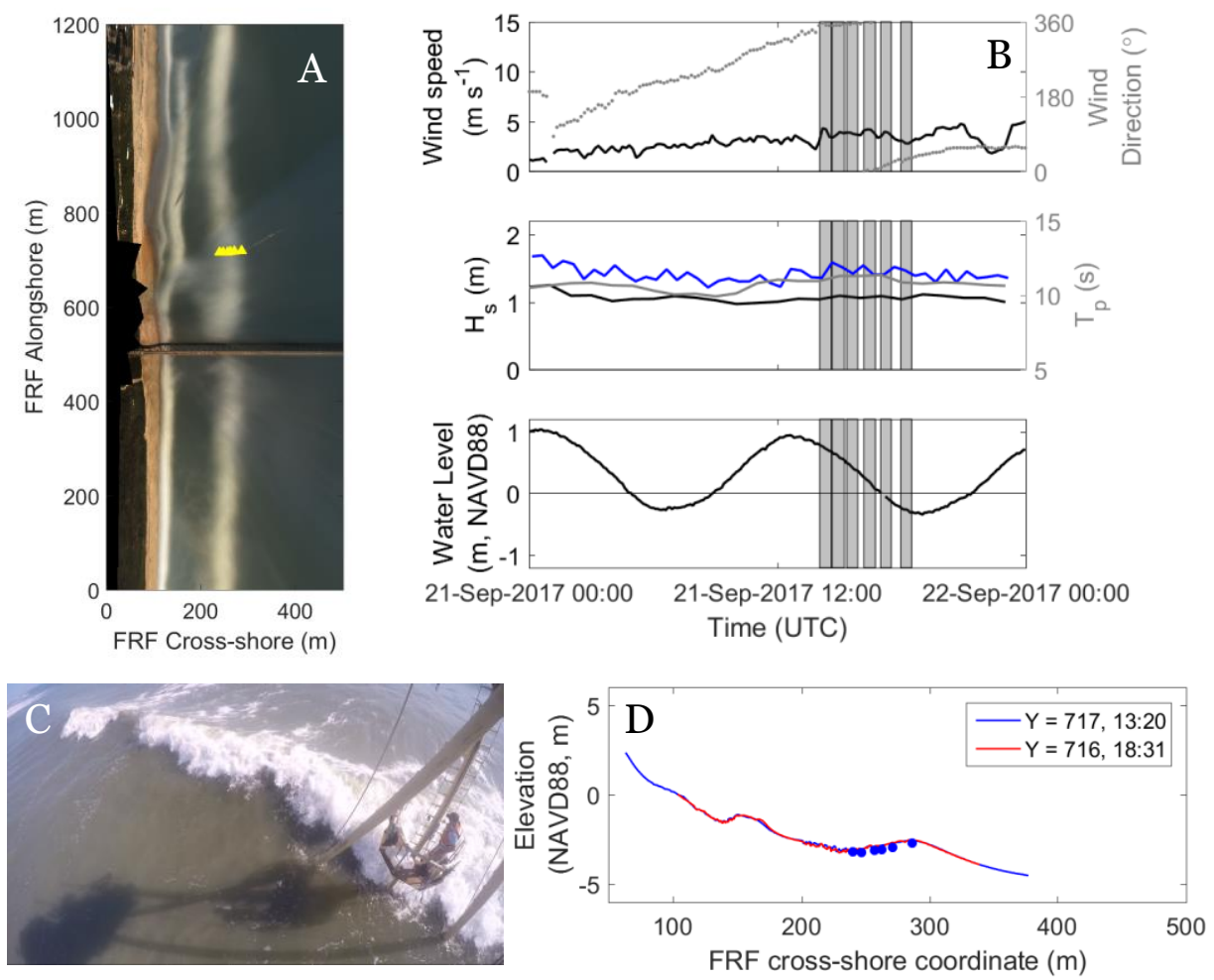

\begin{tabular}{|c|c|c|c|c|c|c|c|c|c|c|}
\hline $\begin{array}{c}\text { Station } \\
\#\end{array}$ & $\begin{array}{c}\text { Start } \\
\text { Time } \\
\text { (UTC) }\end{array}$ & $\begin{array}{c}\text { End } \\
\text { Time } \\
\text { (UTC) }\end{array}$ & $\begin{array}{c}\text { FRF } \\
\text { X }\end{array}$ & $\begin{array}{c}\text { FRF } \\
\text { Y }\end{array}$ & SSC & $\begin{array}{c}\text { Opt } \\
\text { Turb }\end{array}$ & $\begin{array}{c}\text { LISST } \\
\text { ABS }\end{array}$ & $\begin{array}{c}\text { Aqua- } \\
\text { scat }\end{array}$ & ADV & Lidar \\
\hline 1 & $14: 02$ & $14: 35$ & 240 & 716 & $x$ & $x$ & $x$ & $x$ & $x$ & $x$ \\
\hline 2 & $14: 38$ & $15: 13$ & 247 & 716 & $x$ & $x$ & $x$ & $x$ & $x$ & $x$ \\
\hline 3 & $15: 20$ & $15: 52$ & 257 & 716 & $x$ & $x$ & $x$ & $x$ & $x$ & $x$ \\
\hline 4 & $16: 10$ & $16: 43$ & 262 & 718 & $x$ & $x$ & $x$ & $x$ & $x$ & $x$ \\
\hline 5 & $16: 58$ & $17: 29$ & 271 & 718 & $x$ & $x$ & $x$ & $x$ & $x$ & $x$ \\
\hline 6 & $17: 57$ & $18: 28$ & 286 & 719 & $x$ & $x$ & $x$ & $x$ & $x$ & $x$ \\
\hline
\end{tabular}

\section{Description/Field Notes}

Swell from Hurricane Jose which just passed. 1.5 to 2+ meter wave faces and muddy water. Start near high tide with crumbly waves. Waves getting noticeably steeper during station 4 . 


\section{9-Sep-2017}
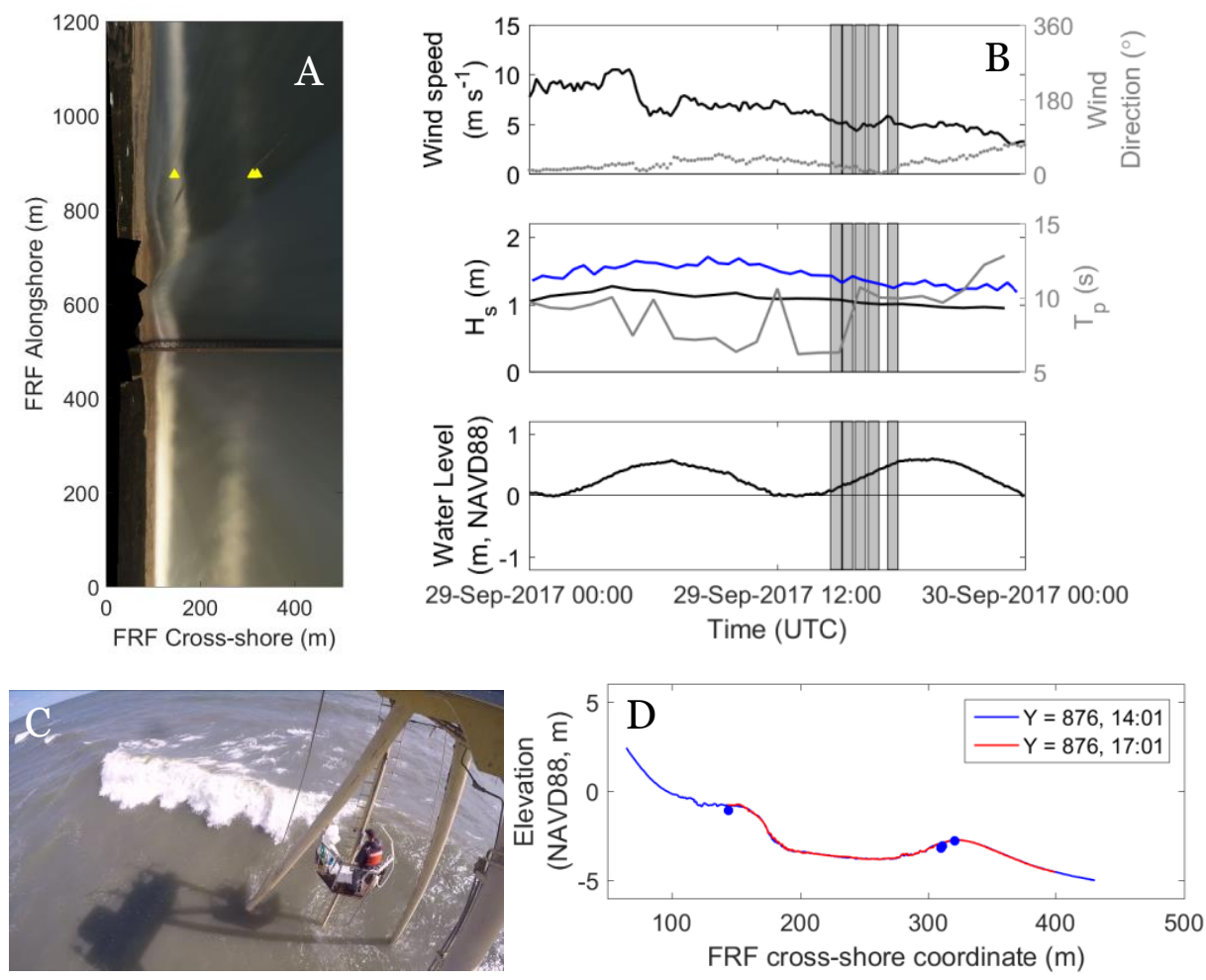

\begin{tabular}{|c|c|c|c|c|c|c|c|c|c|c|}
\hline $\begin{array}{c}\text { Station } \\
\#\end{array}$ & $\begin{array}{c}\text { Start } \\
\text { Time } \\
\text { (UTC) }\end{array}$ & $\begin{array}{c}\text { End } \\
\text { Time } \\
\text { (UTC) }\end{array}$ & $\begin{array}{c}\text { FRF } \\
\text { X }\end{array}$ & $\begin{array}{c}\text { FRF } \\
\text { Y }\end{array}$ & SSC & $\begin{array}{c}\text { Opt } \\
\text { Turb }\end{array}$ & $\begin{array}{c}\text { LISST } \\
\text { ABS }\end{array}$ & $\begin{array}{c}\text { Aqua- } \\
\text { scat }\end{array}$ & ADV & Lidar \\
\hline 1 & $14: 34$ & $15: 07$ & 320 & 875 & $x$ & $x$ & $x$ & $x$ & $x$ & $x$ \\
\hline 2 & $15: 09$ & $15: 39$ & 311 & 875 & $x$ & $x$ & $x$ & $x$ & $x$ & $x$ \\
\hline 3 & $15: 46$ & $16: 16$ & 310 & 875 & $x$ & $x$ & $x$ & $x$ & $x$ & $x$ \\
\hline 4 & $16: 24$ & $16: 55$ & 310 & 875 & $x$ & $x$ & $x$ & $x$ & $x$ & $x$ \\
\hline 5 & $17: 20$ & $17: 50$ & 144 & 874 & $x$ & $x$ & $x$ & $x$ & $x$ & $x$ \\
\hline
\end{tabular}

\section{Description/Field Notes}

Dropping swell after passage of Hurricane Maria. First day safe for sampling. Water muddy. NNE winds and sloppy conditions. Mix of short (7 sec) and longer period swell. 


\section{3-0ct-2017}
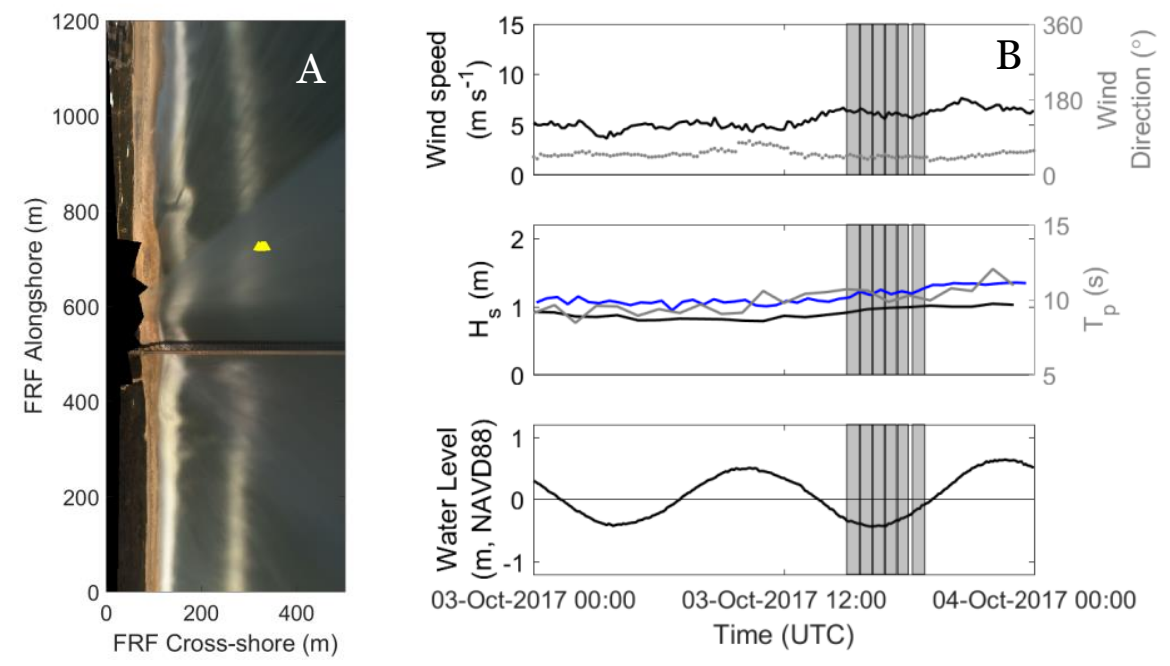

03-Oct-2017 00:00 03-Oct-2017 12:00 04-Oct-2017 00:00 Time (UTC)

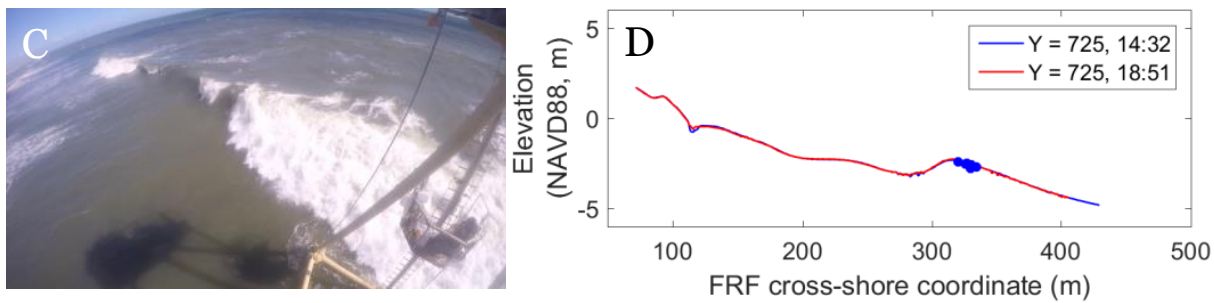

\begin{tabular}{|c|c|c|c|c|c|c|c|c|c|c|}
\hline $\begin{array}{c}\text { Station } \\
\#\end{array}$ & $\begin{array}{c}\text { Start } \\
\text { Time } \\
\text { (UTC) }\end{array}$ & $\begin{array}{c}\text { End } \\
\text { Time } \\
\text { (UTC) }\end{array}$ & $\begin{array}{c}\text { FRF } \\
\text { X }\end{array}$ & $\begin{array}{c}\text { FRF } \\
\text { Y }\end{array}$ & SSC & $\begin{array}{c}\text { Opt } \\
\text { Turb }\end{array}$ & $\begin{array}{c}\text { LISST } \\
\text { ABS }\end{array}$ & $\begin{array}{c}\text { Aqua- } \\
\text { scat }\end{array}$ & ADV & Lidar \\
\hline 1 & $15: 00$ & $15: 37$ & 320 & 723 & $\mathrm{x}$ & $\mathrm{x}$ & $\mathrm{x}$ & $\mathrm{x}$ & $\mathrm{x}$ & $\mathrm{x}$ \\
\hline 2 & $15: 39$ & $16: 13$ & 327 & 723 & $\mathrm{x}$ & $\mathrm{x}$ & $\mathrm{x}$ & $\mathrm{x}$ & $\mathrm{x}$ & $\mathrm{x}$ \\
\hline 3 & $16: 15$ & $16: 48$ & 330 & 723 & $\mathrm{x}$ & $\mathrm{x}$ & $\mathrm{x}$ & $\mathrm{x}$ & $\mathrm{x}$ & $\mathrm{x}$ \\
\hline 4 & $16: 51$ & $17: 23$ & 330 & 724 & $\mathrm{x}$ & $\mathrm{x}$ & $\mathrm{x}$ & $\mathrm{x}$ & $\mathrm{x}$ & $\mathrm{x}$ \\
\hline 5 & $17: 27$ & $17: 57$ & 334 & 723 & $\mathrm{x}$ & $\mathrm{x}$ & $\mathrm{x}$ & $\mathrm{x}$ & $\mathrm{x}$ & $\mathrm{x}$ \\
\hline 6 & $18: 09$ & $18: 44$ & 325 & 723 & $\mathrm{x}$ & $\mathrm{x}$ & $\mathrm{x}$ & $\mathrm{x}$ & $\mathrm{x}$ & $\mathrm{x}$ \\
\hline
\end{tabular}

\section{Description/Field Notes}

Small sloppy waves. Muddy water. Generally $<1$ meter. Onshore wind, choppy mostly spilling waves. 
04-0ct-2017
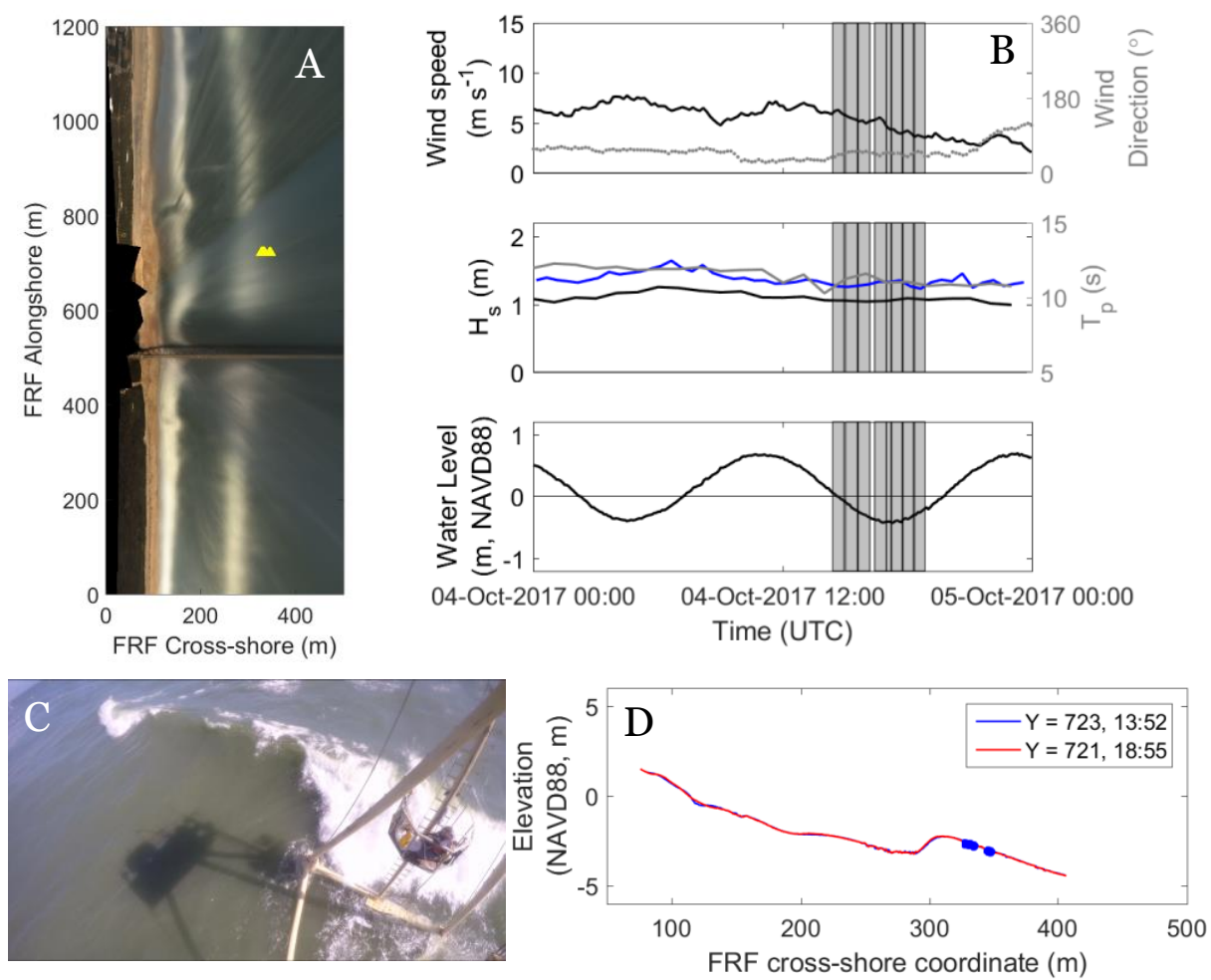

\begin{tabular}{|c|c|c|c|c|c|c|c|c|c|c|}
\hline $\begin{array}{c}\text { Station } \\
\#\end{array}$ & $\begin{array}{c}\text { Start } \\
\text { Time } \\
\text { (UTC) }\end{array}$ & $\begin{array}{c}\text { End } \\
\text { Time } \\
\text { (UTC) }\end{array}$ & $\begin{array}{c}\text { FRF } \\
\text { X }\end{array}$ & $\begin{array}{c}\text { FRF } \\
\text { Y }\end{array}$ & SSC & $\begin{array}{c}\text { Opt } \\
\text { Turb }\end{array}$ & $\begin{array}{c}\text { LISST } \\
\text { ABS }\end{array}$ & $\begin{array}{c}\text { Aqua- } \\
\text { scat }\end{array}$ & ADV & Lidar \\
\hline 1 & $14: 24$ & $14: 56$ & 331 & 723 & $x$ & $x$ & $x$ & $x$ & $x$ & $x$ \\
\hline 2 & $15: 01$ & $15: 35$ & 327 & 722 & $x$ & $x$ & $x$ & $x$ & $x$ & $x$ \\
\hline 3 & $15: 37$ & $16: 11$ & 330 & 722 & $x$ & $x$ & $x$ & $x$ & $x$ & $x$ \\
\hline 4 & $16: 25$ & $16: 58$ & 347 & 722 & $x$ & $x$ & $x$ & $x$ & $x$ & $x$ \\
\hline 5 & $16: 59$ & $17: 12$ & 347 & 722 & $x$ & $x$ & $x$ & $x$ & $x$ & $x$ \\
\hline 6 & $17: 14$ & $17: 44$ & 345 & 722 & $x$ & $x$ & $x$ & $x$ & $x$ & $x$ \\
\hline 7 & $17: 47$ & $18: 17$ & 334 & 722 & $x$ & $x$ & $x$ & $x$ & $x$ & $x$ \\
\hline 8 & $18: 20$ & $18: 50$ & 334 & 722 & $x$ & $x$ & $x$ & $x$ & $x$ & $x$ \\
\hline
\end{tabular}

\section{Description/Field Notes}

Same approximate location as previous day with slightly larger waves and less muddy water. Onshore winds. 
05-0ct-2017
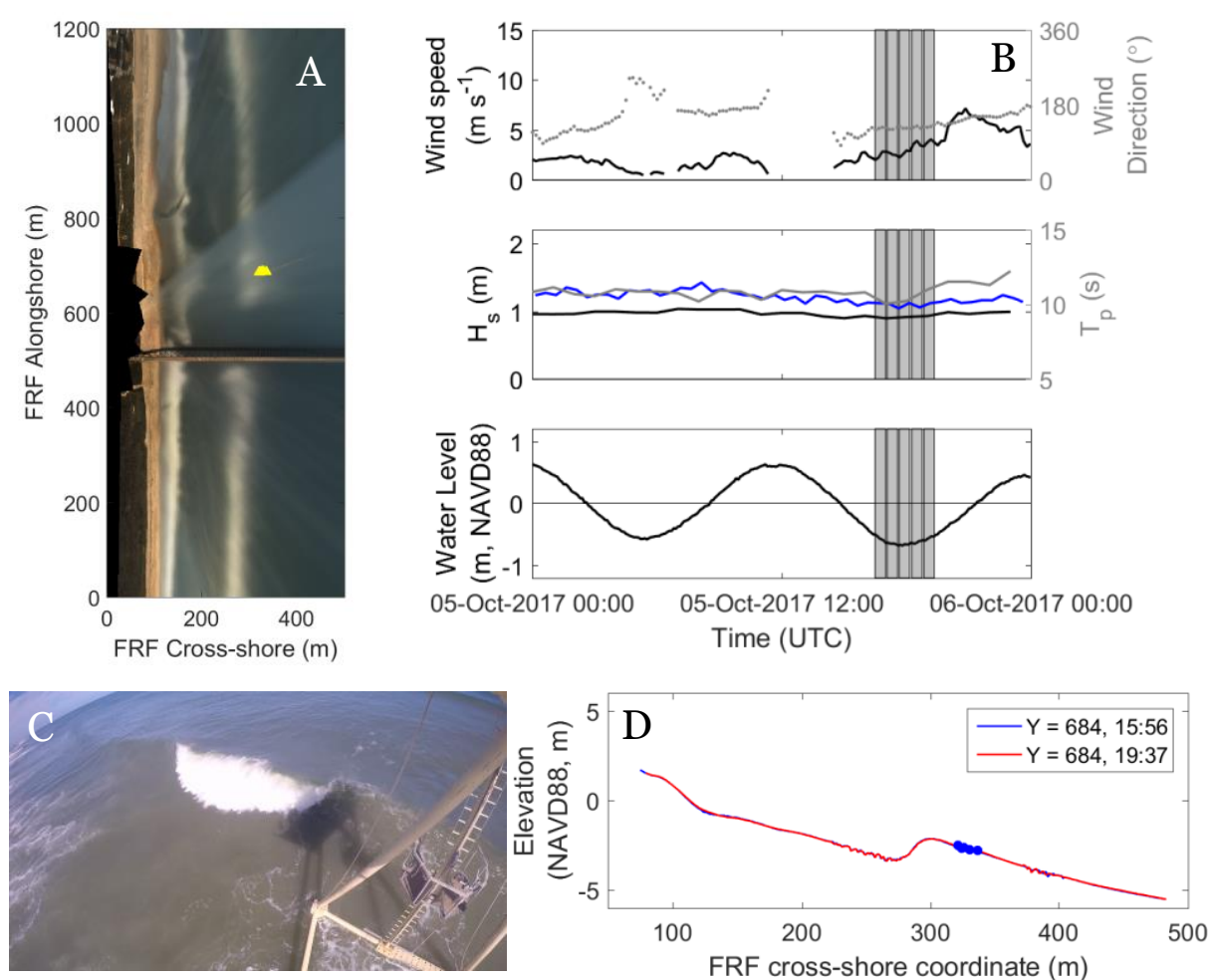

\begin{tabular}{|c|c|c|c|c|c|c|c|c|c|c|}
\hline $\begin{array}{c}\text { Station } \\
\#\end{array}$ & $\begin{array}{c}\text { Start } \\
\text { Time } \\
\text { (UTC) }\end{array}$ & $\begin{array}{c}\text { End } \\
\text { Time } \\
\text { (UTC) }\end{array}$ & $\begin{array}{c}\text { FRF } \\
\text { X }\end{array}$ & $\begin{array}{c}\text { FRF } \\
\text { Y }\end{array}$ & SSC & $\begin{array}{c}\text { Opt } \\
\text { Turb }\end{array}$ & $\begin{array}{c}\text { LISST } \\
\text { ABS }\end{array}$ & $\begin{array}{c}\text { Aqua- } \\
\text { scat }\end{array}$ & ADV & Lidar \\
\hline 1 & $16: 29$ & $16: 59$ & 321 & 686 & & $x$ & $x$ & $x$ & $x$ & $x$ \\
\hline 2 & $17: 04$ & $17: 34$ & 324 & 686 & & $x$ & $x$ & & $x$ & $x$ \\
\hline 3 & $17: 39$ & $18: 09$ & 326 & 686 & & $x$ & $x$ & & $x$ & $x$ \\
\hline 4 & $18: 15$ & $18: 45$ & 336 & 686 & & $x$ & $x$ & & $x$ & $x$ \\
\hline 5 & $18: 50$ & $19: 20$ & 330 & 687 & & $x$ & $x$ & & $x$ & $x$ \\
\hline
\end{tabular}

Description/Field Notes

No SSC samples and Aquascat batteries died while sampling. 


\section{6-0ct-2017}
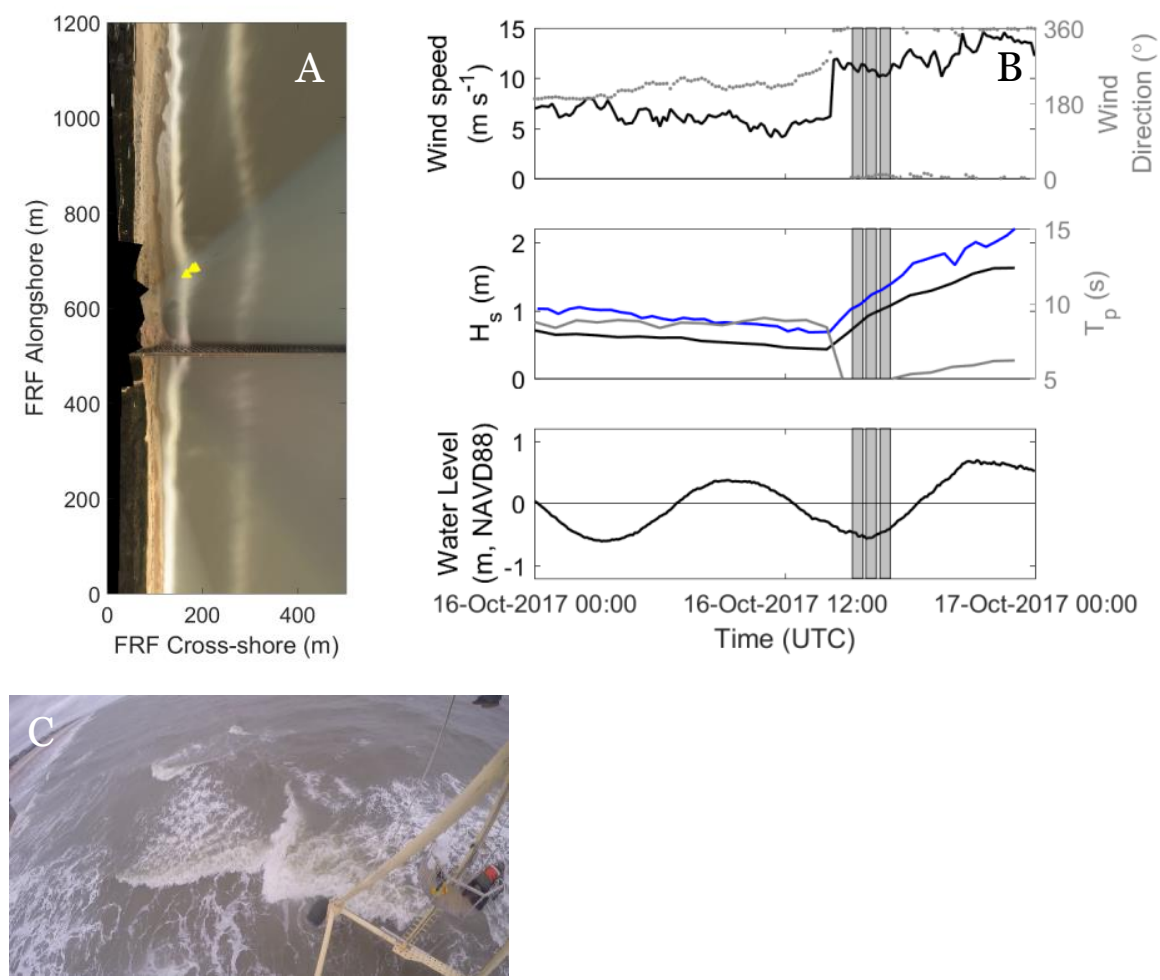

\begin{tabular}{|c|c|c|c|c|c|c|c|c|c|c|}
\hline $\begin{array}{c}\text { Station } \\
\#\end{array}$ & $\begin{array}{c}\text { Start } \\
\text { Time } \\
\text { (UTC) }\end{array}$ & $\begin{array}{c}\text { End } \\
\text { Time } \\
\text { (UTC) }\end{array}$ & $\begin{array}{c}\text { FRF } \\
\text { X }\end{array}$ & $\begin{array}{c}\text { FRF } \\
\text { Y }\end{array}$ & SSC & $\begin{array}{c}\text { Opt } \\
\text { Turb }\end{array}$ & $\begin{array}{c}\text { LISST } \\
\text { ABS }\end{array}$ & $\begin{array}{c}\text { Aqua- } \\
\text { scat }\end{array}$ & ADV & Lidar \\
\hline 1 & $15: 13$ & $15: 43$ & 166 & 670 & & & & & & $x$ \\
\hline 2 & $15: 52$ & $16: 22$ & 185 & 685 & & & & & & $x$ \\
\hline 3 & $16: 33$ & $17: 03$ & 180 & 683 & & & & & & $x$ \\
\hline
\end{tabular}

\section{Description/Field Notes}

Shore break sampling. No suspended sediment sensors or samples collected. 


\section{8-0ct-2017}
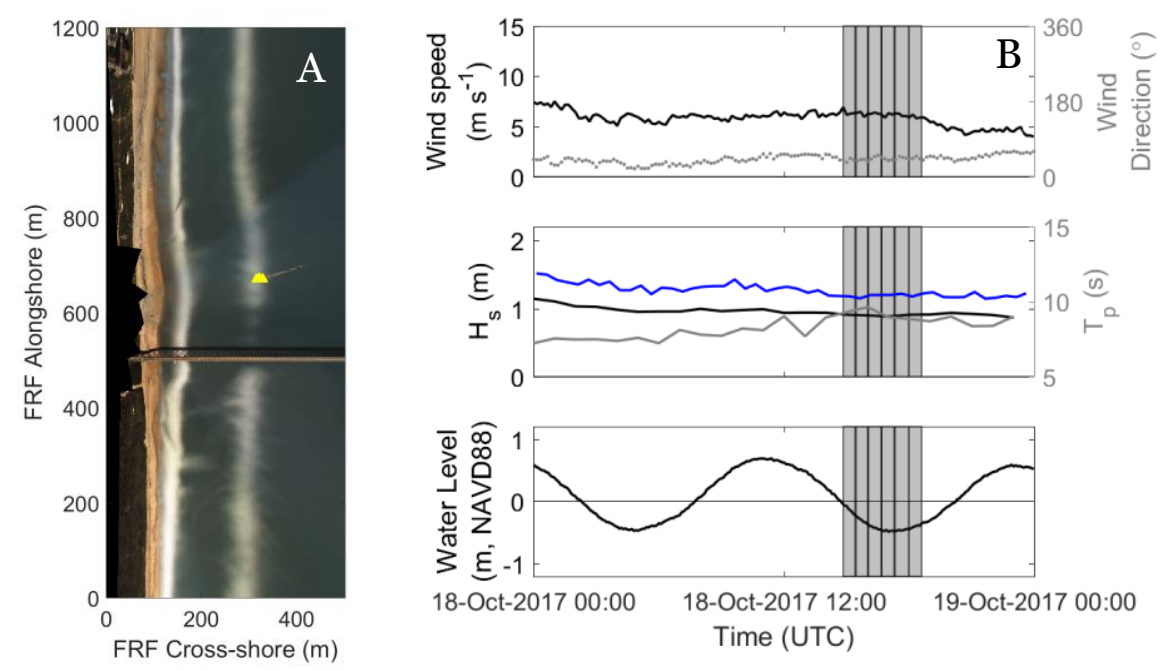

18-Oct-2017 00:00 18-Oct-2017 12:00 19-Oct-2017 00:00 Time (UTC)
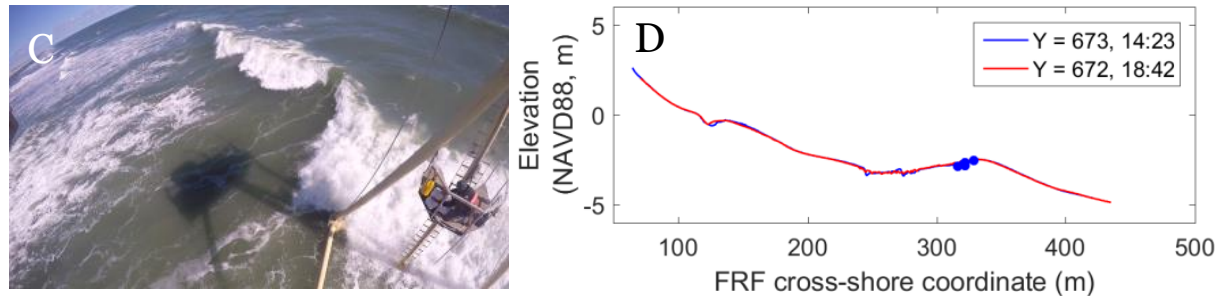

\begin{tabular}{|c|c|c|c|c|c|c|c|c|c|c|}
\hline $\begin{array}{c}\text { Station } \\
\#\end{array}$ & $\begin{array}{c}\text { Start } \\
\text { Time } \\
\text { (UTC) }\end{array}$ & $\begin{array}{c}\text { End } \\
\text { Time } \\
\text { (UTC) }\end{array}$ & $\begin{array}{c}\text { FRF } \\
\text { X }\end{array}$ & $\begin{array}{c}\text { FRF } \\
\text { Y }\end{array}$ & SSC & $\begin{array}{c}\text { Opt } \\
\text { Turb }\end{array}$ & $\begin{array}{c}\text { LISST } \\
\text { ABS }\end{array}$ & $\begin{array}{c}\text { Aqua- } \\
\text { scat }\end{array}$ & ADV & Lidar \\
\hline 1 & $14: 50$ & $15: 24$ & 316 & 671 & $x$ & $x$ & $x$ & $x$ & $x$ & $x$ \\
\hline 2 & $15: 27$ & $16: 00$ & 322 & 671 & $x$ & $x$ & $x$ & $x$ & $x$ & $x$ \\
\hline 3 & $16: 03$ & $16: 39$ & 321 & 671 & $x$ & $x$ & $x$ & $x$ & $x$ & $x$ \\
\hline 4 & $16: 41$ & $17: 16$ & 328 & 670 & $x$ & $x$ & $x$ & $x$ & $x$ & $x$ \\
\hline 5 & $17: 19$ & $17: 58$ & 321 & 672 & $x$ & $x$ & $x$ & $x$ & $x$ & $x$ \\
\hline 6 & $17: 59$ & $18: 35$ & 322 & 671 & $x$ & $x$ & $x$ & $x$ & $x$ & $x$ \\
\hline
\end{tabular}

\section{Description/Field Notes}

About 1 meter wave faces. Onshore winds. Gray-green, not very muddy water. 


\section{9-0ct-2017}
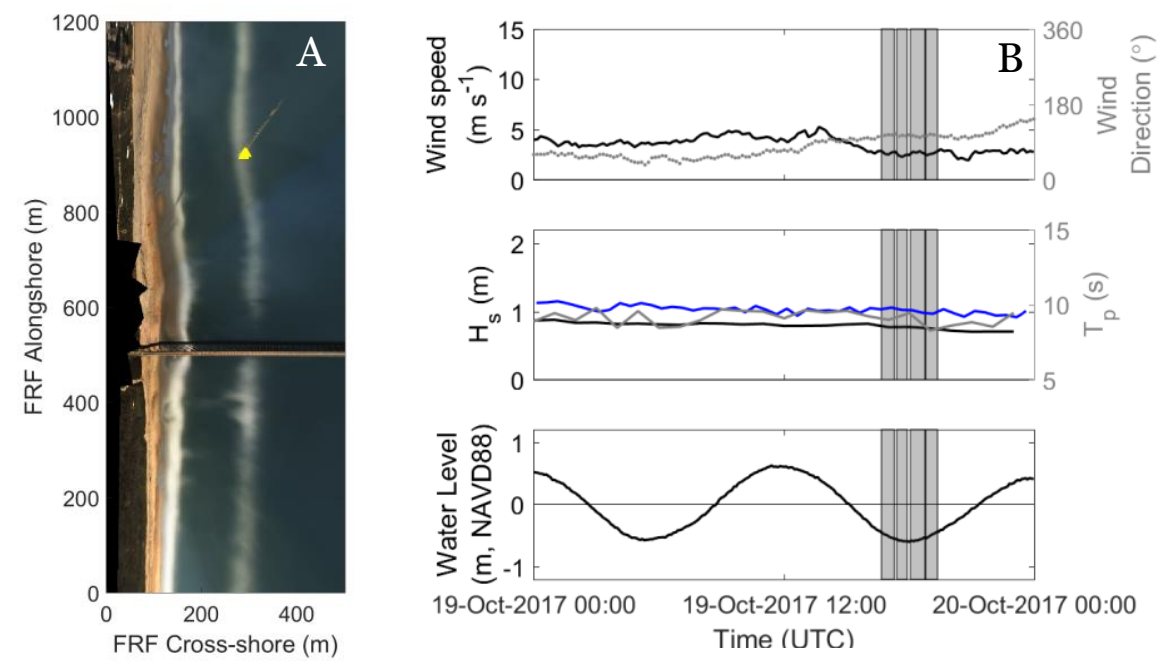

19-Oct-2017 00:00 19-Oct-2017 12:00 20-Oct-2017 00:00 Time (UTC)
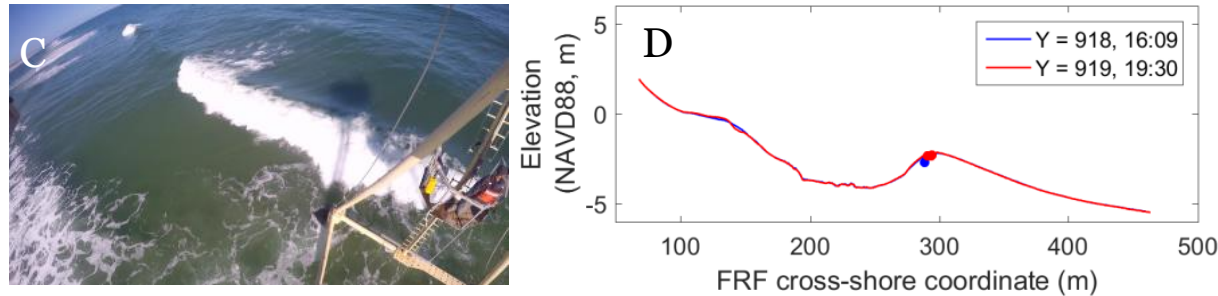

\begin{tabular}{|c|c|c|c|c|c|c|c|c|c|c|}
\hline $\begin{array}{c}\text { Station } \\
\#\end{array}$ & $\begin{array}{c}\text { Start } \\
\text { Time } \\
\text { (UTC) }\end{array}$ & $\begin{array}{c}\text { End } \\
\text { time } \\
\text { (UTC) }\end{array}$ & $\begin{array}{c}\text { FRF } \\
\mathrm{X}\end{array}$ & $\begin{array}{c}\text { FRF } \\
\mathrm{Y}\end{array}$ & SSC & $\begin{array}{c}\text { Opt } \\
\text { Turb }\end{array}$ & $\begin{array}{c}\text { LISST } \\
\text { ABS }\end{array}$ & $\begin{array}{c}\text { Aqua- } \\
\text { scat }\end{array}$ & ADV & Lidar \\
\hline 1 & $16: 40$ & $17: 17$ & 288 & 918 & $\mathrm{x}$ & $\mathrm{x}$ & $\mathrm{x}$ & $\mathrm{x}$ & $\mathrm{x}$ & $\mathrm{x}$ \\
\hline 2 & $17: 24$ & $17: 54$ & 294 & 922 & $\mathrm{x}$ & $\mathrm{x}$ & $\mathrm{x}$ & $\mathrm{x}$ & $\mathrm{x}$ & $\mathrm{x}$ \\
\hline 3 & $18: 03$ & $18: 45$ & 290 & 922 & $\mathrm{x}$ & $\mathrm{x}$ & $\mathrm{x}$ & $\mathrm{x}$ & $\mathrm{x}$ & $\mathrm{x}$ \\
\hline 4 & $18: 47$ & $19: 21$ & 293 & 922 & $\mathrm{x}$ & $\mathrm{x}$ & $\mathrm{x}$ & $\mathrm{x}$ & $\mathrm{x}$ & $\mathrm{x}$ \\
\hline
\end{tabular}

\section{Description/Field Notes}

About 1 meter mostly spilling but some plunging waves. Clear green water. 


\section{0-Oct-2017}
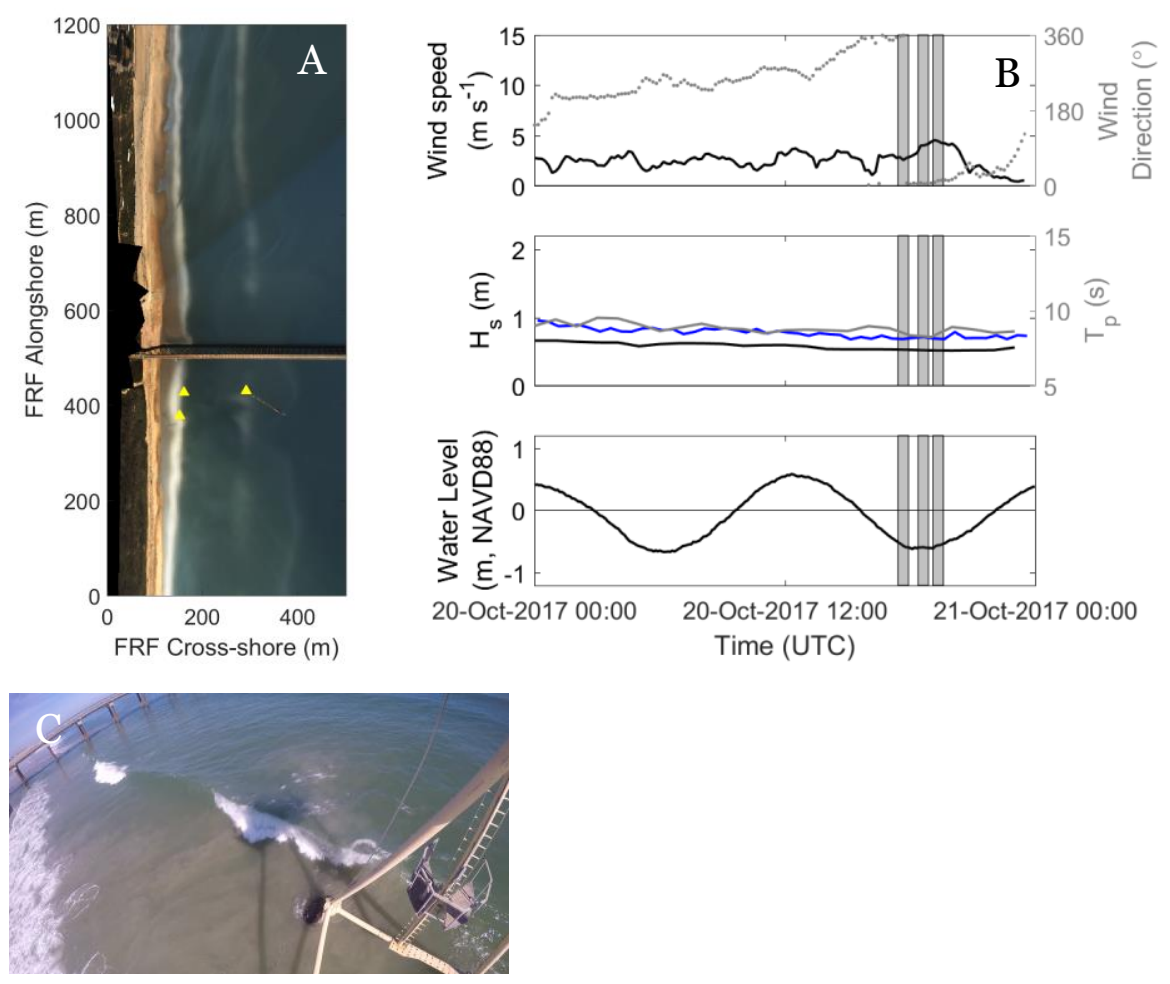

\begin{tabular}{|c|c|c|c|c|c|c|c|c|c|c|}
\hline $\begin{array}{c}\text { Station } \\
\#\end{array}$ & $\begin{array}{c}\text { Start } \\
\text { Time } \\
\text { (UTC) }\end{array}$ & $\begin{array}{c}\text { End } \\
\text { Time } \\
\text { (UTC) }\end{array}$ & $\begin{array}{c}\text { FRF } \\
\text { X }\end{array}$ & $\begin{array}{c}\text { FRF } \\
\text { Y }\end{array}$ & SSC & $\begin{array}{c}\text { Opt } \\
\text { Turb }\end{array}$ & $\begin{array}{c}\text { LISST } \\
\text { ABS }\end{array}$ & $\begin{array}{c}\text { Aqua- } \\
\text { scat }\end{array}$ & ADV & Lidar \\
\hline 1 & $17: 25$ & $17: 55$ & 161 & 427 & & & & & & $x$ \\
\hline 2 & $18: 22$ & $18: 52$ & 292 & 430 & & & & & & $x$ \\
\hline 3 & $19: 05$ & $19: 35$ & 152 & 378 & & & & & & $x$ \\
\hline
\end{tabular}

\section{Description/Field Notes}

Small waves. Only lidar. 2 shore break and 1 offshore station. 


\section{5-0ct-2017}
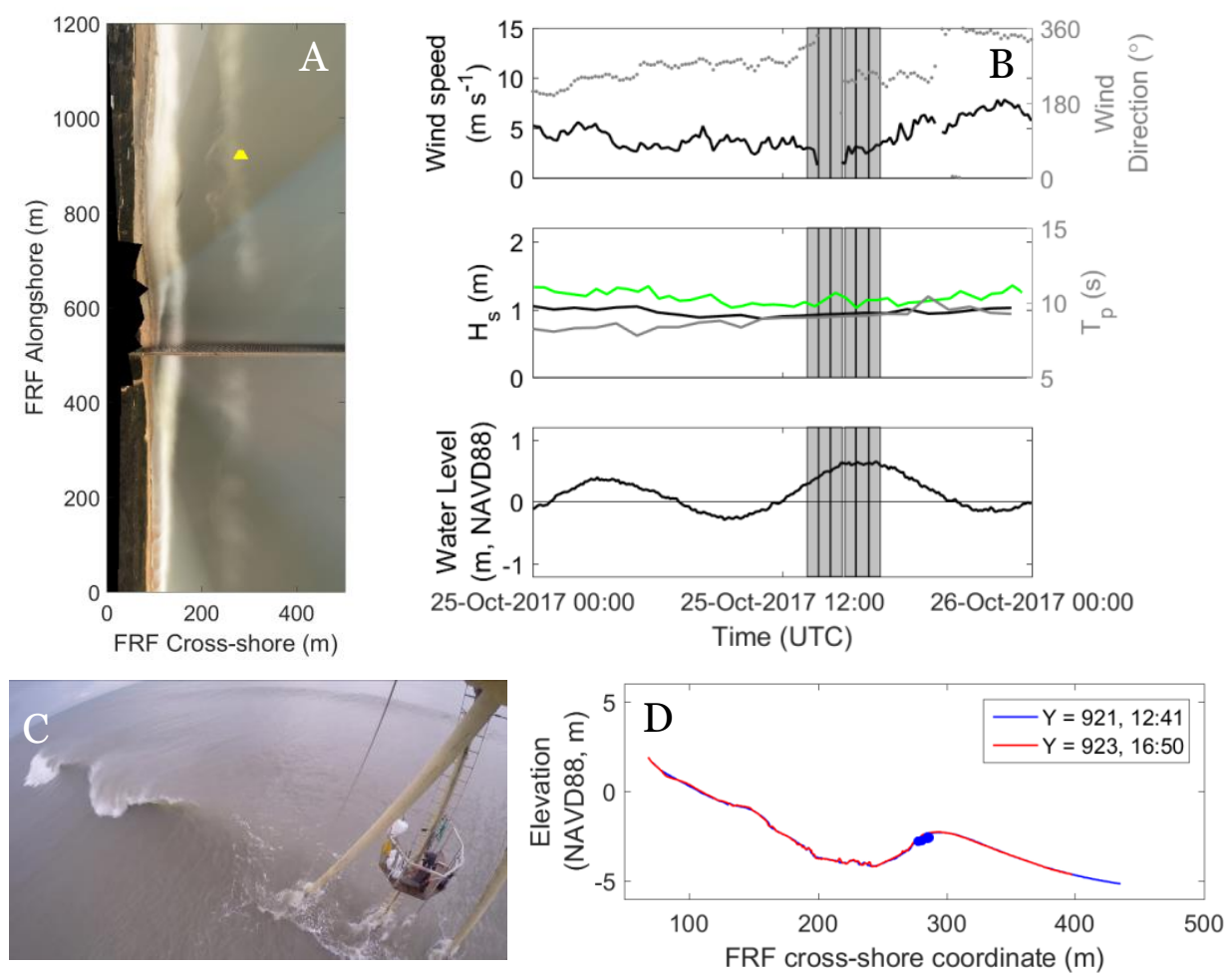

\begin{tabular}{|c|c|c|c|c|c|c|c|c|c|c|}
\hline $\begin{array}{c}\text { Station } \\
\#\end{array}$ & $\begin{array}{c}\text { Start } \\
\text { Time } \\
\text { (UTC) }\end{array}$ & $\begin{array}{c}\text { End } \\
\text { Time } \\
\text { (UTC) }\end{array}$ & $\begin{array}{c}\text { FRF } \\
\text { X }\end{array}$ & $\begin{array}{c}\text { FRF } \\
\text { Y }\end{array}$ & SSC & $\begin{array}{c}\text { Opt } \\
\text { Turb }\end{array}$ & $\begin{array}{c}\text { LISST } \\
\text { ABS }\end{array}$ & $\begin{array}{c}\text { Aqua- } \\
\text { scat }\end{array}$ & ADV & Lidar \\
\hline 1 & $13: 11$ & $13: 43$ & 286 & 920 & $x$ & $x$ & $x$ & $x$ & $x$ & $x$ \\
\hline 2 & $13: 44$ & $14: 17$ & 285 & 920 & $x$ & $x$ & $x$ & $x$ & $x$ & $x$ \\
\hline 3 & $14: 19$ & $14: 52$ & 281 & 921 & $x$ & $x$ & $x$ & $x$ & $x$ & $x$ \\
\hline 4 & $15: 00$ & $15: 30$ & 285 & 920 & $x$ & $x$ & $x$ & $x$ & $x$ & $x$ \\
\hline 5 & $15: 33$ & $16: 08$ & 278 & 921 & $x$ & $x$ & $x$ & $x$ & $x$ & $x$ \\
\hline 6 & $16: 10$ & $16: 42$ & 278 & 921 & $x$ & $x$ & $x$ & $x$ & $x$ & $x$ \\
\hline
\end{tabular}

\section{Description/Field Notes}

About 1.5 meter waves. Muddy water. Offshore winds. Water starting to clear up on stations 5 and 6 . Waves get mushy as tide fills in. 


\section{6-0ct-2017}
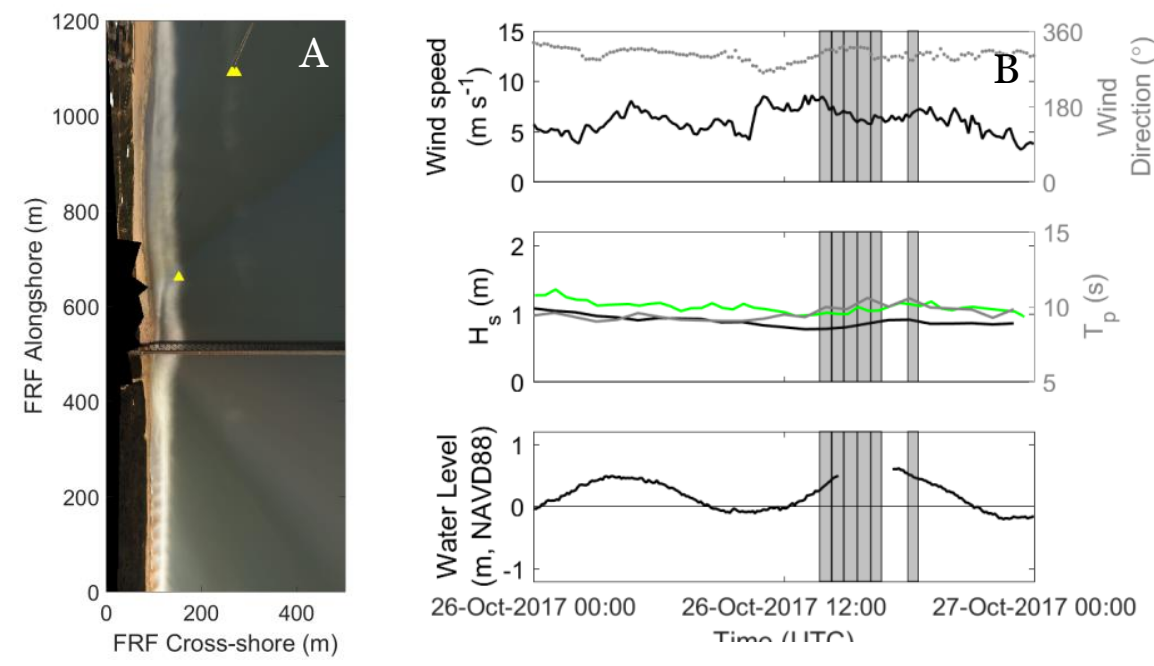

26-Oct-2017 00:00 26-Oct-2017 12:00 27-Oct-2017 00:00
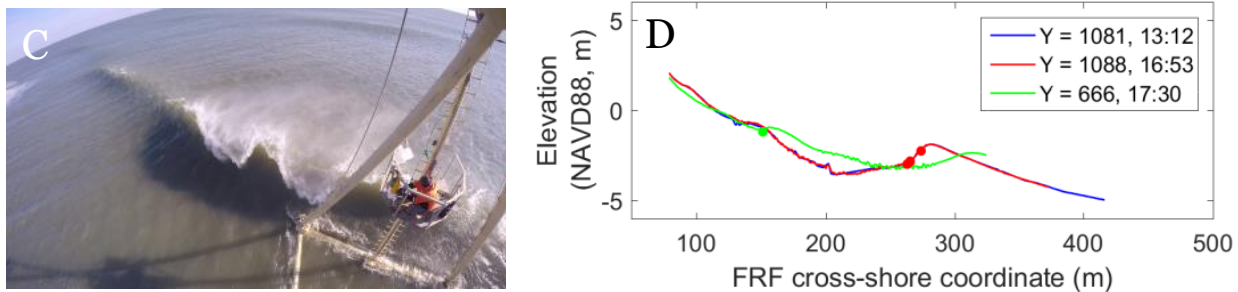

\begin{tabular}{|c|c|c|c|c|c|c|c|c|c|c|}
\hline $\begin{array}{c}\text { Station } \\
\#\end{array}$ & $\begin{array}{c}\text { Start } \\
\text { Time } \\
\text { (UTC) }\end{array}$ & $\begin{array}{c}\text { End } \\
\text { Time } \\
\text { (UTC) }\end{array}$ & $\begin{array}{c}\text { FRF } \\
\text { X }\end{array}$ & FRF Y & SSC & $\begin{array}{c}\text { Opt } \\
\text { Turb }\end{array}$ & $\begin{array}{c}\text { LISST } \\
\text { ABS }\end{array}$ & $\begin{array}{c}\text { Aqua- } \\
\text { scat }\end{array}$ & ADV & Lidar \\
\hline 1 & $13: 42$ & $14: 16$ & 274 & 1090 & $x$ & $x$ & $x$ & $x$ & $x$ & $x$ \\
\hline 2 & $14: 18$ & $14: 51$ & 265 & 1090 & $x$ & $x$ & $x$ & $x$ & $x$ & $x$ \\
\hline 3 & $14: 52$ & $15: 30$ & 265 & 1090 & $x$ & $x$ & $x$ & $x$ & $x$ & $x$ \\
\hline 4 & $15: 31$ & $16: 09$ & 263 & 1090 & $x$ & $x$ & $x$ & $x$ & $x$ & $x$ \\
\hline 5 & $16: 10$ & $16: 40$ & 263 & 1090 & $x$ & $x$ & $x$ & $x$ & $x$ & $x$ \\
\hline 6 & $17: 56$ & $18: 26$ & 152 & 661 & $x$ & $x$ & $x$ & $x$ & $x$ & $x$ \\
\hline
\end{tabular}

\section{Description/Field Notes}

Waves a little over 1 meter. Pretty clean conditions. Grayish brown somewhat muddy water. Final day of sampling. 


\section{Acronyms and Abbreviations}

3D

.nc

. $\mathrm{ncml}$

.pcap

ABS

ADV

$\mathrm{cm}$

CRAB

ERDC

FOV

FRF

$\mathrm{g} / \mathrm{L}$

GPS

$\mathrm{Hz}$

INS/GNSS

$\mathrm{L}$

LOI

$\mathrm{m}$

$\mathrm{MHz}$

$\min$

$\mu \mathrm{m}$

$\mathrm{nm}$

Opt turb

sec

SSC

THREDDS

USACE

UDP

UTC three-dimensional netCDF file extension (file designation) netCDF Markup Language file extension (file designation) packet capture (file designation) acoustic backscatter sensor acoustic Doppler velocimeter centimeter Coastal Research Amphibious Buggy

US Army Engineer Research and Development Center field of view

Field Research Facility

grams per liter

Global Positioning System

hertz

Inertial Navigation System/Global Navigation Satellite System

liter

loss on ignition

meter

megahertz

minute

micron, micrometer

nanometer

Optical turbidity

second

suspended sediment concentration

Thematic Realtime Environmental Distributed Data Services

US Army Corps of Engineers

User Datagram Protocol

Coordinated Universal Time 


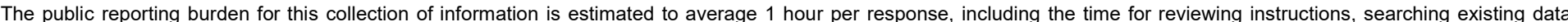

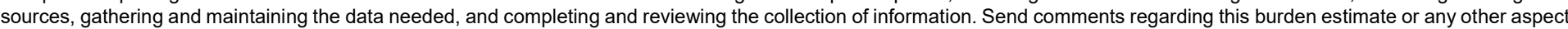

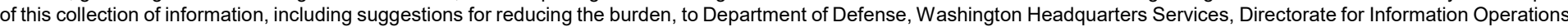

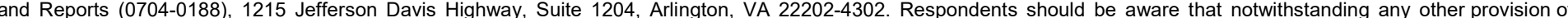
law, no person shall be subject to any penalty for failing to comply with a collection of information if it does not display a currently valid OMB control number.

PLEASE DO NOT RETURN YOUR FORM TO THE ABOVE ADDRESS.

\begin{tabular}{l|l|l}
\hline 1. REPORT DATE & 2. REPORT TYPE & 3. DATES COVERED (From - To) \\
November 2019 & Final Report
\end{tabular}

\section{TITLE AND SUBTITLE}

Quantifying Wave Breaking Shape and Suspended Sediment in the Surf Zone 5a. CONTRACT NUMBER

5b. GRANT NUMBER

5c. PROGRAM ELEMENT NUMBER

$611102 \mathrm{~T} 2200$

5d. PROJECT NUMBER

471930

5e. TASK NUMBER

$6.1 \mathrm{~T} 22$

5f. WORK UNIT NUMBER

8. PERFORMING

ORGANIZATION REPORT

NUMBER

ERDC/CHL TR-19-22

1261 Duck Road

Duck, NC 27949

\section{SPONSORING/MONITORING AGENCY NAME(S) AND ADDRESS(ES)}

US Army Engineer Research and Development Center

10. SPONSOR/MONITOR'S ACRONYM(S)

ERDC-CHL

Coastal and Hydraulics Laboratory

3909 Halls Ferry Road

Vicksburg, MS 39180-6199

11. SPONSOR/MONITOR'S REPORT NUMBER(S)

\section{DISTRIBUTION/AVAILABILITY STATEMENT}

Approved for public release; distribution is unlimited.

\section{SUPPLEMENTARY NOTES}

\section{ABSTRACT}

This technical report describes a field experiment conducted from 18 November 2016 to 26 October 2017 at the Coastal and Hydraulics Laboratory, Field Research Facility, as part of a 6.1 Military Engineering Basic Research Project titled New Field Measurements and Parameterizations to Predict Wave Breaking Shape from Environmental Forcing. This report provides an overview of the project, presents the motivation and goals of the project, describes the suite of instrumentation and experimental procedure, documents the field data collection effort, and catalogs the raw data products.

\section{SUBJECT TERMS}

Data collection platforms, Ocean waves, Sediment transport, Suspended sediments, Water waves

16. SECURITY CLASSIFICATION OF:

\begin{tabular}{|l|l|l|}
\hline a. REPORT & b. ABSTRACT & c. THIS PAGE \\
Unclassified & Unclassified & Unclassified \\
\hline
\end{tabular}

17. LIMITATION OF
ABSTRACT

SAR
18. NUMBER OF PAGES

62 19a. NAME OF RESPONSIBLE PERSON

Patrick J. Dickhudt

19b. TELEPHONE NUMBER (Include area code)

252-261-6840 